"THOSE FLAMING LIPS:

\title{
EXPLORING THE SEXUAL SUBJECTIVITY OF A WOMAN EXPERIENCING CHRONIC VULVAR PAIN"
}

\author{
by \\ Rebekka Wallace, H.B.A. \\ A Thesis submitted to the Faculty of Graduate Studies and Research \\ in partial fulfilment of the requirements for the degree of \\ Master of Social Work
School of Social Work
Carleton University
Ottawa, Ontario \\ January, 2007 \\ (C) Copyright \\ 2007, Rebekka Wallace
}




$\begin{array}{ll}\begin{array}{l}\text { Library and } \\ \text { Archives Canada }\end{array} & \begin{array}{l}\text { Bibliothèque et } \\ \text { Archives Canada }\end{array} \\ \begin{array}{l}\text { Published Heritage } \\ \text { Branch }\end{array} & \begin{array}{l}\text { Direction du } \\ \text { Patrimoine de l'édition }\end{array} \\ \begin{array}{l}\text { 395 Wellington Street } \\ \text { Ottawa ON K1A ON4 }\end{array} & \begin{array}{l}\text { 395, rue Wellington } \\ \text { Ottawa ON K1A ON4 } \\ \text { Canada }\end{array}\end{array}$

Your file Votre référence ISBN: 978-0-494-23368-9 Our file Notre référence ISBN: 978-0-494-23368-9

NOTICE:

The author has granted a nonexclusive license allowing Library and Archives Canada to reproduce, publish, archive, preserve, conserve, communicate to the public by telecommunication or on the Internet, loan, distribute and sell theses worldwide, for commercial or noncommercial purposes, in microform, paper, electronic and/or any other formats.

The author retains copyright ownership and moral rights in this thesis. Neither the thesis nor substantial extracts from it may be printed or otherwise reproduced without the author's permission.
AVIS:

L'auteur a accordé une licence non exclusive permettant à la Bibliothèque et Archives Canada de reproduire, publier, archiver, sauvegarder, conserver, transmettre au public par télécommunication ou par l'Internet, prêter, distribuer et vendre des thèses partout dans le monde, à des fins commerciales ou autres, sur support microforme, papier, électronique et/ou autres formats.

L'auteur conserve la propriété du droit d'auteur et des droits moraux qui protège cette thèse. $\mathrm{Ni}$ la thèse ni des extraits substantiels de celle-ci ne doivent être imprimés ou autrement reproduits sans son autorisation.
In compliance with the Canadian

Privacy Act some supporting forms may have been removed from this thesis.

While these forms may be included in the document page count, their removal does not represent any loss of content from the thesis.
Conformément à la loi canadienne sur la protection de la vie privée, quelques formulaires secondaires ont été enlevés de cette thèse.

Bien que ces formulaires aient inclus dans la pagination, il n'y aura aucun contenu manquant.

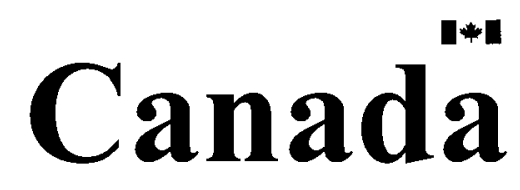




\begin{abstract}
Nine years ago, I began to experience a sharp, burning pain in my vulva during intercourse. While not a usual topic for a Social Work Master's thesis, my journey to find a diagnosis and a cure has led me to study social work and sex therapy. Over the last nine years, I have sought the help of twenty-six health practitioners, experienced inappropriate touching by two of my physicians, was told that my condition was psychological, physical and/or biopsychosocial, and spent thousands of dollars on ineffective treatments. This thesis is a critical reflection on my narratives of these experiences. To achieve this, I use an autobiographical method that draws upon feminist and narrative approaches to research. Using a feminist Foucauldian theoretical framework, I explore the ways in which power, sexuality and subjectivity intersect.
\end{abstract}




\section{Acknowledgments}

This project would not be complete without the acknowledgement of those people who supported me over the past three years.

I would like to extend my sincere gratitude to the members of my Supervisory Committee, Dr. Sarah Todd and Dr. Gerald de Montigny for their guidance and unique contributions offered throughout this process. They took on a project that required a certain level of risk and I commend them for their open minds and commitment to alternative research.

As well, for the past nine years, my family, friends and colleagues have offered immense support while I made sense of my vulvodynia. Through it all, their openness, love and humour were always welcome distractions. I especially want to thank my mother, Brenda Wallace, who gave up many hours of sleep to offer up her brilliant editing skills! I also owe a particular debt to Marc-André who demonstrated true love by providing unending support and encouragement during those final hours!

Finally, I would like to thank all my partners for showing me that love and intimacy can come in a multitude of forms. 
Table of Contents

INTRODUCTION

LITERATURE REVIEW 7

Background of Chronic Vulvar Pain $\quad 7$

SEXUALITY $\quad 11$

SEX THERAPY $\quad 12$

FEMINISM AND SEXUALITY

SEXUAL SUBJECTIVITY $\quad 19$

BODY METAPHOR $\quad 22$

NARRATTVE APPROACHES TO SOCLAL WORK PRACTICE 23

STIGMATIZATION $\quad 26$

REPRESENTATIONS OF THE SELF

RESEARCH QUESTIONS

THEORETICAL FRAMEWORK

$\begin{array}{ll}\text { METHODOLOGY } & 36\end{array}$

CHAPTER 1: PLEASURE AND PAIN 41

SCRIPT \#1: DISCLOSING "HIDDEN" FANTASIES

SHIFTING POWERS THROUGH CONFESSION

GeNDERED UNDERSTANDINGS OF PleAsURe $\quad 47$

GIRIS, BOYS AND "CONFESSING" FANTASIES $\quad 48$

SEXUAL METAPHORS

CHAPTER 2: NAVIGATING THE MEDICAL SYSTEM

SCRIPT \#2: THE CAMPUS DOCTOR

GENDERED NARRATIVES OF PAIN

DISCOMFORTED DISCLOSURES

SCRIPT \#3: PLACING TRUST IN THE HANDS OF THE DOCTOR

SCRIPT \# 4: BROKEN TRUST AT THE HANDS OF THE PHYSICIAN

SCRIPT \# 5: NAMING THE PAIN

SCRIPT \#6: DIAGNOSIS

$\begin{array}{lr}\text { EMPLOYING THE SEX THERAPY APPROACH } & \mathbf{8 7}\end{array}$

SCRIPT \#7: PERSONAL PROBLEMATIC OF SEX THERAPY 87

CHAPTER 3: SHIFTING FROM PAIN TO PLEASURE 95

Vulvar PaIn, SELF AND FANTASY 96

SCRIPT \#8: BECOMING “WHOLE” AND FINDING SEX THERAPY 98

THE ART OF DISCLOSURE (OR LACK THEREOF) 103 
CHAPTER 4: REFLECTIONS ON SOCIAL WORK PRACTICE 109

REFLECTIONS OF WRITING THE THESIS

HOW MY NARRATIVES WILL MAKE ME A BETTER COUNSELLOR

REFLECTIONS ON THE RESPONSIBLE COUNSELIING PROCESS

REFLECTIONS ON SEXUALITY WITHIN THE SOCIAL WORK PROFESSION

REFERENCES 133

APPENDIX A 147

KEY CONCEPTS

APPENDIX B 149

LIVING WITH VULVODYNLA: BRIEF OUTLINE OF MY EXPERIENCES

APPENDIX C 156

Painful sex? Read This... 


\section{LIST OF FIGURES}

Figure 1: FEMALE SEXUAL RESPONSE CYCLE (BASSON, 2001)

FIGURE 2: MY OWN SEXUAL RESPONSE MODEL - AN ADAPTATION

FIGURE 3: EXAMPLE OF MY PERSONAL SEXUAL HISTORY)

\section{LIST OF TABLES}

TABLE 1: LIST OF TREATMENTS SINCE 1999 


\section{Introduction}

I began writing my narratives of living with vulvar vestibulitis nine years ago, however I never imagined them taking shape in the form of a Master's thesis. While I wrote papers on the topic of vulvar pain ("French Fries Don't Heal Vaginas," 2005; "Overcoming Vulvar Vestibulitis: Making the Personal Political, 2003), and presented at social work conferences ("Those Flaming Lips: Giving Voice to Women Living with Chronic Vulvar Pain," 2005), ${ }^{1}$ I always felt I needed additional space and time to delve deeper and make sense of this condition and its impact on my own life. Until recently, I had always looked at how this experience affected the lives of "others" and never explored how it has informed and greatly altered the way I understand my sexuality, body and self.

This thesis became a project to unpack my understanding of my subjective self. Employing a qualitative autobiographical methodology, it is an analysis of the ways in which I have constituted myself as a sexual subject ${ }^{2}$ over the past nine years. While it is not an autobiography per se, it uses the autobiographical method to explore the ways I have become to know myself as a feminist woman who lived with chronic vulvar pain (for a similar approach see Brookes, 1992). More importantly, it is an in-depth exploration into the ways I constituted myself through the identities of feminist, woman, chronic pain sufferer, sexual being, therapist, partner and, perhaps most relevant to this project, social worker.

\footnotetext{
' This conference presentation is the foundation upon which this thesis was formed.

${ }^{2}$ Foucault rejects the idea that we have real or fixed identities. Rather, he argues that the self is understood within discourse and is made sense of through interactions. Thus, the self we experience is constituted through social, cultural, political and historical relations (2006).
} 
I began this project by looking at information from a variety of disciplines, only to discover numerous gaps in the literature (see Literature Review, page 10). One significant silence in the literature results from the lack of work written by women who experience vulvar pain and how this experience shapes their sexuality. While this thesis fills this gap in so far as I describe my own experiences, it does not include the voices of other women. I chose this approach to my work because I wanted to engage in a process of understanding how my vulvar pain shaped the intersections between how I practice as a counsellor and my identification with social work as a profession. In other words, I not only wanted to challenge my self as the author who has lived with vulvar pain for nine years, but also as a future sex therapist planning to work with individuals and couples negotiating sexual difficulties. I believe that entering a therapeutic relationship with clients who share common experiences may stimulate my own projections and, in the process, raise concerns regarding counter transference.

Consequently, I decided to shift my outward gaze inward so as to interrogate the therapeutic relationship in which clients come to share their story with a 'professional' (Turner, 2002). As I intend to become the 'professional' in this relationship I began to wonder how I can make assessments, diagnoses and judgements of others, when I have yet to make sense of my own story, including my own experience of having lived with vulvar pain? Thus, such an exploration became the purpose of this thesis. 
To help me unpack my story, I have organized my project into four chapters: 1) Pleasure and Pain, 2) Navigating the Medical System, 3) Shifting from Pain to Pleasure, and 4) Reflections and Relevance to Social Work Practice. By organising the chapters in this way, I was able to breakdown the specific interpretations of my unique experiences. This process allowed me to unpack the various ways I have come to understand my sexuality from childhood to the present. It also helped me to identify the significant moments where power and sexuality intersect with my sexual and vulvar pain experiences.

A caveat about my mode of story telling, each chapter employs the use of scripts. The first chapter of my thesis explores my early experiences of pain and the ways in which it intersected with pleasure. The snapshot is extremely personal in that it relies upon an interrogation of my sexual fantasies, desires and pleasures. However, I believe it offers me the critical platform from which to jump to the next chapter. Chapter two, Navigating the Medical System, takes the reader through my various interactions with physicians, sex therapists, and medical and alternative treatments. It situates this project by providing a background into the complications of "confessing" my sexual history (Foucault, 2003), addressing the stigmatization of sexual pain and locating my agency when battling the indiscretions of male physicians in positions of power. The next chapter shifts focus from the medical system to my own subjugated body. 3 It focuses attention on my 'healing' process, including disclosing my pain to

\footnotetext{
${ }^{3}$ Working from Foucault's description of subjectivity, the body can be understood as actively constituting and, simultaneously situated within historical, cultural, political and social discourses (Foucault, 2003).
} 
partners, searching for alternative health approaches and deciding to become a sex therapist. My final chapter explores how this project is relevant to social work practice.

It is important to note that the representation of my self and my sexuality are multilayered. In mapping the "I," I worked to locate myself in an historical context (Gilmore, 1994; Smith, 1999). However, the "I" I offer here is dramatically different than that "I" would have written five years ago. As such, my representation is fluid and changed in the very writing of this thesis (Chanfrault-Duchet, 2000).

When I began the project, I assumed that I could write each script chronologically. Instead, I found that my scripts evolved into layers, each informing the other to underscore significant moments. Probyn (1993) argues, "[i]mages of the self arise from the 'livedness' of the interaction of individual and social and then return as a critical tool to analyze and cut into the specificity of the social formation" (29). Thus this project is one in which I draw upon descriptions of my lived experiences in order to understand the ways in which the social world shapes the experience of chronic vulvar pain. It also challenges me to explore the complexities or unique experiences of sexuality from a dynamic perspective, one that shifts and decentres my understanding of vulvar pain.

It is believed that millions of women around the world have experienced or are experiencing chronic vulvar pain (Harlow \& Stewart, 2003). The origins of the pain can be physical (disability, acute, chronic or palliative illness, surgeries) (Glazer \& Rodke, 2002; Kaufman, Silverberg \& Odette, 2003; Stewart \& Spencer, 
2002) or psychological in nature (sexual/physical abuse, fear of sexual intimacy, cultural or religious influences) (Berman \& Berman, 2001; Binik, Bergeron \& Khalifé, 2000; Haefner, Collins, Davis, et al., 2005; Hall, 2004; Kleinplatz, 2001; Maltz, 2001; Meana \& Binik, 1994; Meana, 1995; Meana \& Binik, 1997; Monga et al., 1998; Schrover, 2000). Arguably, social workers play an important role in supporting vulvar pain sufferers as individual and family therapists, advocates for marginalized communities (such as women living with disabilities) and researchers. Yet, I have found little academic work on the qualitative experience of women living with this condition. More specifically, I was unable to find a published study on vulvar pain written from an autobiographical academic perspective, specifically in social work, in Canada. The writing of this thesis, therefore, provides me with the opportunity to explore my experience from a feminist perspective.

A reflective exploration of my vulvar pain narratives allows me to examine the intersections between a very personal or intimate "condition" and the ways in which these intersections influence my relationships with others. These interactions move beyond the personal or intimate relationships with my partner to my relationships with my medical, academic and social communities. Vulvodynia, then, has become a bridge between the seemingly personal to the institutional. The experience of vulvar pain became my primary focus; one could argue it was my life. For those with whom I was interacting, meanwhile, it was simply a problem or condition to be addressed either in their relations with me, such as my physicians, my partners or my family and friends. As a woman living 
with vulvar vestibulitis, the dynamics of pain extended outward such that my pain came to enter me into an array of institutional and professional relations.

Professionally, this thesis works to illustrate my commitment to incorporate sexuality into my future practice as a therapist and social worker. Sharing such personal narratives I would hope also serves to give critical insight into one woman's unique experience of vulvar pain. It helps me enter into a dialogue between where my boundaries lie as both one who desires to become a therapist and one who has lived an experience of vulvar pain. These can be contradictory spaces and thus, this dialogue challenges me to think of where appropriate self-disclosures and the "presentation of the professional self" fit into my future professional clinical practice. 


\section{Literature Review}

\section{Background of Chronic Vulvar Pain}

Chronic vulvar pain, also called vulvodynia, is an "under diagnosed, difficult-to-treat gynaecological disorder" (Masheb et al., 2004: 315). The International Society for the Study of Vulvar Disease (ISSVD) offers one commonly accepted definition and suggests that vulvar pain is characterized as chronic burning or knife-like pain and pain on vulvar contact, without visible lesions, experienced by women for over a period of three months. 4 More specifically, the ISSVD uses the following language to describe and classify vulvar pain:

ISSVD Terminology and Classification of Vulvar Pain 2003 (Moyal-Barracco \& Lynch, 2004)

A) Vulvar Pain Related to a Specific Disorder

1) Infectious (e.g. candidiasis, herpes, etc.)

2) Inflammatory (e.g. lichen planus, immunobullous disorders, etc.)

3) Neoplastic (e.g. Paget's disease, squamous cell carcinoma, etc.)

4) Neurologic (e.g. herpes neuralgia, spinal nerve compression, etc.)

B) Vulvodynia

1) Generalized

a) Provoked (sexual, nonsexual, or both)

b) Unprovoked

c) Mixed (provoked and unprovoked)

2) Localized (vestibulodynia, clitorodynia, hemivulvodynia, etc.)

a) Provoked (sexual, nonsexual, or both)

b) Unprovoked

\footnotetext{
${ }^{4}$ Please see Appendix A, "Key Concepts" for detailed definitions of the specific vulvar pain conditions.
} 
c) Mixed (provoked and unprovoked)

While this terminology and classification are useful, there exists little recognized training for physicians to learn about the condition and to ensure its proper diagnosis (Haefner et al., 2005). Further, culture, economic status or geography (rural spaces versus urban spaces, upper-middle class versus lower middle class) influence women's abilities to access appropriate diagnosis and treatment (Harlow \& Stewart, 2003).

Compounding the difficulties confronting women, "[w]hen practitioners can't find the source of a problem, they deem it 'essential' [of unknown origin]" (Glazer \& Rodke, 2002: 17) and consequently assume that it must be psychological. Such assumptions leave women without appropriate physical treatment options, labels them as "unstable" and makes them feel as though their physical symptoms warrant no further investigation or that they are to blame (Glazer \& Rodke, 2002; Haefner et al., 2005; Harlow \& Stewart, 2003; Stewart \& Spencer, 2002). Further, it causes women to believe that their symptoms are "in their head" and works to limit them and their partners with regards to physical treatment options (Binik, Bergeron \& Khalifé, 2000).

In light of the apparent lack of information regarding vulvar pain, it is surprising to read that 16 percent of American women may be suffering from vulvodynia (Harlow \& Stewart, 2003). This translates to approximately 18 million women in the United States living with a condition about which we have very little information and who are, as a result, living in virtual silence. 
Unfortunately, we know no more about the situation in Canada, as researchers have not gathered the quantitative data to explore the number of Canadian women suffering from vulvar pain.

Most knowledgeable researchers and medical practitioners are divided on vulvar pain regarding origins and treatments. Reviewing the medical literature, for example, I found that a debate exists concerning the possible connection between vulvodynia and irritable bowel syndrome (IBS), the human papillomavirus (HPV), fibromyalgia or vaginismus (Abramov, Wolman \& David, 1994; Bornstein, 1996; Marinoff \& Turner, 1992; Rosenthal, 2003; Stewart \& Spencer, 2002). Equally debatable are the causes of the condition. Prior to diagnosis, many physicians assume that sexually transmitted infections, childbirth, surgeries or injuries are to blame for the invisible pain sensations (Barni \& Mondin, 1997, Glazer \& Rodke, 2002; Stewart \& Spencer, 2002). Consequently, they prescribe therapies such as estrogen creams, antidepressants, anti-seizure medication (Morris \& Mukhophadyay, 2003; Stewart \& Spencer, 2002), the oxalate diet (Glazer \& Rodke, 2002), physical therapy, trigger point therapy (Abramov, Wolman \& David, 1994; Davies \& Davies, 2004) and, as a last resort, surgery (Edwards, 2003; Rosen \& Kellogg-Spadt, 2003; Rosenthal, 2003; Stewart \& Spencer, 2002; Weijmar Schultz et al., 2005). These therapies can be successful if/when complimented with other physical therapies and counselling. With regards to my own healing, I have been using Gabapentin, an anti-seizure medicine, with a great degree of success in conjunction with 
trigger point therapy and pain management techniques (i.e., unscented soap, etc.).

Psychologists and social workers, on the other hand, are more apt to believe that sexual violence, pain disorders, sexual aversion, erotophobia and abuse are associated with the condition and to suggest sex therapy, cognitivebehavioural therapy or sensate focused, brief intensive therapy (Binik, Bergeron and Khalifé, 2000; Graziottin, 2001; Kleinplatz, 2001; Maltz, 2001; Meana \& Binik, 1994; Meana \& Binik, 1997b).

The literature also includes a prominent debate within the medical field as to whether or not vulvar pain is a pain condition or a sexual dysfunction. Binik, Bergeron and Khalifé (2000) argue that, despite being presented as a sexual problem, "the same pain experienced during intercourse can typically be elicited in nonsexual situations such as gynaecological examinations, tampon insertion, and so on" (156). There does appear to be a consensus among psychologists, physicians and sex therapists regarding whether chronic vulvar pain will evolve into a sexual dysfunction, or whether a multidisciplinary approach is necessary for treatment (Binik, Bergeron and Khalifé, 2000; Glazer \& Rodke, 2002; Lynch, 1986; Meana \& Binik, 1994; Stewart \& Spencer; 2002). The most successful treatments seem to evolve from a biopsychosocial perspective with a multidisciplinary team of physicians, physiotherapists and sex therapists/psychologists (Binik, Bergeron \& Khalifé, 200o; Meana \& Binik, 1997b). As described in the literature, vulvodynia is a complex condition that 
affects women and their partners sexually, physically, emotionally and psychologically.

\section{Sexuality}

As mentioned previously, the complexities of diagnosing and treating chronic vulvar pain affect the sexual relationships and understandings women have with themselves, their partners and their community (Bergeron \& Binik, 1997; Bergeron \& Binik, 1997b; Binik, Bergeron \& Khalifé, 2003; Meana, 1995). The stigma of having a sexual pain disorder or dysfunction further compounds the difficulties women face in accessing support (Glazer \& Rodke, 2002). As such, it was important to consider the ways in which research concerning sexuality is being conducted prior to delving into my personal sexual subjectivity.

Informed by the World Health Organization's definitions of sexuality 5 and sexual health ${ }^{6}$, I work from the premise that sexuality includes both pleasure and pain, intercourse and outercourse, and physical and emotional intimacy (Kaufman, Silverberg \& Odette, 2003; Kleinplatz, 2001). However, a great deal of literature concerning sexuality and sexual health focuses on the illnesses or dysfunctions of the sexual body? (Kaplan, 1974; Leiblum \& Rosen, 2000; Masters \& Johnson, 1966; Schover, 2000, Stewart \& Spencer, 2002). Erectile dysfunction, vaginismus, hypoactive arousal disorder and dyspareunia (painful sex) are examples of sex dysfunctions commonly studied by sex researchers and

5 Please see Appendix A, "Key Concepts" for the definition of sexuality

6 Please see Appendix A, "Key Concepts" for the definition of sexual health

${ }^{7}$ I define the sexual body as that which encompasses the physical, emotional, spiritual, intellectual and cultural experience of sex as it intersects with the physical body. 
therapists (Binik, Bergeron \& Khalifé, 2000; Kaplan, 1974; Kleinplatz, 2001; Masters \& Johnson, 1966). These writings are often written post fact (as opposed to researching the 'before' sexual healthy body and the 'after' unhealthy body). With the exception of few such as Kleinplatz (2001), most researchers and therapists work from a normative "male focused" sexuality. This can be defined as being goal oriented or viewing healthy sexuality as the achievement of penile/vaginal intercourse ending in orgasm (Binik, Bergeron \& Khalifé, 2000; Kaplan, 1974; Leiblum \& Rosen, 2000; Masters \& Johnson, 1966).

Other historical or socially constructed norms are the assumptions that penile/vaginal intercourse only occurs between two attractive, healthy, ablebodied, passionately aroused partners (Kaufman, Silverberg \& Odette, 2003). These assumptions can influence women's sexual scripts. Plummer (2002), more specifically, defines sexual scripts as those that, “...emerge in encounters...to make 'sexual sense' of selves, situations and others" (23). Foucauldian adherents meanwhile would argue that sex and sexuality "are to be understood as historically specific and socially constructed, through modern discourse" (Horowitz, 1987: 62). From within this discursive network, the literature on which this thesis relies outlines key concepts that I use in my work. These include; discipline and control, the sexual body, and gendered sexuality. These concepts have informed women's experiences of sexual abuse/assault, sexual dysfunctions, chronic pain and/or disability (Hall, 2004; Leiblum \& Rosen, 1991; McInnes, 2003; Money, 1994; Plummer, 2002). In turn, they inform my own 
understanding of my sexual body, my personal and sexual scripts and my experiences of living with chronic vulvar pain.

\section{Sex Therapy}

Shifting problematic or restrictive views of sexuality is the primary focus of sex therapy (Shaw, 2001). Credited for laying the foundations of the profession, Masters and Johnson's book, Human Sexuality (1966), was seen as being both groundbreaking and revolutionary (Daniluk, 1998). Moreover, their behaviouroriented approach worked in tandem with their sexual response model (desire, arousal, orgasm and resolution). This served to teach therapists to use the previously mentioned, sensate focused, brief intensive therapy (Masters, Johnson \& Kolodny, 1995). While their work does provide an interesting foundation for the sex therapy profession, it has been critiqued for being male/goal oriented and not exploring how cultural, social, political and spiritual factors intersect with women's sexual lives (for examples of this critique see Kaschak and Tiefer, 2001 and Kleinplatz, 2001).

Helen Singer Kaplan wrote the next most relevant text, titled The New Sex Therapy: Active Treatment of Sexual Dysfunctions in 1974. While the text played a pivotal role in shaping sex therapy, it disregarded women's sexual pain. Rather, she identified women's sexual dysfunctions as vaginismus, ${ }^{8}$ coital orgiastic dysfunction, 9 general sexual dysfunction, and even included the more dated diagnosis of penis envy (Kaplan, 1974). Using Masters and Johnson's

${ }^{8}$ Please see the Key Concepts section for a definition for vaginismus.

${ }^{9}$ Coital orgiastic disorder is the inability to achieve orgasm through coitus or penile-vaginal intercourse. 
research as her guide, Kaplan stated, "only a small percentage of female sexual dysfunctions [are] due to physical disease' [and] in the great majority of cases, the dysfunction is psychological in origin" (Kaplan, 1974: 344). It is important to note that research has been conducted that contradicts Kaplan's assertion regarding the absence of physical disease (see for example, Binik, Bergeron \& Khalifé, 2002; Glazer \& Rodke, 2002; Stewart \& Spencer, 2002).

The behavioural therapy model was the next step in the evolution of sex therapy. Lo Piccolo (1978) took Kaplan's earlier research and incorporated a more complex theoretical basis that included: (1) mutual responsibility, (2) information, education, and permission giving, (3) attitude change, (4) anxiety reduction, (5) communication and feedback, (6) intervention in destructive sex roles, lifestyles, and family interactions and (7) prescribing changes in sex therapy. These additions were important, but they too were situated within a male/goal centred (ejaculation/orgasm) model.

During this period, sex researchers and therapists were beginning to explore how physical, emotional, spiritual, intellectual and cultural experience intersected with the sexual body (Gagnon, 1963; Lief, 1963; Lief, 1965). It was during this time that marriage, social contexts and scripting began making their way into the sex therapy practice. This change was relevant to sex therapists and researchers because the concept of sexuality moved beyond the psychological and internal gaze of the woman and onto the social structures that influenced her sexual experiences. While much of the literature focuses on men and male sexual dysfunctions (Masters \& Johnson, 1966; Kaplan, 1988; Money, 1994), women's 
sexuality was also gaining relevance in the medical and social science fields (see for example, Boston Women's Health Book Collective, 1998; Dodson, 1996).

Sexual satisfaction, sexual desires and an expanded understanding of sexual responses (beyond goal oriented phallic/coital intercourse) began to seep into sexual research. Also, included was recognition that women with disabilities (Kaufman, Silverberg \& Odette, 2003; Price \& Shildrick, 1998; Schover, 2000) and postmenopausal woman were also sexual beings (Basson, 2001; Daniluk, 1998; Dodson, 1996; Leiblum \& Segraves, 1995; Loulan, 1984,). That is not to say that the research had moved outside a male/goal-oriented paradigm (Kleinplatz, 2001). Testosterone studies, invasive pharmaceutical interventions and a focus on female libido as equal to male libido continued to dominate the research and ultimately ignored the cultural, social, political and gender politics that greatly influenced women's sexuality (Berman and Berman, 2001; Kleinplatz, 2001b; Leiblum \& Rosen, 2000). This stream of research continues to dominate today.

In Canada, sex therapy is a growing profession. While I have found little historical research about the practice, we know that Dr. Stephen Neiger is credited for bringing Masters and Johnson's behavioural approach to Canada (Barrett et al., 2001, cited in Francoeur, 2001). Neiger challenged the standing assumption that psychotherapy was the best tool to work with clients with sexual dysfunctions and, in contrast, argued that,

...many [sexual problems were] a product of inadequate education, cultural taboos, and the anxiety and negative reinforcement generated by unrealistic performance expectations" (cited in Francoeur, 2001, n.p.). 
His views played an important part in changing the landscape of care in Canada. Nonetheless, there exist many limitations to changing these expectations.

Barrett, et al. (cited in Francoeur, 2001) argue that sex therapy in Canada is limited if only because counselling is offered by a myriad of professionals, none focusing particularly on sexuality. Unlike most other professions, sex therapy is unregulated and no national body exists to oversee costs, establish guidelines or guarantee quality behaviour on behalf of the practitioner outside of her or his own professional organisation (i.e., College of Social Workers, American Association of Marriage and Family Therapists). This can produce varying levels of care offered to clients across Canada wanting to work through sexual dysfunctions or chronic pain conditions. It also creates difficulties when practitioners are expected to undergo private training (i.e., the expensive Sexual Attitude Reassessment Weekend) and be knowledgeable about the medical, psychological or educational complexities that often intersect with the experience of dysfunctions. With few therapists trained in sex therapy and fewer schools providing this training, the waiting lists present many problems to clients requiring case specific treatment (BESTCO, 2004). Moreover, unlike the American Association of Sex Educators, Counsellors and Therapists (AASECT), there exists only one body that supports the profession in Canada. Created to "develop standards and criteria by which the profession could be voluntarily and self-regulated," The Board of Examiners of Sex Therapists and Counsellors of Ontario (BESTCO) emerged in 1975 from the Ontario Association of Marriage and Family Therapists (OAMFT) (BESTCO, 2004). This is not to say that a 
unified perspective on sexuality is needed or is necessarily beneficial. Sex therapy in Canada creates an opportunity for diverse practice by doctors, therapists, social workers, nurses and clergy and in diverse settings like hospitals, agencies or private clinics. It also challenges a universal categorisation of sexuality (i.e., heteronormative, pain free, penile/vaginal, etc.); thus opening space to make sense of sexuality in multiple ways. In short, I would argue that a diverse approach to sex therapy provides clients with services that are creative, decentred and shifting. However, in order to ensure some degree of protection for the client, it would be helpful to have broad measures of accountability.

Another barrier to effectively supporting people with sexual pain problems is that our under funded social services consider sexuality to be a luxury (Tiefer, 1996). This makes sex therapy an often inaccessible resource. At this time, only physicians and psychiatrists are able to bill the provincial health care systems for treatment of sexual dysfunctions and concerns. Further, few insurance companies cover the cost of sex therapy that is provided outside of the more accepted marriage and family therapies. As such, costs for adequate support are prohibitive and present many barriers (i.e., including personal embarrassment, limited finances, cultural taboos, accessibility). The costs are not only financial. With regards to time, to address many female sexual dysfunctions and specifically vulvar pain, it may require many appointments and treatments to find the appropriate support/cure. It follows, then, that when Dr. Glazer (2002) conducted his online study about which women experience vulvodynia, the majority of the patients were white, middle class and from urban centres 
(www.vulvodynia.com). This sample, according to Harlow and Stewart (2003), is not representative of vulvar pain sufferers.

\section{Feminism and Sexuality}

Accessing sexual resources (i.e., therapy, tools, research and credibility) proved to be a formidable task over the past nine years. While I was fortunate to come from a privileged position of being a white, middle-class woman, living in a progressive city in Western Canada during the initial years of my condition, I still faced many barriers in receiving support. My earlier experiences with the medical system involved being tested for numerous sexually transmitted infections (STI), asked about my sexual practices, told to use more lubrication when engaging in sexual intercourse and even labelled as frigid and sexually averse. At no point in the first three years did physicians conclude that my vulvar pain was a physical condition. Instead they were baffled by the invisibility of my 'sexual complaint' and without undergoing more complex and in-depth testing (i.e., Q-tip test, MRI, biofeedback), they determined it as being psychological.

As I tried to make sense of this repeated experience, I began to see that my "sexual problem" appeared to make general physicians uncomfortable and I was led to believe that my sexuality did not "warrant" medical help. It was after multiple experiences with doctors that I chose to make my personal experiences of living with chronic pain a very political and public issue. In reviewing the literature concerning vulvar pain and its relationship to feminist identities, I discovered that very little is written from a personal perspective beyond that 
which is on the internet. ${ }^{10}$ At the same time, I found that there are a growing number of books being written by feminist leaning practitioners about women's general sexuality (Kleinplatz, 2001; Kleinplatz, 2001b, Maltz, 2001; Stewart \& Spencer, 2002). These resources helped me to make sense of the ways that sexuality is connected to women's health. The politics of sexuality led me to ask: how does being a woman, living in a patriarchal defined society inform my pain narrative? To answer this question, I delved deeper into the ways in which my feminist politics were cultivated in part and in interaction with my vulvar vestibulitis.

\section{Sexual Subjectivity}

Many feminist authors have used Foucault's writings to make sense of subjectivity, sexuality, power and knowledge (Chatterji, Chattoo \& Das, 1998; Diedrich, 1998; Diprose, 1998; Harowitz, 1987; Stacey, 1997; Vasseleu, 1998; Weir, 1998). While Foucault did not focus his attention on women's lives, his work on the discourse of sexuality and subjectivity has been useful to many feminist theorists (Phelan, 1990). Foucault states that individuals do not have an inherent or static identity. Rather, he argues that subjects are created through discourse (Foucault, 1997). Drawing on this theoretical position, Probyn's (1993) book, Sexing the Self, explores the ways in which women's sexual bodies are multilayered and complex. She writes,

\footnotetext{
10 There are many websites, such as www.vilvarhealth.com, www.angelfire.com $/ \mathrm{md} / \mathrm{vulvardisorders/, \quad www.branwen.com/rowan} \mathrm{and}$ www.vulvarpainfoundation.org/ that provide women with support groups, list serves and information regarding vulvar pain.
} 
... [o]ne way of imaging this self is to think of it as a combination of acetate transparencies: layers and layers of lines and directions that are figured together and in depth, only then to be rearranged again" (Probyn, 1993: 1).

The idea of rearranging our layered self is important if only because I see my sexual self in a constant state of flux. Thus, there exists a meshing and fracturing of my self that is in constant state of renegotiation; thus making it difficult to describe myself in coherent, simple terms.

In further cultivating the self, individuals participate in behaviours, form certain attitudes and construct manners of living, which, give "rise, finally, to a certain mode of knowledge..." (Foucault, 1988: 45). This knowledge is not objective, but is interpreted through exchanges with others (Brookes, 1992). In conjunction with the 'discursive self,' knowledge becomes a key element in this project to understand my self (Miehls \& Moffatt, 2000; Price \& Shildrick, 1998). My narratives, as evident in Chapter 2: Pleasure and Pain and Chapter 3: Navigating the Medical System, work to explicate the sites of power (i.e., the gendered bedroom, the clinic, and the therapeutic relationship) and the ways in which I constructed/obtained knowledge that worked through me to form a sense of resistance. Gilmore (2001) describes this process as "scenes of selfconstruction, whether via sexual self-definition and self actualization or through disciplinary processes of power, involved looking back in order to look forward" (34). In short, sexuality, self, knowledge and power are fractured, informed by outside forces and are in their very essence inseparable. These are common themes throughout this paper. 
The project of cultivating one's subjectivity, however, requires an understanding of truths ${ }^{11}$ within the context of self-actualization. Foucault (1990) argues that normality and deviance are constructed through the unconscious and conscious repetitions of dominant discourses. Adding to that, Kogan and Gale (1997) contend, through macro level power relations and the interaction with others,

...discourses are reproduced... and produce an individual's sense of whom and what she is. The extent to which a person may resist participation in a particular discourse is negotiable to some degree, and can provide space for alternative actions and an alternative sense of subjectivity (2).

While discourse is a social phenomenon, our narratives and practices are local performances of discourse. As such, the ways in which we negotiate how we perform or engage in discourse can be altered, shifted or decentred and therefore opens the possibility to challenge our dominant narratives. The notions of shifting or reauthoring are common themes found in the narrative therapy/research literature (Blumenreich, 2004; Carr, 1998; Enns, 2004; Kohler Riessman \& Quinney, 2005; Presser, 2005). Moreover, the reimagining of dominant practices present interesting opportunities for sex therapists wanting to support their clients living with vulvar pain in shifting their sexual scripts and what Stacey (1997) calls the "body metaphor."

${ }^{11}$ I understand truths to be incapable of concrete or permanent understanding; rather, I understand them to be situated within a certain historical and culturally constructed context. 


\section{Body Metaphor}

I often used cancer narratives as a resource to better understand subjectivity construction and the project of storytelling within the context of illness (Diprose, 1998; Stacey, 1997; Thomas-MacLean, 2000). A common theme throughout much of this cancer literature is the metaphor (Belenky et al., 1997; Gilmore, 1994; Stacey, 1997) and its ability to challenge the common cancer narrative. Stacey (1997) writes,

According to contemporary biomedical discourse, a malignant tumour is the result of abnormal cell development; ... it might be read as indicative of other deviant developments, such as those connected with gender and sexuality. Body metaphors here produce evidence of deviant medical and sexual states....In the absence of a punishing God, our internalised sense of guilt has bodily repercussions and makes our transgressions visible for all the world to see....Cancer is the self at war with the self(62).

It becomes clear that subjectivity, the metaphor and the illness are intimately intertwined. The sick person's subjectivity is often situated within a vulnerable or victim location in which her illness is interpreted as "one's fault." This was certainly my experience. Further, in a society that values heroines and heroes, remaining chronically ill equates physical/emotional/psychological failure (Parsons, 1951; Stacey, 1997). As it pertains to my thesis, the interpretation that my vulvar pain is a result of something I have done has very real consequences. Compounded by my own guilt, are my experiences with the medical system, my partners and my social support system. For example, being misdiagnosed with having sexually transmitted infections, being labelled as being frigid or being uncommitted to a cure suggests that I am to blame. My interpretation of this 
suggestion intersected with my internalised guilt. I explore this concept in more detail in Chapter 3: Navigating the Medical System.

\section{Narrative Approaches to Social Work Practice}

"[K]nowledge is power, and self-knowledge can empower people" (Kelley, 1996: 463).

In the 1980s, Michael White and David Epston, two family therapists from Australia and New Zealand respectively, created narrative therapy and brought it into the sphere of family therapy. Popularized after their first book, Narrative Means to Therapeutic Ends, the approach was, and continues to be, a popular tool for social workers, counsellors and family therapists. In fact, it has particular use for the latter group who "search for the meanings of events and behaviours as preconditions for action" (Kelley, 1996: 462). In practicing social work, narrative approaches provide us with a unique tool to work with diverse communities. Consequently, I use the narrative approach (working with scripts) to integrate my theoretical approach into practice.

Kelley (1996) argues that narrative therapy acts as "a new paradigm for viewing human change" (462). Other theorists argue that it is an important "metaphor for conceptualizing constructivist and postmodern themes in counselling" (Kopala \& Keitel, 2003: 16). Applied in various forms, women can use such approaches to make sense of their experiences and then work with them to take action and re-author the stories that, situated within a larger context, shape their lives (Kelley, 1996). For instance, one possible narrative may be the 
re-shaping of identity from victim to survivor. This has direct implications when working with women who have experienced domestic or physical violence, especially as it recentres women as the experts in their own lives (Morgan, 2000).

The work of White and Epston, however, did not occur within an academic vacuum. They were influenced by both postmodern social theories including poststructuralism, and individuals from varying disciplines: Michel Foucault (social historian); Jacques Derrida (literary critic); Jerome Bruner (social psychologist); Victor Turner and Edward Bruner (anthropologists); Chris Weedon, Rachel Hare-Mustin and bell hooks (feminist theorists); and Gregory Bateson (systems theorist) (Besley, 2001; Kopola \& Keitel, 2003; Nylund \& Nylund, 2003). White and Epston's narrative approach emerged from a literary constructivist method that worked to pull apart the storyline and, thus, to tease out the meaning behind the dominant story. It then worked to "externalize" that problem and "reframe" it to be understood in a different manner (Besley, 2001; Kelley, 1996; Kopola \& Keitel, 2003; White \& Epston, 1990). This reframing process works well within a constructed narrative insomuch as it views stories as dynamic and multilayered.

The narrative approach offers the possibility to operationalise postmodern theory (which works at the macro level), at a micro level. That is to say, Freedman and Combs (1996), suggest that four main ideas evolved from the "worldview" of postmodern thought:

1. Realities are socially constructed through four processes: typification, institutionalization, legitimization and reification. 
2. Realities are constituted through language.

3. Realities are organized and maintained through narrative.

4. There are no essential truths ${ }^{12}(22-35)$.

Therefore, postmodern social theories are concerned with deconstructing the "universal claims, and 'grand theories' or 'totalizing theories,' such as Marxism, socialism and capitalism" (Lundy, 2004: 40). The narrative approach meanwhile deconstructs the "plot" and "characters" of the story line (Kelley, 1996: 463). Further, just as the postmodern philosopher sees "truth [a]s the product of language or social discourse and [a]s not objective or universal" (Lundy, 2004: 40), ${ }^{13}$ the narrative theorist see stories as the product of experience and social environments and argues that they cannot be objective or universal (Kelley, 1996).

White drew on Foucault's notion of discourse to suggest that the client is capable of reauthoring her narratives (Freedman \& Combs, 1996). At times, this approach has been reinterpreted as situating women as "experts" in their own lives. This reinscription of narrative approaches highlights a tension between Foucauldian analysis, which views the "expert" positions with ambivalence, if not outright suspicion (Besley, 2001), and feminist approaches that, instead of deconstructing expert positions, tend to inverse them so that women are resituated as experts in their own life. Within a feminist analysis, the expert position provides women with the possibility to facilitate their own change and

\footnotetext{
${ }^{12}$ It is interesting to note that in the process of claiming that there are "no essential truths" one is making an essentialist statement.

${ }^{13}$ Lundy (2004) positions her text as countering postmodernism
} 
make sense of their own self. Within a counselling model, the counsellor is removed from the normative expert role and instead, is posited within a (feminist) "productive and ethical" role (Besley, 2001: 82). That is to say, it becomes no longer the purpose of the counsellor to empower the woman; rather it is her purpose to facilitate a space where the woman can achieve a new understanding of her self in the process of reframing her own dominant narrative. In contrast, Foucauldian approaches to counselling attend more to the uncertainty of the many ways our experiences can be defined and challenge the interests that lie behind the dominant narratives we use (Besley, 2001; Trotter et al., 2006).

Concerning this project, I found the narrative approach of rescripting dominant scripts to be very useful in the last two chapters. It provided shape to my feminist and Foucauldian framework. Further, critically reflecting upon my dominant pain narrative and reframing it as one part of an entire "self," as opposed to the essentialised self (i.e., contained and static), provided me with the space to understand my vulvar pain as something manageable. Further, it helped me to reclaim my sexual body and make sense of the other narratives, such as stigmatization.

\section{Stigmatization}

Stigma, while arguably not one of my more dominant narratives, is a theme throughout this critical reflection. I understand stigma to involve those negative assumptions that underlie our thoughts and actions. The processes 
through which we socially construct sexuality, sexual "problems" and sexual illnesses are woven into these assumptions and can be evidenced in the way we treat sex. ${ }^{14}$ For instance, having a problem "down there" invites victim blaming because of the way western society problematises sexually transmitted infections (STIs), menstruation and women's sexual pleasure (Boston Women's Health Collective, 1998; Foucault, 1990; Kaufman, Silverberg \& Odette, 2003; Plummer, 2002; Stewart \& Spencer, 2002). While vulvar pain is rarely associated with STIs, the proximity and proclivity to sexual play, often leads to assumptions that the women did something "wrong," 15 leaves women feeling stigmatized and at fault (Glazer \& Rodke, 2002; Stewart \& Spencer, 2002). These assumptions inform the ways in which we negotiate the pain condition vis-à-vis what we see played out within our social structures (i.e., the media, family, school, friends, etc.). Further, these negotiations are part of the process of constructing our "social and moral order" (Juhila, 2004: 261). Put differently, if our "identity" does not conform to what Juhila defines as "culturally dominant categorizations" we become stigmatized (2004: 260).

While Juhila was referring to the stigmatized identities of women and men living in a shelter, the way in which she explores how residents "talk back" is

\footnotetext{
${ }^{14}$ Foucault (1990) argues that certain mechanisms of power were (and arguably are) located on the sexual body, using both disciplinary and regulatory techniques, to "ensure the physical vigor and the moral cleanliness of the social body; [mechanisms of power] promised to eliminate defective individuals, degenerate and bastardized populations" (54).

${ }^{15}$ Glazer \& Rodke (2002) outline six Myths and Misconceptions associated with vulvar pain. They assert that Vulvodynia: 1) is not an STI; 2) does not cause cancer or increase risks of getting it; 3 ) is not in women's heads; 4) is not correlated with a higher incidence of past sexual abuse; 5) may co-exist, but is not caused by HPV, vaginal yeast infections or urinary tract infections; and 6) can be treated and women can live normal healthy lives that include "good sex" (26-27).
} 
relevant to this thesis (see also bell hooks, 1989). The act of talking back can be best described as a dialogue,

...consisting of acts which comment on and resist stigmatized identities related to culturally dominant categorization and which have the function of presenting the difference between one's own self or a group and the dominant definition...subtle negotiation which calls into question dominant categorizations and evokes the possibilities of alternative identities" (Juhila, 2004: 263).

The process of talking back suggests resistance from members of marginalized communities to "their given subjectivity." Furthermore, given the large amount of literature written about the convergence of stigma and sexuality, our physical, emotional, psychological, cultural and religious identities play into our understanding of what sex "should look like" (Diprose, 1998; Foucault, 1990; Plummer, 2002; Stewart \& Spencer, 2002). These concepts, stigma and stigmatisation, certainly apply to my own way of understanding my sexual pain narrative. While it is well documented that stigma is intimately linked with subjectivity of a woman living with vulvar pain, my thesis and the way in which it is constructed is my way of "talking back."

\section{Representations of the Self}

The process of talking back to stigma and making sense of our sexual bodies through metaphors requires some understanding about how we define truths and represent our selves. Our definition of truths becomes implicit in our construction and representation. Gilmore (1994) argues, "[t]he autobiographical subject is a representation and its representation is its construction. The 
autobiographical subject is produced not [only] by experience but by autobiography" (25). In saying that, truthfulness requires a level of ethical responsibility on behalf of the storyteller/autobiographer. As my mother would say, "it is how the story is told." Put differently, the construction of self emerges and takes shape in the myriad occasions of telling one's story (Brookes, 1992).

In reviewing the literature, there is a great deal written on the subject of reflection as it pertains to narrative theory (Elbaz-Luwisch, 1997; Fraser, 2004; Muntigl, 2004; Overcash, 2003; Presser, 2005). At the same time, using personal critical reflection through autobiography poses certain challenges. For instance, in comparison to other quantitative or qualitative methodologies, there exist few resources that explore this particular qualitative approach in depth. This suggests that an autobiographical methodology is still relatively marginalized in the social sciences. As well, I was unable to find a resource that focuses on using autobiography to explore one's personal construction of sexuality (which, as evident in the literature review, encompasses many personal, social and cultural barriers/stigmas) as a model for understanding. Notwithstanding, other models exist that I was able to use as a benchmark from which to work, such as Probyn's (1993) cultural studies interpretation of selves, Gilmore's (1995, 2001) work on autobiography and Foucault's work on subjectivity, sexuality, power and knowledge $(1988,1990,1997,2003,2006)$. 


\section{Research Questions}

In light of my literature review, I used the following questions to guide my research:

1. How has my diagnosis of vulvar vestibulitis informed/changed my understanding of my sexual self?

2. Whether, and if so, how does my sexual subjectivity inform my future occupation as a social worker and sex therapist?

\section{Theoretical Framework}

Rainbow (2003) wrote that no one framework should ever be used to research people. Specifically, she argued that women are complex and highlighted the influences that power, gender and sexuality have in constructing social identities. While often conflicting, Foucault and feminist theorists share many areas of interest, such as power, resistance, sexuality and knowledge. These are also the themes that I use to highlight the complexities of my sexuality in relation to vulvar pain. Each offers a unique lens through which I can examine my experience with chronic vulvar pain and the social forces that influence that reading. To help frame the thesis, I also use a narrative approach, specifically in Chapters 3 and 4 . I do this to ground the thesis within a strong therapy framework that compliments Foucault's theoretical and feminist political positioning(s).

Vulvar pain is arguably connected to or "influenced by the political and social climate in which people live" (Enns, 2004). For example, not conforming 
to a normalized understanding of sex (i.e., once a week, heterosexual, missionary position, pain free, penile-to-vaginal coitus) fractures what many of us of been raised to believe about intercourse (Kaplan, 1974; Masters, Johnson \& Kolodny, 1995; Money, 1994). Consequently, space is opened that makes room for alternative or multiple sexual experiences, thus possibly pushing us outside the margins of normative acceptance (Working Group, 2001). The very act of this marginalisation politicizes our personal sexuality.

Within a largely patriarchal medical system, many feminists assert that there also exists a hierarchical power structure - men are above/before/in charge of/ smarter than women (Gamble, 2001). These inequities can be seen in health providers' approaches to women - responding to them with paternalistic behaviours, imposing societal values upon/through women's bodies and ignoring women's concerns and complaints (Boston Women's Health Book Collective, 1998; Conn \& Fox, 1998; Ehrenreich \& English, 1973). It is also important to note that many women, because of their gender, typically comply with "medical" experts (Mitchinson, 1979). However, their compliance is not always met with competent support. In fact, according to Rosenthal (2004) and Stewart and Spencer (2002), female genitalia remain one of the forgotten areas of women's bodies and, as a result, there exist a limited number of books focussing on vulvar health. Doctors and patients are thus, hard pressed to find up-to-date and factual information.

One feminist reading of our early medical history suggests that it was characterised by a campaign to eradicate the midwife or the healer and to replace 
in her absence, the male scientific professional who used positivist approaches to "heal" (Ehrenreich \& English, 1973). By creating historically located and culturally specific boundaries and definitions around natural processes (i.e., menstruation, sexual pleasure, birthing and/or birth control), people in modern society came to believe that the woman's body is no longer within her control. For instance, Conn and Fox (1998) argue that women,

...grow up with the idea that medicine is an exact science, that proof positive exists for every treatment...to trust them to make decisions for us, in the belief that they are skilled and dedicated humanitarians whose professional standing reflects their superior intelligence and years of technical training" (36).16

This quote reasons that our sex-role conditioning (that which ensures we adhere to our maleness and femaleness) ${ }^{17}$ has fused with our medical conditioning of compliance and confession (Foucault, 1990). Foucault (1990) argues that the complexities involved in shifting bodily surveillance from the church to the medical institution are multiple and manifested through multiple sites of power.

One example of this could be a gendered adherence on how both women and men behave in the doctor's office. Sherwin (1979) would go so far as to argue that, "[d]octors, like most of the population, tend to view women as weak, illogical, dependent and not fully rational" (6). While most researchers may contend that our medical system has evolved in the last 50 years, the

\footnotetext{
${ }^{16}$ It could also be argued that men grow up with the same beliefs. Yet, a gendered power difference exists between men and women in relation to roles executed by medical professionals, such as men being physicians and women being midwives and healers. The shift that took place from midwifery and health as responsibilities of women to medical science taken from the hands of women and placed into the hands of medical science makes it such that a gendered reading is both plausible and relevant.

${ }^{17}$ Female roles include behaviours like passiveness, compliance or gentleness, while male roles involves behaviours like assertiveness, decision-making and aggression (Conn \& Fox, 1998; Mitchinson, 1979).
} 
assumptions regarding necessary compliance to healthcare and the patriarchal framework upon which those assumptions have been built have shifted little (see for example Lorber and Moore, 2002).

One group that has been vocal in response to the continuing medical and sexual oppression of women is The New View of Women's Sexuality (Working Group). Inspired by feminist practice, this movement offers us with a refreshing approach that specifically challenges the medicalisation of women's bodies, the "pharmaceuticalisation" of women's sexualities and the "patriarchalisation" of intimate relationships (Kaschak \& Tiefer, 2001). Comprised of social scientists, psychiatrists, academics and medical professionals, the Working Group argues that women's issues do not conform to the Masters and Johnson's (1966) sexual response model (desire, arousal, orgasm, resolution). Instead, they call for a different understanding of women's sexualities.

First, they contend that the complexities of women's social/political/cultural/economic lives require a gendered reading of their sexuality. Second, they believe that one cannot remove the relational context from their sexualities, as suggested by the Diagnostic and Statistical Manual of Disorders (DSM-IV) (Kaschak \& Tiefer, 2001). Third, they believe that not all women experience pain, sex, relationships, or love in the same way. Finally, they state that there is no "one treatment fits all" approach. In its place, the Working Group defines sexual problems as:

...discontent or dissatisfaction with any emotional, physical, or relationship aspect of sexual experience, [that] may arise in one or more of the following interrelated aspects of women's lives: 
1. Sexual Problems due to socio-cultural, political, or economic factors;

2. Sexual problems relating to partner and relationship;

3. Sexual problems due to psychological factors; and,

4. Sexual problems due to medical factors (2001: 5-7)

By using this framework, I am able to examine my chronic vulvar pain as an issue of well-being and health as opposed to a deficit in my sexual ability.

Intermeshing feminist politics with a Foucauldian reading of power and sexuality are important theoretical underpinnings of this thesis. I frame my thesis using the work of French philosopher and social historian, Michel Foucault, to guide my understanding of power/knowledge/self. Situating myself as an insider, rather than claiming the space of an objective observer, allows me to reflect on how I understand power, knowledge and self-representation and their influence in my own life as it relates to my vulvar pain experience. It equally allows me to examine the agencies of regulation (i.e., the clinic, the profession of sex therapy, societal readings of fantasy and heterogeneous sexualities) that exist in our society. I see the absence/silence of women (who suffer from vulvar pain) in the research, counselling practices and possible treatments as illustrative of the mechanisms of power that work through the medical health system. Yet, it is important to note that these mechanisms are not void of consent. Further, there are elements of resistance that work to disrupt the experience of repression or control. As one who has been living with vulvar pain and has been navigating the medical system in search of support, I feel that I am in the unique position to begin making sense of the complex mechanisms that 
take shape in the form of patriarchy, the medicalisation of my body and the pharmaceuticalisation of my sexual pain. ${ }^{18}$

A Foucauldian reading of power, knowledge and social discourse provides the next layer of my theoretical framework. Foucault contributes three conceptual tools that are most relevant to this thesis. First, his approach identifies power as complex, decentred and shifting. It is manifested through people as opposed to upon them. This occurs through a discursive process. Foucault states that,

We must make allowance for the concept's complex and unstable process whereby discourse can be both an instrument and an effect of power, but also a hindrance, a stumbling block, a point of resistance and a starting point for an opposing strategy. Discourse transmits and produces power; it reinforces it, but also undermines and exposes it, renders it fragile and makes it possible to thwart it (Foucault 1990, 102).

Discourse as a theoretical phenomenon makes room for complex understandings of social forces, power, self and sexuality.

Second, Foucault asserts knowledge as power. In the book, Power/Knowledge (Gordon, 1980), Foucault suggests that knowledge becomes power within an economy of discourse. My thesis, which is an exercise of personal and social work academic reflection, is part of my own larger and complex discourse. To make sense of the complexities, I work from the position that knowledge can be understood as having an object (what is known) and its

\footnotetext{
${ }^{18}$ While there are certainly advantages to remaining outside of the medical system with regards to diagnosing and treating vulvar pain, the reality is that most women see their physicians first (this is discussed later in this thesis) and costs for alternative treatments may not be covered by provincial health insurance. As such, working within to educate and shift the patriarchal organisation of the medical system may prove to be a more pragmatic approach to responding to vulvar pain.
} 
"other." The "other," in the case of this paper, is the person who receives the knowledge (Foucault, 1988). However, a technology of power is created when specialist knowledge exists. My desire to become a sex therapist is an excellent example of this, especially as I work to obtain a professional degree in social work, specializing in sexuality. I would argue that this positioning places me in the privileged location of both defining experiences (i.e., sexual dysfunction) and treating them. In doing so, my specialized knowledge produces a unique position with the potential to both challenge and disrupt the expert position.

Foucault (2006) also suggests that we must understand experiences (i.e., sexual dysfunctions) not as transparent reflections of an objective reality, but rather as constructed through discourse. He posits that we must look at where power/knowledge is situated as opposed to who created it $(1980,2006)$. This suggests that the individual is as important to the experience of power/knowledge as social structures. Further, social discourse renders the players (i.e., individual and social systems) as complicit in producing those structures we understand as repression. This opens a space of resistance, which Foucault suggests is always coupled with power (1990: 95). My thesis, which explores the way in which power/knowledge informed my reflections, works to resist the powers that have worked through me and have been produced by me. Using elements of the narrative approach (scripts, reauthoring, and counselling techniques), these reflections examine how I make sense of my self, as well as how I understand my relationship with the world and the social forces through which they are constructed or mediated. 


\section{Methodology}

The act of telling can serve many purposes - to remember, argue, justify, persuade, engage, entertain, and even mislead an audience (Bamberg and McCabe cited in Riessman \& Quinney, 2005: 395).

My decision to use the autobiographical method was inspired by the writings of Anderson (2000), Belenky, Clinchy, Goldberger and Tarule (1997), Brookes (1992), Gilmore (1994 and 2000), Grumet (1980) and Stacey (1997). Each author provided me with the approaches to analyse and reconceptualise my discursive truths and my subjectively experienced sexual body. Haug et al. suggests that the autobiographical process is a "way of working through ideology" (cited in Brookes, 1992: 44). Given that I was working from a feminist Foucauldian framework, I found that the autobiographical process facilitated a rich analysis of the significant moments raised throughout this thesis.

My methodology incorporated two phases that were inspired by Grumet's (1980) essay, "Autobiography and Reconceptualization." The first phase involved writing eight detailed scripts that were rich in description and provided what she refers to as, "educational experiences" (26). To do this, I wrote for thirty-minute periods, using free association, and mapping to assist the process. Once I completed the thirty minutes, I then edited the scripts to ensure readability for my audience. To these I added emails, journal entries and maps that I had written prior to and during the writing of this paper.

The second phase involved analysing the narratives and working to "ascertain what [was] missing in the text as well as to recognize patterns and themes that often surface[d] in each of the apparently disparate narratives" 
(Grumet, 1980: 28). It is here that I interwove academic papers, as well as my own writings, into my analysis.

The process of using the autobiographical method requires a certain discipline that I found difficult to employ. I did not want this paper to be a cathartic exercise that lacked critical reflection or theoretical examination. As a result, I chose to incorporate Tenni, Smyth and Boucher's (2003) suggestions for working with autobiographical data:

1. Find good data

2. Have an involved supervisor

3. Use different theoretical constructs to inform the interrogation of the data

4. Take personal, professional and theoretical risks.

Having an involved supervisor was critical to my process. Professor Sarah Todd and I often met to discuss the obstacles I faced throughout this exercise. She then helped me tease out the points that would be most notable in my narratives. Moreover, her knowledge about autobiographical methodology, feminist and Foucauldian epistemology and sexual subjectivity was valuable.

While many would argue that writing an autobiographical thesis is a risk unto itself, I found that there were many opportunities where I could have taken the safer road. Offering up my sexual history and then critically reflecting upon the ways in which gender, power and subjectivity intersected with that history was daunting. My scripts, prior to the editing stage, were raw and left me feeling overwhelmingly exposed. What remains in my thesis is equally risky, but the language and the level of exposure are lessened. Gilmore (1994) offers, 
That self-representational moment, structured and experienced as an exercise in truth production, reveals something crucial about autobiography. In that discursive setting, where truth is known at least partially through its proximity to risk, identity emerges not as a thing in itself patiently awaiting the moment of revelation but as the space from which confession issues...Sexuality as what is confessed, or the topos of truth, is represented through the nexus of gender, identity, and authority (106)

Notwithstanding, I worked very hard to honour the importance of taking risks throughout this paper. Without them, I feel the learning process would have meagrely scratched the surface and I would not have accomplished what I set out to do in the initial project.

Four themes are woven through my narrative:

\section{1) Pleasure and Pain}

- Using memory and past journal entries, this theme is explored by examining my experience of disclosing fantasies, gender play, childhood sexuality and feeling obligated to engage in intercourse despite not feeling emotionally or physically aroused. It is a discussion on how pleasure intersects with gendered normative behaviours.

\section{2) Navigating the Medical System}

- This theme is articulated using articles, memories and journals, critically reflected upon my experiences of working with gynaecologists, physiotherapists and a sex therapist in search of a diagnosis and treatments for my vulvar pain. It raises issues of stigmatization, self-diagnosis, misdiagnosis and the multiple structural barriers to healing

\section{3) Shifting from Pain to Pleasure}

- Employing memories, emails and journals, I address this theme by exploring my path of healing once having received a diagnosis and some helpful treatments. It examines the transition of my dominant script from being one of having chronic vulvar pain to managing chronic vulvar pain as a woman. 


\section{4) Reflections and Relevance to Social Work Practice}

- I delve into this theme using memories and journal articles to academically reflect upon the influence of social work in sex therapy practice, as well as the ways in which my thesis has informed my future sex therapy practice.

Tenni, Smyth and Boucher (2003) argued that to be successful in using autobiographies,

The focus on self and our practice, as researchers and practitioners, requires that we reveal, in all its complexity and as authentically as we can, what we do, how and why we do it and what this means about us and the field or context in which we operate (3).

I have worked to weave my "inherently messy" (Tenni, Smyth \& Boucher, 2003:

3) narratives into my feminist and Foucauldian theoretical framework as a means of making sense of my experiences. The following chapter is the beginning of that journey and discusses the ways the pleasure is not only a gendered experience, but the way in which we understand it is individually, interpersonally and institutionally written upon the body. 


\section{CHAPTER 1: Pleasure and Pain}

Confession is intimately connected to sex if only because it is something to be confessed (Foucault, 1990). Foucault argues that those wanting to create a standard of appropriateness, which was to shift sexuality into a re/productive exercise, produced sex as a discourse. The fracturing of sexualities into deviant, perverse or unproductive states occurred when norms (i.e., heterosexual, marital copulation) were manufactured by social forces, but at no time was sex ever silenced. In fact, sexuality was being talked about continuously, particularly by the clergy, the professors, the physicians and the lawmakers (Foucault, 1990). It was through categorising and normalising sexuality, that a language of sex was created:

...mixoscopophiles, gynecomasts, presbyophiles ... and dyspareunist women. These fine names for heresies referred to a nature that was overlooked by the law, but not so neglectful of itself that it did not go on producing more species, even where there was no order to fit them into" (Foucault, 1990: 43)

It is interesting to note that dyspareunist women fit into the heretic species of sexual deviants. This deviance was linked to the non-reproductive status of those women suffering from the condition.

I could posit that my discomfort in confessing my "deviant nature" (i.e., dyspareunia/vulvar vestibulitis) stems from this historical understanding of sexuality. But, this would be too simple an answer. The complexities are such that my sexual discomfort was influenced by my family, my church, my belief in my own sexual prowess, as well as my partners' comfort in discussing sexuality 
(among other pressures). Notwithstanding, the need to confess, or to engage in a discourse that produced "truth" is a desire that Western society has internalised and practiced as the norm:

...Western societies have established the confession as one of the main rituals we rely on for the production of truth...It plays a part in justice, medicine, education, family relationships, and love relations...One confesses in public and in private, to one's parents, one's educators, one's doctor, to those one loves; one admits to oneself, in pleasure and in pain, things that would be impossible to tell to anyone else, the things people write books about. One confesses - or is forced to confess" (Foucault, 1990: 58-59).

I recognise that this thesis, using the autobiographical approach, works to confess

in public those things that I previously found impossible to confess. It also helped me to pull apart the significant moments of my sexual subjectivity and lays the foundation for developing vulvar vestibulitis.

\section{Script \#1: Disclosing "Hidden" Fantasies}

The following script describes my memories of relevant sexual experiences and my disclosure of a "hidden" childhood sexual relationship.

...I had a few partners by then and all had been very positive experiences. We were in our late teens, early twenties and acted out very heteronormative sexual play. That is, we acted out the male-female, penile-vaginal, sexual intercourse. It was with those men that I learned to accept and feel comfortable with gender-prescribed, male/female binary norms in the bedroom (men often taking orgasmic priority, masculine men/feminine women), the realities and costs of daily birth control, as well as sharing and acting out fantasies.

One experience that stands out is a partner disclosing his fantasy of gender play (i.e., me acting as a man and he, a woman). At first I didn't really know what to expect. It was a completely new experience that sat outside the margins of my sexual comfort. However, I was inexperienced sexually and felt that to be a good lover I shouldn't judge and should try 
to be open to it. Unfortunately, it was during these sexual plays, that I began to experience vulvar pain. It was not that my mind was not aroused by the idea of cross-dressing, but I found that my body would clench up and I found penetration extremely painful. Soon all sexual intercourse became impossible.

...It required an immense amount of courage for my partners to share their fantasies with me. It conjured up feelings of a deeper intimacy. With the one partner who had disclosed to me his excitement towards gender play, I remember that I in turn confessed that, "I fantasized about women." I felt powerful. I also told him that I had played sexually with an older girl friend as a child. It was the first time I had told anyone about that. I guess that it was because of the way I told him, but after sharing the entire story, he interpreted it in a way that I was taken advantage of by this childhood girl friend. I didn't correct him and it felt safer than the alternative. I assume that I was still ashamed of being as sexual as I was and for fantasizing about women. Anyways, his sympathy for me turned me on. I sought it and the attention.

Although there are many directions I could take in the analysis of this script, the

themes I have chosen to explore are rupturing of power through confession, gendered experiences of sexuality and sexual fantasies, and the intersection of vulvar pain and sexual fantasy. While they are not directly associated to my vulvodynia, they are key to understanding the historical context of my sexual subjectivity.

\section{Shifting Powers through Confession}

...[T]he agency of domination does not reside in the one who speaks (for it is he who is constrained), but in the one who listens and says nothing; not in the one who knows and answers, but in the one who questions and is not supposed to know. And this discourse of truth finally takes effect, not in the one who receives it, but in the one from whom it is wrested (Foucault, 1990: 62).

As evidenced by the quote above, sharing a fantasy is multifunctional and involves agency that is both constrained and manufactured on behalf of both 
partners. On one hand it asks the partner to "tell the truth of sex" (Foucault, 1990: 57) for the sake of learning or gaining intimacy. On the other hand, it acts as a form of confession, an,

...obligation...now relayed through so many different points, [it] is so deeply ingrained in us, that we no longer perceive it as the effect of a power that constrains us; on the contrary, it seems to us that truth, lodged in our most secret nature, "demands" only to surface...

Not only is the confession of fantasy a call for action through words, it is also a production of truth (Foucault, 1990). However, confessing a fantasy can work through feelings, test relationships, mask fears and, arguably, destroy or benefit the partnership.

The script describes the mutual confessions with a partner regarding our sexual experiences and fantasies (my first sexual experience with a childhood girl friend and my partner's fantasy of gender play). I believe these confessions were superficially oriented to diminish the power within our relationship. That is to say, confessing the hidden discourse of "sexual deviance"19 (Foucault, 1990) produced a discourse of being (or not being) accepted. Each role (the narrator/the listener) opens up a space to construct a sense of belonging and power. For instance, my partner seemed to gain power by telling his story to someone who was seemingly non-judgemental, supportive and willing to embrace his fantasy. In telling this story, his fantasy was given a voice and shaped the dynamics of our relationship. I secured a space of power in the intimacy of the experience while my partner, who placed himself in a vulnerable situation, risked rejection. He trusted me, and therefore, his trust in me, which

\footnotetext{
${ }^{19}$ That which is not part of the heteronormative, marital copulation.
} 
was neither earned nor warranted, gave me a sense of power over him. For both of us, the telling of one's truths, as evidence of intimacy, created a false sense of balance and security. It served to create a feeling of legitimacy, making our stories appear acceptable and, more importantly, non-deviant.

There is, however, another possible reading of this script. I found Foucault's notion that the storyteller's agency is constrained in the sharing of the story (" $[t]$ he agency of domination does not reside in the one who speaks" (Foucault, 1990: 61)), as well as the idea that the agency of domination is in the hands of the listener helpful in unpacking my script. I, in turn, identified my disclosure about my sexual experience with my childhood girl friend as a powerful narrative. After hearing my secret, as the one who "is not supposed to know," my partner was resituated in a more powerful position. I only wanted to tell the story to someone I trusted. This anchored me in a vulnerable space because I placed the possibility of trust and acceptance in the hands of the listener.

My sexual experience with this childhood girl friend led to feelings of shame and guilt. These feelings were influenced by the stigma of homosexuality that I had learned through my interactions at school and lack of experience with seeing same sex relationships in urban Alberta. Consequently, I had attached such profound meaning to the "homosexuality" of the act that I was reluctant to share it with just anyone. ${ }^{20}$ My partner's interpretation of the experience as

\footnotetext{
${ }^{20}$ The meaning to which I refer relates to the historical period when this script takes place. It occurred during the mid 1980s, which was the height of associating HIV/AIDS to queer
} 
something about which I should not feel guilty dislocated my original thoughts of it being something shameful, and my responsibility.

Although I was a few years younger than my childhood girl friend, it would appear that, from the perspective of my partner, it was this difference that moved our experience from an innocent encounter to abuse. It was a process of replacing one truth (innocence) with another truth (abusive). I contend, however, that we were equally curious and engaged. Unfortunately, not knowing until much later in my life that this was age appropriate sexual play (Renshaw, 1988 cited in Masters, Johnson and Kolodny, 1995), I spent the past twenty years constructing a narrative of shame around my sexuality and in turn what was transformed over time into a sexual attraction to women. In short, this childhood experience led me to believe that I was queer.

It is curious that I allowed my own story to be changed so abruptly and profoundly in the space of a bedroom conversation. On one hand, his interpretation that I was "taken advantage of" provided me with the perfect out. I became no longer complicit in the experience and, therefore, I assumed I had no control in the situation. On the other hand, the power that I took in telling another person that I had been intimate with a girl, something I identified as requiring courage and strength, was diminished by saying that I was powerless in my decision to explore my sexuality with this girl friend.

I now recognise that I chose to accept his interpretation of the experience as abusive and out of my control and that this choice defined my dominant because I had "sex" with my same sex friend, we were both at risk of HIV. 
childhood sexual narrative. The rupturing of my (so-called) truths, those that challenge heteronormative ${ }^{21}$ and homonegative ${ }^{22}$ understandings of sexual exploration as children (and as women), becomes part of unpacking my sexual subjectivity, which is one of the goals that this project aims to accomplish. While at the time I did not attach gendered meaning to this narrative, I believe now that examining my pleasure, guilt and exploration through the lens of gender also provides me with a helpful framework to understand my sexual script.

\section{Gendered Understandings of Pleasure}

Researchers, feminists and philosophers contend that gender and sexuality are inextricably linked (Chapkis, 2002; Collins, 2002; Kaplan, 1988; Levine, 2002; Parker, Barbosa \& Aggleton, 2000; Sawicki, 1988). Collins (2002), argues,

The sex/gender system consists of marking the categories of biological sex with socially constructed gender meanings of masculinity and femininity...Sexuality is socially constructed through the sex/gender system on both the personal level of individual consciousness and interpersonal relationships and the social structural level of social institutions (194).

That is to say that as a woman with biologically female organs, gendered meanings are inextricably tied to how I negotiate the world on individual,

\footnotetext{
${ }^{21}$ I define heteronormativity as the structures (beliefs, policies and institutions) that uphold rigid categories of "male" and "female." These categories are used to define a person's gender, gender identity, gender roles, sexuality, sexual orientation, sexual desires and sexual roles and their expected male and female behaviours. For example, male behaviours may include being masculine, strong, dominant, or patriarchal, while female behaviours often include being feminine, weak, submissive, and compliant.

${ }^{22}$ This is new term moves us away from homophobia (which literally translates into being "afraid of homosexuals") to being a more accurate description of the negativity and heterosexism that exists in our society.
} 
interpersonal and institutional levels. In saying that, perhaps the process of framing my sexual experience as a "confession" is situated within a gendered paradigm of sexual pleasure.

There are two parts to this thought. First, in speaking of my experience of sex play with my partner, I failed to include that I felt pleasure in the act of the sexual play with my childhood girl friend. Besley (2005) writes:

When one is considering the self, and self-indulgence and desire tend to be downplayed since they are often viewed as something not quite proper or appropriate, especially by the 'moral majority'..." (366).

I would argue that my omission goes further insomuch as it is one of guilt. At first, I felt guilty because I had enjoyed the sexual play with my childhood girl friend. However, due to my reading of what I imagined was my partner's rearticulation of my confession of the experience, I altered my telling to fit into his analysis. Given that feeling pleasure in so-called abusive situations is considered unacceptable, I felt embarrassed in my enjoyment of the act and therefore chose not to speak about it. However, if I had framed the narrative as a script of innocent exploration and sexual joy, would he have interpreted it as an abusive situation? One cannot say, but the rescripting of this narrative has had dramatic impacts on the way I see and interpret my sexual history and my sexual fantasies. ${ }^{23}$

\footnotetext{
${ }^{23}$ This section is relevant to the overall thesis project insomuch as in the process of writing my scripts this story surprisingly emerged. Having not addressed it for many years, I feel that it has played a large role in the development of my sexual subjectivity and my future role as a sex therapist.
} 


\section{Girls, Boys and "Confessing" Fantasies}

The research of Hsu et al. (1994), Kinsey, Pomeroy, Martin and Gebhart (1953) and Zurbriggen and Yost (2004) suggest that many people experience having sexual fantasies at some point in their lives. In this relationship, my partner and I required a sense of trust before feeling comfortable disclosing those fantasies and experiences to one another. My purpose in choosing the term "disclosure" is twofold. It implies a feeling of wrongness, guilt, stigma or shame about the story to be told. For my partner, sharing his sexual fantasy became a disclosure because stigma and guilt are often associated with cross-dressing (Rudman \& Fairchild (2004). Sanchez, Crocker and Boike (2005) contend that "people who deviate from gender norms may meet with harsh disapproval" (1445). Butler (1990) echoes this by arguing that North American society is compelled to see "good" individuals as those who maintain "causal or expressive lines of connection among biological sex, culturally constituted genders, and the 'expression' or 'effect' of both in the manifestation of sexual desire through sexual practice" (17). It is unsurprising therefore that my partner appeared uncomfortable with sharing and acting out his fantasies to play with gender. Yet, I was compliant in participating in the fantasy, despite not feeling aroused by it. I credit this experience as correlating with my first experiences of vulvar pain (please see pages 53-59 for further information).

John Gray (1992), author of Men are from Mars and Women from Venus, suggests that women want intercourse to feel loved and men use intercourse to say 'I love you.' This truism is far too simplistic. It also grossly underestimates 
women's sexual desire. For me there was pleasure involved in sex. I enjoyed the playful submissiveness that I found in sexual intimacy and saw it as a contrast to my everyday life. ${ }^{24}$ The irony, of course, is that in being submissive, I also performed pleasure for my partners (and myself). In the process of performing pleasure "to feel loved", I asserted agency by commonly "faking orgasms." I would argue that I "performed" these orgasms for three reasons: 1) so my partners would not think of me as sexually inadequate, 2) to protect my partners' ego, and 3) to hasten the end of the sexual act. My performance of being a sexual woman and a good lover was compromised when I started feeling vulvar pain.

To verbalise that I was not enjoying his fantasy, I felt would directly affect what I perceived to be my partner's 'fragile' ego. For example, it was not uncommon for him to repeatedly ask me if I liked the fantasy or if it turned me on. Yet, I decided not to tell my partner how I felt about his fetish. This perhaps was a rationalised response to the courage I felt it took for him to disclose, and then act on his fantasy. This, coupled with my perceived need to fake orgasms, was part of my performance of being the 'good lover.'25 This begs the question whether either of us were honest with one another. Were his questions genuinely concerned with how I felt or was he content hearing that I enjoyed the fantasy; thus challenging the victim position (of being condemned or judged negatively for his desires)? In contrast, was my decision to remain silent a response to his

${ }^{24}$ This is in reference to my performance of being a "strong, in control, feminist" acted out in my public life.

${ }^{25}$ I also feel the need to mention that my experience of performing orgasms was not limited to this one dominant narrative. Rather, this was very much a learned behaviour from previous partners. The relevance of including such intimate information in this thesis then becomes about expanding how I see my sexual subjectivity being constructed beyond my experiences of vulvar pain. 
perceived 'fragile' ego, or a bolstering of my own 'good lover' act? I would argue that my behaviours (making sounds of performed pleasure, not honestly answering when it hurt and feeling the pressure to be a good lover) were gendered (and thus learned) to address and move through uncomfortable situations:

...Western culture has never wavered from its commitment to an androcentric model of sex that popularly, medically, and legally requires only penetration and male orgasm for it to be legitimated as the "real thing." Female orgasm, though valued at sometimes more than others, has never been obligatory to authenticate the act. Women as well as men have shared these assumptions, however much such a definition contradicts and challenges their physiological experience (Morantz-Sanchez, 2000).

Although I may not know the answer to why we behaved in such a way, whether they were performances of shared assumptions or commitments to the androcentric model of sex, I believe it is likely they were a meshing of both. In reflection, the disclosure of his fantasy and my sexual experience did not bring us together or enhance our intimacy. Rather, it increased the gap between the ways in which we communicated both inside and outside the bedroom.

\section{Sexual Metaphors}

Learned behaviours not only manifest, but also are produced and reproduced in multiple ways. Stacey (1997) describes illness as a metaphor (Stacey, 1997) and, in the scope of making sense of my illness, I often wondered if my sexual body was trying to tell me something. Associating my vulvar pain with my partner's fetish, in the beginning, meant that I saw this condition as psychological and embedded within that relationship. I questioned whether the 
condition was "...simply the language of the psyche writ large on the body" (Stacey, 1997: 44). While my stresses of living with a partner, exploring his new sexualities and discovering my own body may have made me more vulnerable to the pain, the "textual body" 26 led me astray on the path of healing. That is to say, my metaphor became such that I saw myself to blame for my pain condition that I was not open to alternative sexualities and therefore, was a bad lover.

However, Sontag (1977) counters,

...illness is not a metaphor, and the most truthful way of regarding illness -and the healthiest way of being ill- is one most purified of, most resistant to, metaphoric thinking" (cited in Stacey, 1997: 45).

But I am not sure how one identifies truthfulness in relation to illness as it is heavily laden with interpretation (thus opening the space to become metaphoric). Perhaps it is here that introducing how the physiological, psychological and social manifestations of the pain work together to challenge the idea of the metaphor. I use a tangible, physiological model that outlines desire to shift my understanding of the pain from metaphoric to experienced.

Currently Basson's (2001) Female Sexual Response Cycle is one of the best models I have found to represent female sexual responses (see Figure 1). It is appropriate to use in this thesis because it illustrates how the lack of sexual stimuli may have very real physiological effects.

\footnotetext{
${ }^{26}$ The body upon which the metaphor is figuratively written.
} 
Figure 1: Female Sexual Response Cycle (Basson, 2001)

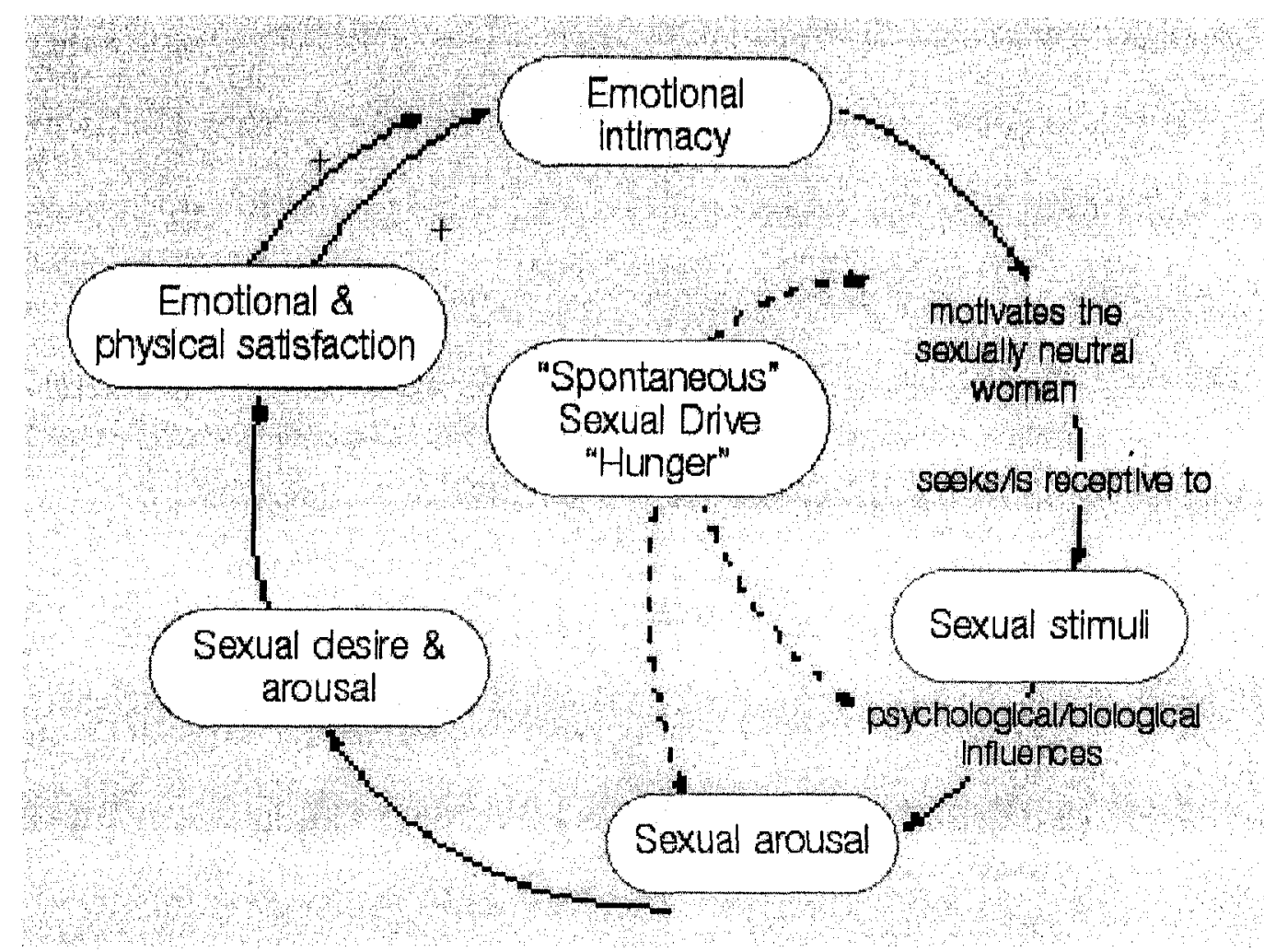

This model suggests that when women experience emotional intimacy (or are being spontaneously sexually driven) they are open to becoming sexually stimulated. This openness leads them to be aroused (which can include engorgement of the labia, shifting of the uterus, increased lubrication). Sexual arousal can therefore lead to a desire to engage sexually with their partner. Once desire and arousal occur, sexual inter/outercourse follows, and according to this model, creates the conditions of possibility for women to be sexually, emotionally and physically satisfied. This sense of sexual, emotional and physical connection and satisfaction leads to emotional intimacy between the partners, thus constituting a cyclical pattern. 
In my situation, I was unable to attain the known physiological responses that follow the sexual stimuli stage, such as engorgement of the labia, clitoris and vestibular bulbs, lubrication within the vagina and, with the aid of the Bartholin glands, of the vestibule and a rising of the uterus. Instead, my sexual response cycle resembled Figure 2. Notably, it was the inability to first experience psychological and biological responses that led to my lack of sexual arousal. Although, I was not stimulated by my partner's fantasies or role-plays, I continued to engage in our sex play; thus causing increasing trauma to the dry and unaroused vulva and vaginal walls. Binik, Bergeron and Khalifé (2000) describe it best by saying:

The pain that you experience during intercourse is the result of different causes that develop over time and become connected to each other in a negative feedback loop. For example, one cause involves physical factors related to the nerves of your vulva (vagina, uterus, etc.), which appear to be hypersensitive to touch and friction. This original injury may have been caused by an infection, virus, allergy or any local irritation to the area" (169).

The pain in my vulva, and my inability to find a treatment to treat it (be it therapeutic or medical), means that it has evolved. While it has always been acute (localized in two specific areas), the sensations have changed. Initially the pain was dull and it felt as though I was not producing enough lubrication; thus making intercourse feel dry and abrasive. After a few months, however, the pain escalated and became more profound and sharp. When explaining to people how it felt, I often described it as small razor nicks in the vestibule being doused with vinegar or acid. 
Figure 2: My Own Sexual Response Model - An Adaptation

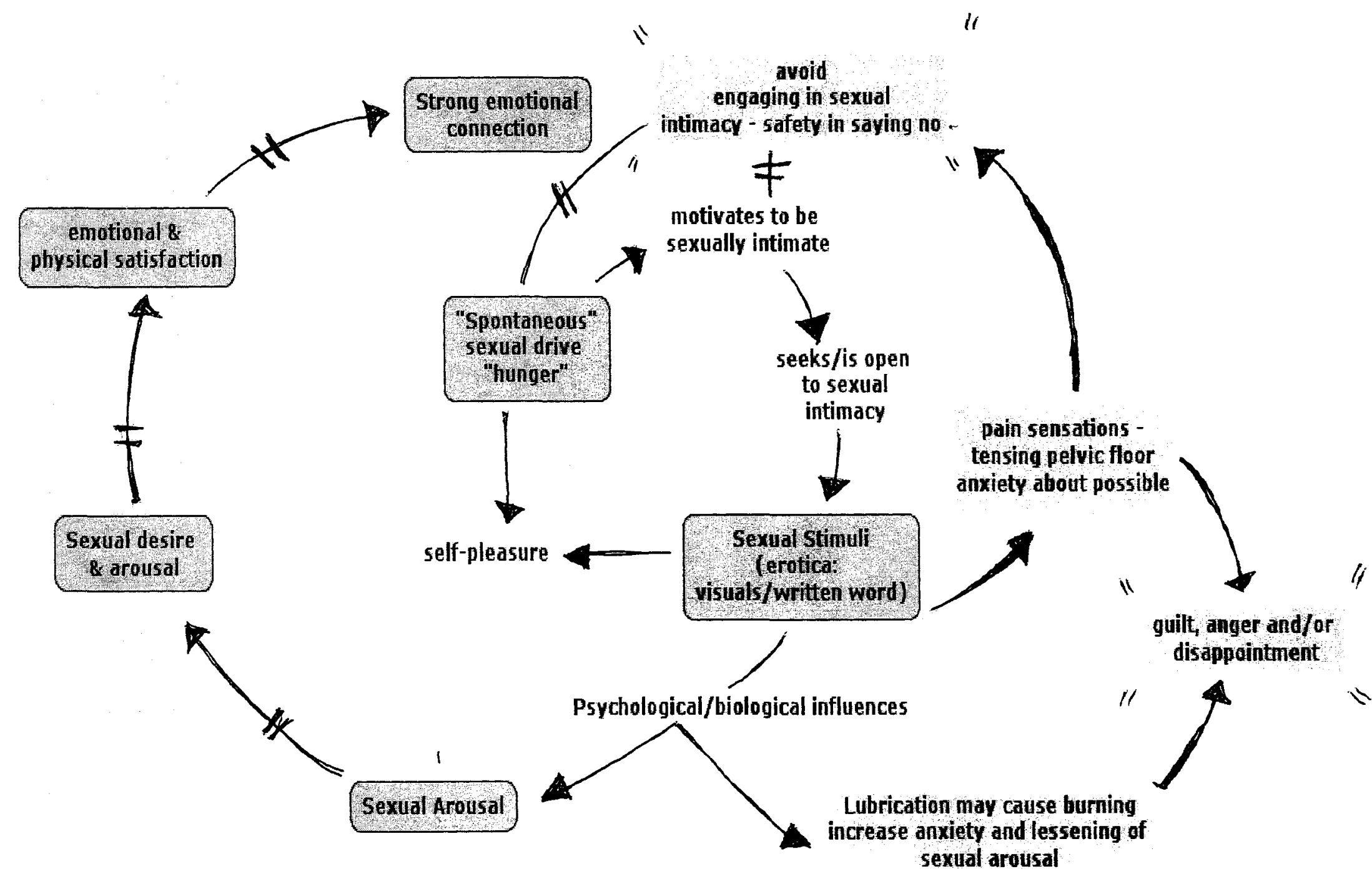


From my own research, as well as the information given to me by my most recent specialist, we believe that the chronic rubbing of the vestibule created a physical memory and ultimately caused allodynia and hyperalgesia ${ }^{27}$ in my vulvar area. This theory is well documented and is now commonly accepted by many experts in the field (Stewart \& Spencer, 2002; Weimer Shultz et al., 2005). Researchers now believe that chronic rubbing against the already raw vaginal walls and of the vestibule aggravates the nerve endings. Berglund, Nigaard and Rylander (2002) argue that "[e]arly regular coitus and long time use of oral contraceptives were factors associated with vulvar pain. Frequently rubbing a vulnerable mucosa may result in irreversible damage and vulvar vestibulitis syndrome" (738). Stewart and Spencer (2002) further this idea, by suggesting that vulvodynia is a result of, ...abnormal pain circuits set up in the central nervous system...VBD [vestibulodynia] is a form of inflammatory pain. The nerve is not injured but is so continuously bombarded by inflammation that signal changes occur in the spinal cord to keep the pain going (299).

Given the success of the anti-seizure medications that I am currently using (please see the following chapter), the above descriptions adequately describe the physical origins of my vulvodynia.

Over the past nine years, I have had to make sense of the ways in which my gendered sexual desires and childhood same sex experience play into my understanding of living with vulvar pain. Each aspect manifested itself in how I understood my sexual subjectivity, which I initially thought was a metaphor for something that I had done. While this chapter locates the origins of my vulvar

\footnotetext{
${ }^{27}$ Allodynia is defined as "touch that should be pleasant causes pain." Hyperalgesia is defined as "something that normally causes a small amount of pain causes excessive pain" (Stewart \& Spencer, 2002).
} 
pain to the multiple experiences of having intercourse and not feeling sexually or emotionally aroused, other elements are at play. For example, my need to place my partner's sexual desires above my own was my way of demonstrating my need to be the "good lover." This gendered posturing of our sexual pleasure fits within a binary of sexual power that is both constructed and reinforced. Reframing what I originally developed as a victim narrative to one that suggests I was agentic in authoring the experience has a powerful meaning. While this chapter was meant only to serve as a foundation for the chapters ahead, in the end it provided me with an opportunity to shift the way I see this script. Through critical reflection, not only do I see now that my original victim narrative was not transparent, but also that I was complicit in the authoring of my sexual scripts. This authoring occurred as part of a larger social discourse with my partner and my self (as I represented it). The following chapter shifts from the bedroom into the examination room. It provides the reader with the next layer for understanding my chronic vulvar pain narrative as it pertains to my multiple and complex medical experiences. 


\section{CHAPTER 2: Navigating the Medical System}

I have organized this chapter somewhat differently only because my experiences with the medical system are fragmented. As mentioned in the introduction, my journey to find medical help for my vulvar pain has led me to over 26 health practitioners (please see Appendix B for a detailed list of my experiences). Only in the last year have I seen a physician who specializes in vulvar vestibulitis. ${ }^{28}$ As such, I felt it necessary to divide my script into multiple parts to give shape to my narrative as a woman with vulvodynia navigating the medical system.

\section{Script \#2: the Campus Doctor}

This script explores my initial visit to the school clinic to inquire about the pain that I was experiencing during sex, the difficulty in discussing sexuality with my physician and my initial experience of having my pain discounted.

March 2006

My partner and I had been having sexual difficulties for a while before I decided to see the campus doctor. I had tried lubrication as well as different positions, but was experiencing sharp burning pain immediately upon penetration and especially right after. Tired of using the frozen pack of peas and cold cloth compresses, my partner repeatedly asked me to see a doctor. As I'm going back almost ten years, this part gets a little fuzzy. I was adamant about seeing a woman doctor, but there was a long wait. I remember seeing those STI posters looming over me in the waiting room and becoming more and more anxious about seeing what was wrong with me. Eventually the nurse showed me into

\footnotetext{
${ }^{28}$ I have found that few physicians specialising in vulvar health (specific to pain and dysfunction) exist in Canada.
} 
the doctor's office where I again waited, but this time awkwardly on the table in my paper dress.

The session began commonly enough, until she began asking me a lot questions about my sex life. It's funny how easily I told her everything (that I had had great, pain free sex before, but now it was really painful and that we couldn't see anything....I remember emphasizing that I always used protection, except for maybe that one time... I felt uncomfortable telling her when I lost my virginity and about the number of partners I had. She probably didn't care, but I was embarrassed.

The exam was painful. Although, like any 'good' doctor, she warmed up the speculum, it was extraordinarily painful. And the swab...I hate it when they swab because it feels like sandpaper inside. She told me that she didn't see anything and, therefore, wanted to test for what was to be the first of many STI tests. I was then told that someone would get back to me and that it was probably nothing, just a yeast infection or Chlamydia. As though Chlamydia was nothing and a nice fall back choice. Until we were sure, she told me to use condoms and lots of lube, which would most likely take the pain away. It didn't.

The tests were negative for STIs and yeast and, after going back to talk to the same doctor about the same pain, she gave me another internal exam, but once again told me that there were no visible problems. She asked me if I thought it was psychological and that perhaps I would be better suited going to the counselling centre. I reaffirmed that the pain was very real and in the end she referred me to see a specialist who she claimed was one of the best physicians she knew. She also gave me a card for the counselling centre, just in case.

This script feels less than accurate. Both when writing it and rereading it, I experience mixed feelings. On one hand, it captures my first experience of what would be a long road. On the other hand, I harbour a great deal of resentment toward this first physician for not providing me with the correct diagnosis. ${ }^{29} \mathrm{I}$ have fantasies that if I had received the right treatment from the beginning, the pain would not have progressed as far and would not be as irreversible. However, her examination, based on the information known about vulvar pain at the time,

\footnotetext{
${ }^{29}$ The tension that exists between my disregard toward this physician and the medical system (that I experienced) in general and my desire for the "correct diagnosis" (i.e., implying that I value the medical system) is one that I negotiated, problematised and struggled with throughout this thesis.
} 
appears thorough. That is to say, there exists a larger historical and social context that perhaps explains why 'the correct' diagnosis or treatment was not found.

Until the mid to late 1990s, the medical community knew little about the condition. My comment about her not "see[ing] anything" alludes to the fact that vulvar pain rarely has visible symptoms. While the vulva can appear red or raw, most often the coloration of the vestibule (naturally being a deeper rose/brownish colour) masks this rawness. As a result, many researchers between 1991-1997 were focussed on seeing how vulvar pain was connected to yeast, lack of lubrication or sexually transmitted infections (Goetsch, 1991; Goetsch, 1996; Marinoff \& Turner, 1992). These connections have since been refuted (Weijmar Schultz et al., 2005). Therefore, it should come as no surprise that my physician was unable to diagnose me appropriately or that she made the assumption that my pain "was probably nothing just a yeast infection or Chlamydia." ${ }^{\prime 0}$ Arguably important is the social (gendered) context that may have influenced her examination and decision that my pain was psychologically oriented.

\footnotetext{
${ }^{30}$ The Planned Parenthood website describes Chlamydia as being caused by bacteria and is common among teenagers and young adults. The symptoms of Chlamydia include discharge, itchy vagina, small amount of bleeding during or after sex, pain in the lower abdomen and pain during urination. I experienced none of these symptoms and, therefore, posit that the physician was making assumptions based on my sexual history (teenage sex) and the suspected prevalence of STIs among university students (Naccache, Manhes, Fortin et al, 1993).
} 


\section{Gendered Narratives of Pain}

Pain is a physiological and psychological gendered experience for both women and men. My unease of speaking to the doctor, and the way in which I felt it necessary to 'excuse' most of my sexual history, is informed by how women are perceived within a patriarchal medical system. The Boston Women's Health Book Collective (1998) writes,

...medicine has achieved social control over women's lives through the special sanctity of the private physician/patient relationship. The relationship between a woman and her doctor is often one of profound inequality on every level, an exaggeration of the power imbalances inherent in many client-professional relationships in our society. This is more likely to be true in a male physician/female patient relationship, but it can be true of female doctor/female patient encounters as well (685)

While I am unsure whether medicine has achieved exclusively "social control over women's lives," the impact of the institution has been profound:

...the medical profession is not criticized primarily because it is a profitmaking concern but because it exercises an uncontrolled power over people's bodies, their health, and their life and death (Foucault, 1982: 780 ).

Although my physician was female, her power, workplace, field of study, and her education about women's sexual bodies arguably were produced within a male centred model (The Boston Women's Health Book Collective, 1998, Sandelowski, 1981). Lorber and Moore (2002) have found that the,

...top positions in large medical centers, medical schools and research centers have been held predominantly by men. These institutions develop medical knowledge, decide what medical students are taught, and determine standard practices for diagnosis and treatment (46). 
Unfortunately, those who are making the decisions have made it such that women's sexual health, specifically sexual pain or vulvar pain are not a priority in medical teaching. At my most recent sexual conference $\left(4^{\text {th }}\right.$ Annual Comprehensive Review of Sexual Medicine, February, 2006), to cite one recent analogy, I was informed that to maintain funding from the pharmaceutical sponsors, seventy-five percent of the workshops had to focus on male sexual dysfunctions as much of their revenue comes from medications geared toward these conditions. This highlighted the gender bias in medical priorities relating to sexual dysfunctions. Although this international conference was attended by both male and female physicians, the disproportionate emphasis on male issues placed women at a disadvantage with regards to new and up coming research on women's sexual health and specifically vulvar pain.

That is not to say that female physicians are not making positive changes within the system. I mentioned that, "[a]lthough, like any good doctor, she warmed up the speculum." In my experience, over the past fifteen years, female physicians have become more cognisant of they ways in which they can better serve women within this male oriented model. For example, I have since undergone medical exams that were conducted by women, in women's clinics, that were not painful. The speculums used were smaller, they were warmed to a comfortable temperature and I was part of the examination process. Having the option to use a mirror or view the exam being conducted on the large television on the wall facilitated this. This process of inclusion lessened the psychological aspects of my pain experience. More than likely, my pelvic floor was more 
relaxed in knowing that I could see what was happening; however, the clinical explanation aside, this method was extremely positive and shifted the exam from a traditional male medical model to a women's health centred approach (please see Chapter 4 for more information about this approach).

Notwithstanding the methods of the first examination, my incorrect diagnosis had many consequences. I received no instruction not to engage in sexual intercourse if it was painful. Perhaps it was assumed that this was common sense, but, as illustrated in the previous chapter, I felt compelled to be sexual with my partner out of fear of not being seen as a loving partner. I also commented that because there were no visible symptoms, my physician "told me to use condoms and lots of lube, which would most likely take the pain away." The result of my partner and I continuing to have intercourse and working through the pain served only to increase my pain. Moreover, my physician's well intended, but misinformed, suggestion had profound impacts on the functioning and my capacity to enjoy my sexual body.

I feel that I must take some responsibility for not going beyond the campus doctor to look for other resources. As mentioned in my script, my partner had to "repeatedly" ask me to seek medical help (yet, we continued to engage in intercourse). I attribute my discomfort in seeing physicians to my sister's experiences with the medical system. ${ }^{11}$ Growing up watching her float in and out of hospitals made it is so that I have never felt comfortable being ill or seeking

\footnotetext{
${ }^{31}$ For reasons of privacy and confidentiality I will not define my sister's illness.
} 
medical help. In addition, my mother's "if you're crying, get off the field" 32 attitude associated illness with weakness. I believe I thought resiliency would win over the pain and that eventually it would just disappear. I have no doubt that this line of thinking had much to do with my fit demeanour, youthful exuberance and a healthy dose of denial.

The pain, however, did not disappear and I had to come to terms with the idea of being "ill." While I recognize that my chronic pain affected my life in a multitude of ways, I was still very uncomfortable with the categorisation of being "ill." I take medication three times a day, I do exercises, I think about it, work through it and it has become a huge part of who I am. Yet, I resist the title. For the purpose of my analysis, however, it provides me with an intriguing framework from which to depart. For instance, once I made the decision to accept that I had chronic pain I was open to accepting medical intervention. I was also open to possible side effects, the costs (both financially and with regards to time) and accepting/working with the medical system. I made the decision to be compliant (consenting to medical interventions) in order to lessen my pain experience.

Mate (cited in Glazer and Rodke, 2002) finds the passivity of women accessing pain relief "distressing." She writes,

... [women] visit their gynaecologist and start using ointments, creams, antidepressants, and/or biofeedback, but remain in moderate to severe pain for weeks or months waiting for the treatment to work (96).

\footnotetext{
${ }^{32}$ This is in reference the many years I played competitive sports as a teenager.
} 
While I cannot speak for other women, my decision to continue taking the medications (despite the serious side effects) had much to do with how I felt about experiencing sexual pleasure (i.e., that it came at a cost) and not wanting to question my physician's 'expertise.' Table 1 charts my treatments over the past nine years, which were diagnosed to me with my "best interests" in mind.

Table 1: List of treatments since 1999

\begin{tabular}{|c|c|c|c|}
\hline Duration & $\begin{array}{l}\text { NAME of } \\
\text { TREATMENT }\end{array}$ & Benefits & Side effects \\
\hline Month & $\begin{array}{l}\text { Estrogen Cream - } \\
\text { nightly }\end{array}$ & None & Numbing, burning \\
\hline 1 year & $\begin{array}{l}\text { Amytryptaline } \text { begin } \\
\text { at } 10 \mathrm{mg} \text { up to } 70 \mathrm{mg}\end{array}$ & $\begin{array}{l}\text { Small } \\
\text { improvement }\end{array}$ & $\begin{array}{l}\text { Dry mouth, } \\
\text { Constipation, } \\
\text { Weight Gain Costly }\end{array}$ \\
\hline 3 months & $\begin{array}{l}\text { Low-Oxalate Diet - } 2 \\
\text { months }\end{array}$ & None & $\begin{array}{l}\text { None - difficulties } \\
\text { finding } \\
\text { foods/recipes, Costly }\end{array}$ \\
\hline 3 months & $\begin{array}{l}\text { Calcium Citrate - } \\
1200 \mathrm{mg} / \mathrm{day}\end{array}$ & None & None \\
\hline $\begin{array}{l}3-4 \\
\text { times }\end{array}$ & $\begin{array}{l}\text { Lidocaine - before } \\
\text { intercourse }\end{array}$ & None & Burning/numbing \\
\hline 1 time & $\begin{array}{l}\text { Buspirone before } \\
\text { intercourse }\end{array}$ & Unsure & $\begin{array}{l}\text { Numbing of entire } \\
\text { body }\end{array}$ \\
\hline 1 month & Galbanela - nightly & None & Burning \\
\hline 1 month & $\begin{array}{l}\text { Hydrocortisone } \\
\text { Cream } 5 \% \text {-nightly }\end{array}$ & None & $\begin{array}{l}\text { Burning } \\
\text { Costly }\end{array}$ \\
\hline Ongoing & Dilation-nightly & $\begin{array}{l}\text { Small } \\
\text { Improvement }\end{array}$ & $\begin{array}{l}\text { Costly, pain on } \\
\text { insertion }\end{array}$ \\
\hline
\end{tabular}




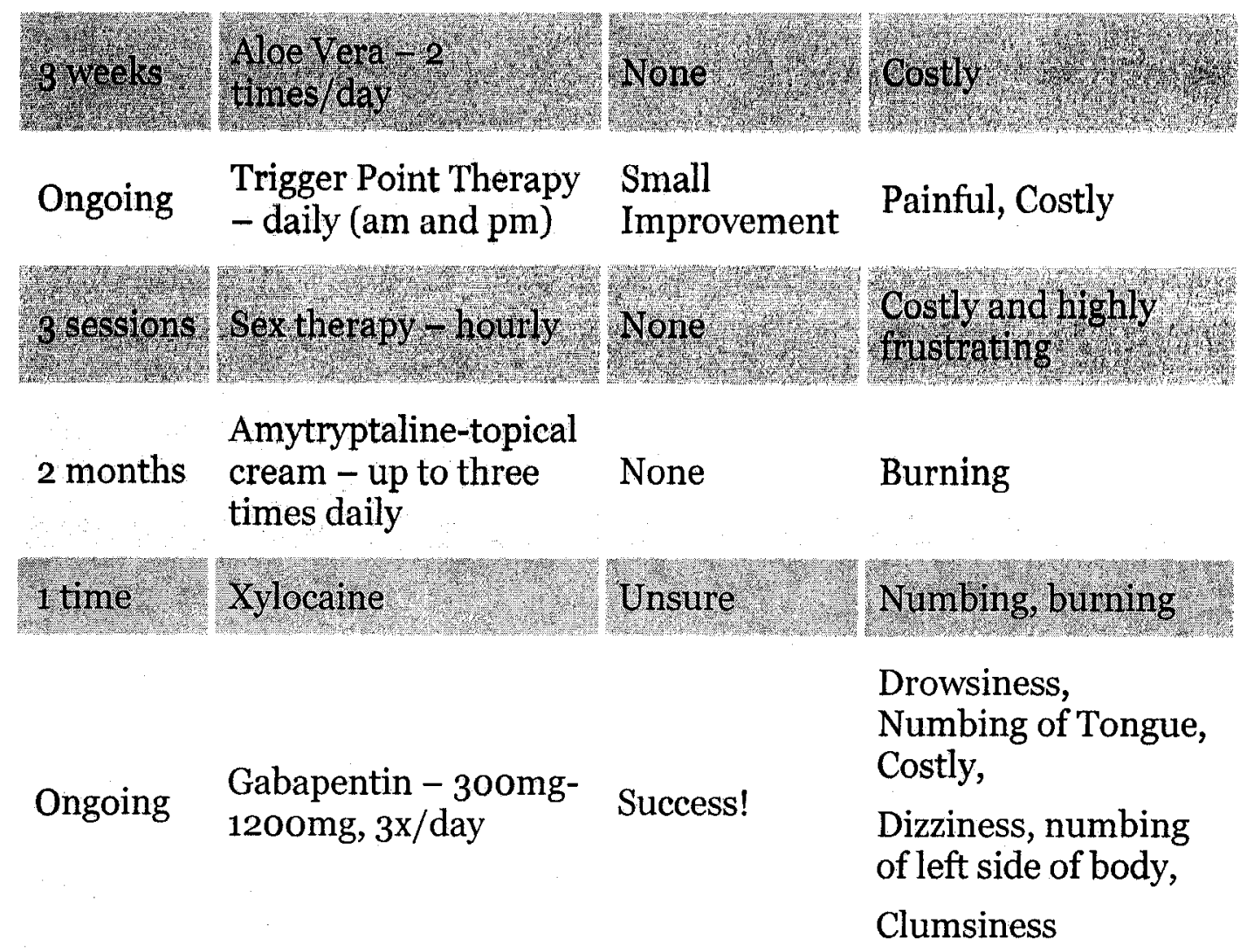

As evident by the short periods of duration, my commitment to each intervention was either halted due to ineffectiveness, cost or increased pain sensations experienced during intercourse or regular daily experiences. However, I, like many of the other vulvar pain sufferers, tried multiple interventions before being able to find the one treatment that fit my needs. My current medication, Gabapentin, is an anti-seizure medication that is described by The Vulvar Guideline (Haefner et al., 2005) as being,

...used to help control some types of seizures in the treatment of epilepsy, but is also used by pain clinics to control various forms of pain. It helps control pain by decreasing the excessive impulses of nerves that transmit pain and by preventing the spread of increased excitation from abnormal to normal neurons (27). 


\section{Side effects of the drugs include:}

- More common--Clumsiness or unsteadiness; continuous, uncontrolled back and forth and/or rolling eye movements

- Less common--Depression, irritability, or other mood or mental changes; loss of memory

- Rare--Fever or chills; cough or hoarseness; lower back or side pain; painful or difficult urination

\section{Side effects that usually do not require medical attention:}

- These possible side effects may go away during treatment; however, if they continue or are bothersome, check with your doctor, nurse, or pharmacist.

- More common--Blurred or double vision; dizziness; drowsiness; muscle ache or pain; swelling of hands, feet, or lower legs; trembling or shaking; unusual tiredness or weakness

- Less common--Diarrhoea; dryness of mouth or throat; frequent

- Urination; headache; indigestion; low blood pressure; nausea; noise in ears; runny nose; slurred speech; trouble in thinking; trouble in sleeping; vomiting; weakness or loss of strength; weight gain (27).

The frustration behind taking this drug is that the side effects are often more difficult to manage than the pain itself (i.e., drowsiness, loss of memory, muscle aches, trouble sleeping, blurred vision, etc.). I have argued here that my decision to be compliant toward taking drugs with such severe side effects (and not searching out second opinions of physicians) stems from having to negotiate a problematic medical system. It is here that I realise I was pursuing both subject positions - the 'compliant patient' and the 'non-complaint patient' (Lupton, 1997). The dual subject positions suggest that my compliance is part of a complex discourse between institutional and local powers, specifically in relation to desire (what I would hope these drugs could accomplish) and sexuality (what I perceived as healthy sexuality). Part of that desire is reinforced through the discursive nature of the practitioner/patient. 


\section{Discomforted Disclosures}

...in the West, sexuality is not generally something about which people are silent and that must be kept secret; it is something one has to confess (Foucault, 2003: 169).

My sexual history, like that of so many, involves many detours and secrets. The following section explores the ways that the technology of confession, via the disclosure of sexual history, "points to our own complicity in constituting ourselves as the subjects of desire, in the face of medical discourse (Foucault, 1980:58-70 cited in Probyn, 1993: 32). Therefore, my discomfort in sharing it with a physician, a perfect stranger, should come as no surprise. My behaviour is not uncommon as patients often feel "embarrassed, ignorant, anxious and inadequate and fear being ridiculed for wanting sex when they are ill, old, or both" (Heath \& White, 2002: 22). The connection between the medical body and the sexual body is intimately intertwined. Diprose (1998) summarizes this idea in saying, "[i]t is no longer possible to assume that we encounter medical discourse...with our sexuality entirely intact or that we leave it unscathed" (33). Further, despite the numerous resources that are available, 33 few medical professionals feel comfortable or know how to talk about sex with "ill" patients. Therefore, my body language, the words I used and my defensiveness to my campus doctor's questions may have had much to do with the way she interpreted my symptoms.

${ }^{33}$ This is in regards to exploring the sexuality of children, families, partners, and etc. 
The fear of disclosing too much about one's sexual history is but one of many barriers existing between doctor/patient relationships. This is also explained by Diprose (1998) where she contends,

The truth of our sexuality is not waiting for exposure in the clinic. Rather sexuality is constituted through confession, in the body of the spoken word (Foucault, 1980). The clinic, like the confessional in general, incites not just the desire to speak but desire itself...the agents of production are also the patients who would have their pleasures and pain represented, to their satisfaction, in the total picture of their medical life (32-33).

The way in which I disclosed my sexual narrative with the physician accomplished multiple tasks that worked to create the "total picture." 34 For instance, my comment about the ease with which I recounted my sexual history is intricately related to the power that I gave my physician regarding my health ("It's funny how easily I told her everything (that I had had great pain free sex before, but now it was really painful and that we couldn't')). I, like many people, have been taught (by parents, teachers, media, etc.) to respond 'honestly' to questions when posed by persons of authority (Foucault, 2003). In doing so, I chose to comply with the doctor/patient relationship. While that gives power to the person in the authoritative position, I too have agency in the act. For example, if we are to assume that "the processes of illness or injury act on an essential body, which can be examined, measured and analysed, and managed in the pursuit of the normative standards of health and physical ability" (Price \& Shildrick, 1998: 232), then it may also be safe to say that it is in the best interest of the patient to comply with being examined, measured and analysed to access

\footnotetext{
${ }^{34}$ I am unsure if it is ever possible to create a "total picture" with regards to medical life, but the phrase may work to describe the brief moment or snapshot used to describe one's sexuality at the time.
} 
better health care. My chosen compliance therefore became my agency within the clinical relationship.

Having established a compliant relationship by setting a precedent for openly answering the questions, I still felt compelled to qualify my answers. For example, in my script, I said that I had practiced safer sex by using condoms, "except for maybe that one time...." This rather falsely emphasized my need to have her believe that I was a competent patient, who knew the "right" way to have sex. Foucault supports this by arguing that, "medicine made a forceful entry into the pleasures of the couple...it carefully classified all forms of related pleasures" (1980: 41).

The very act of opening oneself so blatantly and trustingly would suggest a level of intimacy that rarely exists. Most physicians appear to treat the patient "objectively" and anonymously (Fahy \& Smith, 1999; Price \& Shildrick, 1998; Turner, 1992; Turner, 2002). My campus doctor worked very much in this way. Her warming up of the speculum was perhaps the only display of humanness during the entire exam. For every other moment, she was businesslike and direct. Considering the sexual nature of my complaint, it was interesting that questions about pleasure, desire or joy of sexuality were absent from our discussion. In fact their absence reinforced the assertion that "[g]iven the intimate content of the [exam], it should not be surprising if the patient's sexuality becomes an issue in the encounter (Diprose, 1998: 30). Put differently, the focus of my complaint (vulvar pain) connected intimately to my sexual experience (dyspareunia). If there was a place where we could discuss sexuality 
and all of its gritty, intimate details, one would imagine that the examination room would be appropriate. 35

Also discussed at the $4^{\text {th }}$ Annual Comprehensive Review of Sexual Medicine, February, 2006, was the question of who should be the primary source of support for sufferers of chronic pelvic/sexual/genital pain or sexual dysfunctions. The panel, which included a sex therapist, a general practitioner and an urologist, all felt that their office, respectively, provided an excellent primary space to discuss sexual concerns. However, a study conducted by Temple-Smith, Mulvey \& Keogh (1999) found that patients are not disclosing their sexual problems to general medical doctors. The researchers credited this to the inadequacy of the physicians' sexual history taking skills. They argued that to be able to conduct the history effectively, doctors' would require more education about alternative sex practices, learning the appropriate and nonjudgemental language, addressing their discomforts they may have in discussing the topic, and having increased awareness of possible resources and referrals.

Despite these limitations, a study by Read, King and Watson (1997) found that 70 percent of their survey group believe that sexual matters are very much an appropriate topic for the doctors to address. My experience reinforced these findings. Not only was the physician the first person that I saw regarding my pain symptoms, she was the only health practitioner I thought of seeing for my intimate physical concerns. Yet, I have found over the years that as a woman who had to confess her sexual history multiple times, being able to have a frank, non-

\footnotetext{
${ }^{35}$ While Foucault (2003) does not use the term of appropriate space, he does comment on the role of the examination room in regulating people's health.
} 
judgemental and supportive conversation with my doctor would have provided me with a greater sense of ease and trust.

In light of this, I have found that bringing a sexual history with me to my appointments has allowed me to shape the questions that I now know are most pertinent to the examination and my vulvar pain. The following diagram is an example of this sexual history. While it is not comprehensive, ${ }^{36}$ having the medications and notable events written down has diminished the opportunity for awkward or forgetful moments. It also situated me in a knowledgeable (socially constructed expert) position, thus lessening the authoritative difference between the physician/patient.

\footnotetext{
${ }^{36} \mathrm{My}$ regular sexual history would include ages, dates and more information about my sexual experiences, but, for the purpose of my thesis, this history provides a good example of the kind of information one should be asked or prompted to disclose during the taking of a medical history.
} 


\section{Figure 3: Example of my Personal Sexual History}

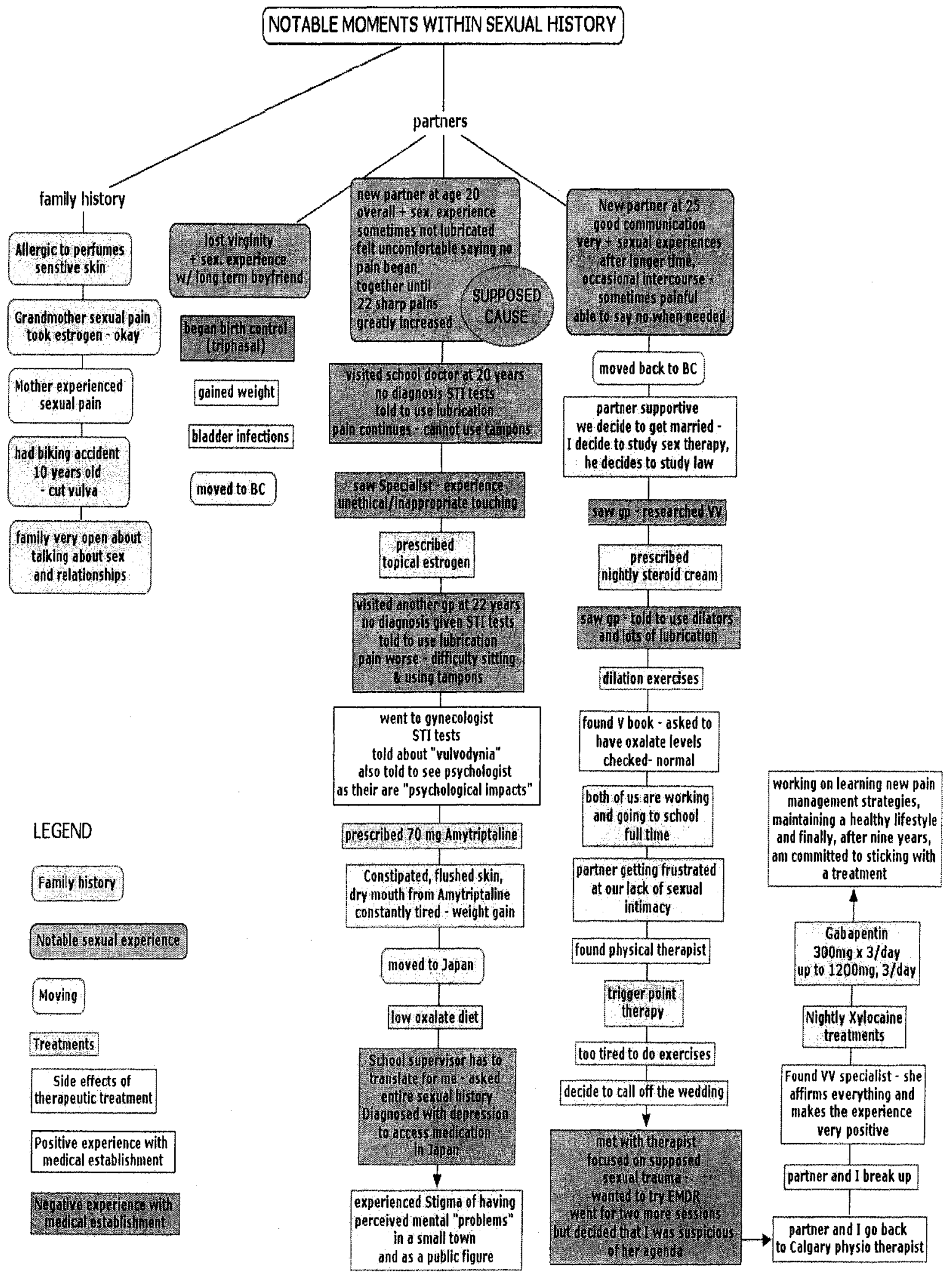




\section{Script \#3: Placing Tmust in the Hands of the Doctor}

The previous sections explored the aspects of disclosure and politics that take place in the examination room. The following section takes the process a bit further by exploring the actual examination and the power and trust that exists on behalf of both the physician and patient. To help me do this, I have used two scripts that describe "experiences" with so-called gynaecological experts. Using the underlying concept of power, this section is a gendered exploration of how the male centred model weaves its way into the physician/patient narrative and ultimately my subjugated body.

\section{March 2006}

I remember waiting a few months to see the gynaecologist. My parents dropped me off, and I am pretty sure by then I had told them that I was experiencing a lot of pain during sex. When I saw the doctor, he brought me into his office and we chatted for a bit. I felt that he patronized me for the entire exam. He sat opposite me, behind this large oak desk in a giant chair. I told him about the pain (emphasizing the sharp and burning aspects) and his questions did not seem to capture the severity of it. He minimized it and then supposed that it was a yeast infection or some other vaginal condition. I don't remember if he ever mentioned the vulva....

...He told me to relax and said that he saw small razor like slits on the vestibule, signifying trauma. He then, with gloves on, but no lubrication or warning, held my one knee and abruptly put his finger inside me. My knees instinctively clamped shut and he kept telling me to relax. I just remember the tears running down my face and feeling completely violated. It was so incredibly painful. But I said nothing. The exam was only a few minutes in total and I walked out with no more information. He handed me a prescription of cortisone cream with estrogen that he said may help with the vestibule tears...

The way in which the physician "sat opposite me, behind his large oak desk, minimized [the pain]" and "told me to relax" would suggest a power/knowledge 
binary that underpins this script. The patriarchal understanding of the male physician examining the female patient is hardly new (see Ehrenreich and English's (1973) text on the history of women healers and the medicalisation of women's bodies). However, this script captures one of my first experiences of feeling 'less than' or "minimized" by a male physician.37 As mentioned in the literature review (see page 33), the patriarchal relation through whom men are above/before/in charge of/ smarter than women shapes this experience (Gamble, 2001). My script suggests that I experienced the physician as very much above/in charge of my body and my condition, specifically in the way that he heard my pain narrative. Using two contrasting organized practices, creating a large physical distance and then telling me to relax, are examples of this power binary. These practices replicate relations of authority that were ultimately inscribed upon my physical body. My reaction ("my knees instinctively clamped shut and he kept telling me to relax. I just remember the tears running down my face and feeling completely violated") is also contextualized by this relation of power.

The power differentials constructed through the medical relationship is one of two places in our world that we are most "voluntarily" vulnerable, the other being in the bedroom. As evidenced by the script above, I opened my body for the physician and " $[h]$ e then, with gloves on, but no lubrication or warning, held my one knee and abruptly put his finger inside me." We open ourselves,

\footnotetext{
${ }^{37}$ That is not to say that my experiences from female physicians have always been positive (please see the beginning of this chapter); however, the heteronormative ways in which we construct the male/physician and female/patient allows us to look at the patriarchal underpinnings inscribed upon my sexual body.
} 
and our bodies to those people whom we trust will keep our best interests in mind. The first step in creating this place of trust is in giving our sexual history. The second way trust is constructed is through the assumption that "the ethical rules" will be carried out on behalf of the medical practitioner. McWilliam and O'Donnell (1998) argue, "the examinee's body, and in particular the female body, comes 'dis/membered' by 'medical' practice" (90); thus highlighting the vulnerable positioning of the patient. The following script is an example of the ways in which the assumption of trust operates as a powerful regulating mechanism to maintain the power dynamics of the physician/patient relationship, even when the rules of ethical practice are broken.

\section{Script \#4: Broken Trust at the Hands of the Physician}

\section{March 2006}

The physician reminded me of Colonel Sanders and I thought that he would be better suited working in some small town in the states. Nonetheless, we talked for a little bit about my pain and my sexual history. I felt hideously awkward telling him about my partners and he made me feel like I was more than a little "promiscuous."

During the exam, he took off his gloves and said something along the lines of "in order for me to really feel the bumps and tissues, I have to take off my gloves." With his bare fingers, he stroked my vulva....virtually ran his fingers up and down the vestibule. Again, I said nothing. I didn't know what to say. I didn't know if what he was saying was true, but he said that he saw nothing that looked remotely out of the ordinary. His solution was for me to see a psychotherapist and of course to use more lubricants. Like all the others before him, he took the swabs to conduct a STI test. 
White and Heath (2002) argue that touching is up to the discretion of the practitioner, but that "practitioners are asked to consider the boundaries or limits of behaviour that serve to protect the best interest of ...the client..." (58). Certain protocols, while not explicitly stated, have become expected $3^{8}$ on behalf of the practitioners; wearing gloves is one of them. Within this script the line between best interest and abuse becomes blurry. I would argue that the stroking of any woman's genitals without a barrier (as thin as it may be) shifts the physician out of the realm of the sexually absent, to the agent of domination (Diprose, 1998). Put in another way,

while the clinician transforms a de facto situation into medical significance, through examination of the patient, the itinerary of her own body conduct is open to the other, rendering the encounter indeterminate and ambiguous (Diprose, 1998: 38).

This introduces an interesting balance between health and the vulnerability of the patient subject. Lupton (1997) writes,

[p]roponents of the medicalisation critique call attention to the notion that patients in general, because of their lack of medical knowledge, are placed in the position of vulnerable supplicants when they seek the attention of doctors, with consequently little opportunity to challenge doctors' decisions (96).

My inability to say anything to my physician about my discomfort in his touching me without gloves was very much a reflection of my vulnerable position or passive body, which was a result of my need for a diagnosis and treatment. I had

\footnotetext{
${ }^{38}$ Given that the vestibule is a mucous membrane, which in my case was aggravated and traumatised, it is fair to reason that gloves are a necessary uniform of the genital exam. While I have not found an explicit rule requiring the use of gloves, my experience has been that all physicians or nurses who have conducted a vaginal or vulvar exam have worn protection on their hands. For more research on the topic, see McWilliam and O'Donnell (1998) who offer an interesting exploration into the pedagogy of the genital exam.
} 
waited for months before I could see this referred "expert" and my inability to find support, consequently began to strain my relationship with my intimate partner at the time. Therefore, not only was my physical body in need of the physician's expertise but, given my living, emotional and social dependence on my partner, I also "put" into his hands my emotional, personal, social and financial well-being. That is to say, my vulvar pain at this point was beginning to influence my public world as much as my private world, including my work, my school, my relationships with friends and family and of course, the relationship with my partner. As such, I needed to access medical care and would compromise my comfort, and some would argue my politics, to receive his support regarding my pain experiences.

\section{Script \# 5: Naming the Pain}

My reasons for being openly vulnerable to the physician's wandering, but purposeful hands was very much for my own supposed best interest. I needed to know what I was living with. I needed a name. The following snapshot captures that moment.

February 2006

On a date with a friend I was perusing the stacks at Chapters on women's health. I came across "Women's Bodies, Women's Wisdom" [(Northrup, 1994)] and it was there for the first time that I found a word that described my pain, "vulvadynia" 39

\footnotetext{
${ }^{39}$ Northrup (1994) spells vulvodynia as "vulvadynia" - this is the one and only time I have seen it spelled in that manner (311-315).
} 
"Vulvadynia." "vulvadynia." I kept saying it over and over again. I didn't want to forget it. I ran over to my friend and told him, "I have vulvadynia." I don't think that I had ever disclosed to him that I had pain down there. It was also the first time I saw that "grimace" that resulted in saying vulva aloud. I didn't care. I had a name and for the first time it felt like something made sense. I read the entire section over and over again... especially the part that said, "no cure." While my heart sank knowing that there was no magical pill, I didn't care. I had a name and it was a start.

The events narrated in this script took place around a year after my last visit to the non-glove wearing gynaecologist. Emotionally, I had given up medical intervention, despite spending much of my time searching for diagnoses online, seeing multiple doctors and perusing all the women's health sections in bookstores. Of course, my community of friends and family offered no shortage of suggestions, but references to a layperson's diagnosis of vaginismus or vaginitis were hardly beneficial.

The moment I had a name however, I felt immediate relief and, "for the first time it felt like something made sense... it was a start." Phyllis Mate, President of the National Vulvodynia Association reaffirms this sentiment by writing:

Since most women have never heard of vulvodynia before being diagnosed, it's not the same as hearing you have breast cancer or heart disease. With those catastrophic illnesses, you have some idea of what to expect. A diagnosis of vulvodynia initially causes bewilderment as well as anxiety (in Glazer \& Rodke, 2002: 94)

I would agree with Mate that the terminology and diagnosis was perplexing as was its association to chronic pain - a condition that I had never considered having. Although I had been suffering for over a year at this time, the permanency of the term "chronic" troubled me, but at the same time, it 
reaffirmed the severity of the condition. An "informant" who participated in a study of back pain sufferers by Glenton (2003) brilliantly commented,

I've spent years trying to accept that I'm sick....It would be nice to have a system so that those of us who are chronically ill could come once a year [to the social security office]. Because then you've got a paper saying "you are sick" (2243).

Similar to this informant's sentiment, the words on the paper gave meaning to the condition and legitimised my pain narrative.

Although I no longer wanted to seek medical support as a result of the "indiscretions" of the two physicians I mentioned in the previous section, having a name inspired me to seek a seek a diagnosis. It was time to fulfil the "cause/cure paradigm" (Thomas-MacLean, 2000) and revisit the doctors. While writing this thesis, it becomes clear that my desire to find help is influenced by the response I receive from the medical community. It is for this reason perhaps, that Freidson (1970) argues, a "diagnosed illness has a social meaning" (cited in Vickers, 2001: 69). It creates a marker by which others can believe that a medical professional also believes that you are ill. With or without that marker, social judgements can emerge.

In light of my battle to be believed about my chronic pain, I would argue that vulvar pain is situated well within the margins of invisible chronic illnesses. Simply defined, an invisible illness is one that is "ascribed to invisible stigma: a condition that is not perceptible, not noticeable, not evident to others. In short a condition unseen by others" (cited in Vickers, 1997: 241). The more detailed definition equally refers to vulvodynia, 
...an ongoing condition; one which may be physical, emotional or cognitive' one that may or may not be, treatable or curable. An unseen chronic illness is one that might be categorised as an instance of "invisible stigma" as Goffman (1963, p.65) has described: a condition that is not perceptible, not noticeable, not evident to others (Vickers, 2001: 64).

Over the past nine years, I would argue that my vulvar vestibulitis, not unlike many of the other chronic vulvar pain conditions, has shifted/emerged/moved through each of these descriptions. For example, when I first presented with painful sex concerns, my pain was physical. When nothing was found, it became cognitive, and soon landed in the emotional category. It was assumed that because I had no visible signs and it was not perceptible by physicians, it must have been "in my head" (Binik, Bergeron \& Khalifé, 2000; Glazer \& Rodke, 2002). The transition from physical to emotional, coupled with having a pain condition in the vulvar region came with it a host of stigmatisation.

Yet, it is interesting to note that within Vickers (2001) list of twenty-eight possible invisible illnesses (i.e., chronic fatigue syndrome, endometriosis, fibromyalgia, stomach ulcers, multiple chemical sensitivities, HIV infection, colitis, etc.); she does not include a genital or sexual pain condition. 40 The absence of genital, vulvar or sexual pain also appears to a common problem when looking at the shelves of mainstream, non-academic or popular literature (Chaitow, 2002; Fishman \& Berger, 2001).41 While I have no concrete data that alludes to why this is, I suspect it has much to do with vicissitude of the illness, from sexual pain (more often associated with cognitive pain) to pelvic/genital

\footnotetext{
${ }^{40}$ Vickers (2001) recognises that the list is not comprehensive.

${ }^{41}$ Egoscue and Gittines (2003) have written texts on ending chronic pain from an exercise perspective. After perusing the indexes of both books, neither of them include genital pain, pelvic pain or sexual pain as part of their discussion.
} 
pain (physical pain). Prior to 2003, unless one had the proper terminology in front of them (vulvodynia, vulvar vestibulitis, clitorodynia, vestibulodynia, etc.), finding literature specific to the illness was very difficult. 42

This absence speaks to our discomfort in discussing women's sexuality and the way that gender intersects with the experience of pain. Gherardi (1995) and Vickers (1997, 2001) both explore how we traditionally regard women as irrational or emotional within the rational "male" organization. While Vickers (2001) was looking at the working space, I believe this translates well for the private spaces as well. I have often spoken of my pain as being severe or in graphic terms ("burns like acid has been poured on to it," "knife in the vulva") so that the listener forms a strong mental image. In doing this, I construct an image that provokes a reaction.

Further, my ability to withstand living with a vulva that feels "burned by acid" situates me in a warrior/heroine position. My language, my ability to work through such a painful day-to-day experience is masculinising and thus, I would argue, legitimising as well. Vickers' (2001) supports this sentiment by describing the archetypal "warrior" as demonstrating, "traits of courage, determination and tenacity" (64). While the warrior narrative proved to be important in my day-today living, there was little movement in my healing. The stagnation involved in me not finding supports to alleviate my vulvar pain could be related to the difficulties I experienced in finding a practitioner who was 1) knowledgeable

\footnotetext{
${ }^{42}$ Access to finding a name for vulvar pain often requires internet, knowledgeable health practitioners, friends with similar experiences or access to university library or medical school resources, such as PubMed, Medline.
} 
about vulvar pain conditions and diagnostic tools, 2) capable of taking a proper sexual history that was neither riddled, with judgements and absent of the necessary questions, and 3) was geographically possible. Nonetheless, it took another full year from the time I read Northrup's (1994) book to the time I received a diagnosis.

\section{Script \#6: Diagnosis}

The impact of not receiving that official diagnosis meant that I felt the medical world, as well as my friends and family did not believe in my disclosures of my pain. Until my experience presented within the following snapshot, I had not met a physician who was aware of vulvodynia or the ways in which to treat it. I had just come home from travelling through Asia, and was living in Calgary for a brief moment in time:

April 2006

Two weeks prior to leaving for Japan, I made an appointment with a resident at the women's health centre at the Foothills hospital. I told Dr. $P$. that I had vulvodynia and asked him if he knew what it was. He not only knew what it was, but asked me if I had been properly diagnosed. I told him I hadn't found anyone who knew about it but that I found the name in a book. I thought he would dismiss me, like the others for bringing my own self-diagnosis to the table, but he didn't.

He told me, instead, that specialists were using a drug called Amytryptaline at low doses because the latest research suggested that vulvodynia was a neurological condition. He did the requisite Q-Tip test and told me that I had vulvar vestibulitis and that this drug would most likely help. He then gave me the instructions and told me to email him while I was in Japan so that he could follow my progress. I was elated. Not only did I have a drug, I had a physician who wanted to "follow my progress" and who believed that it was an actual condition.

After three months of horrible side effects, I tried to email Dr. $P$. but he never responded. I was told a year later that he had left to go home to 
Africa soon after my appointment. When I returned to talk the resident who had taken over his cases, I was asked to take my file to the front desk. It was then that I saw written on the sheet. "Patient suffers from vulvar vestibulitis, but shows no physical signs. Possible psychological condition"

My happiness ("I was elated. Not only did I have a drug, I had a physician who wanted to "follow my progress" and who believed that it was an actual condition") no doubt stemmed from having received an "official diagnosis"; thus, shifting me from the realm of hysteria 43 to one of "legitimately" or scientifically "ill." While having a name was important to me (see the previous section regarding the chronic invisible illness), I also felt I required a physician's approval of my self-diagnosis. Yet, this feeling contradicted my position of the resistant patient in the doctor's office. Accordingly, two themes emerge from this script. The first is the way in which my experience of being disbelieved by so many practitioners had resulted in my internalisation of their negative and positive reactions and the second was my resistance to support by a knowledgeable professional. These work to explain the tensions that exist within my experience with the medical system and the complexities that arise in accessing support.

One would imagine that being offered a diagnosis would bring profound relief (Meana et al., 1999). However, experiencing the gendered position of having a male physician evaluate my female body put me on the defensive. My guard, both as a patient and as a woman, was up and my anxiety was connected

${ }^{43}$ Diedrich (1998) defines hysteria as being linked "not only etymologically but also culturally to the female body, because the female body in relationship to the normatively defined male body is seen as pathological, symptomatic by its very nature" (148). It is a feminine disease that is more an 'image than an illness' (Foucault, 1965 cited in Diedrich, 1998: 148). 
to the way he presented himself physically and within the expert role. In my own words, "I told Dr. P. that I had vulvodynia and asked him if he knew what it was." My feelings of defensiveness, or fear of being hurt physically or emotionally, made it so that I immediately shifted my self into a more powerful position. By "telling" the doctor what I had, I reclaimed my position as a knowledgeable woman/patient. This transformation or reclamation was profound if only because I then realized that I had become a consumer within the health care system as opposed to a passive observer/recipient.

Exercising consumer agency, however, was hardly isolated or without context. I would argue that the plurality of my being able to act as an agent on behalf of my sexual body and perform resistance (as a subordinate female patient talking back to a dominant male physician) was a result of my past experiences with the medical approach. At the time this script was recounted, I had seen many physicians, to little benefit. Further, prior to my discussions with this physician, I did not have a name for the condition. As such, the moment I became aware of the term vulvodynia, I felt the power operated through the medical system was lessened.

As a consumer of medical services, certain assumptions are at play. First, I assumed that I would be accessing services from a knowledgeable practitioner who could support me. Second, I believed that I had developed a respectful relationship with my physician based on the intimate nature of our examination and my knowledge about condition. Consequently, I was disheartened by the virtual halting of support I received from this physician. In a sense I felt as 
though I had been thrown a lifeline, only to have it be pulled away by his not following up of the emails ("I tried to email Dr. P. but he never responded. I was told a year later that he had left to go home to Africa soon after my appointment"). I recognize the structural influences at play, i.e., the constant flux of the hospital environment where physicians, nurses and residents, grants and politics come and go, and that the sole continuation are the patient files that remain. However, this disconnect felt significant to my understanding of the experience. Upon my return to the clinic, I remember speaking to the physician about Dr. P's lack of follow up. She seemed hurried and disinterested in my frustration that a resident had not keep his promise. It was most likely her indifference, which made me feel as though I did not matter, influenced how I interpreted my file "Patient suffers from vulvar vestibulitis, but shows no physical signs. Possible psychological condition." Once again, my dominant script, the one that I had slowly begun to reauthor as suffering from a physical pain condition, was psychological.

It is interesting that at this time in my life, I was still looking at the condition as either exclusively physical or psychological in origin. It was only until much later that I came to realize that the physical aspects of my pain were also psychologically and socially influenced. As such, a shift took place in my line of thinking to accept the importance of sexual therapy in conjunction with physical therapies. 


\section{Employing the Sex Therapy Approach}

The medicalisation of sexual dysfunctions in the mid 1980 s and early 1990 s has meant that more women are seeking treatment from their physicians because it is believed that their negative sexual experiences are often physically and/or biologically founded (Schover \& Leiblum, 1994; Tiefer, 1994; Tiefer, 1996). However, it is well documented that the physical aspects of any sexual pain or dysfunction are best treated along side the therapeutic approach (Glazer, \& Rodke, 2002; Meana et al., 1999). Meana et al., (1999) and Binik, Bergeron and Khalifé (2000) have done extensive studies on the role of the biopsychosocial approach. They adhere to the belief that dyspareunia is best treated with the support of a multidisciplinary team, such as physical therapists, gynaecologists and sex therapists.

\section{Script \#7: Personal Problematic of Sex Therapy}

In the following script, I explore how sex therapy became one of my final obstacles along the path of my sexual healing.

April 2006

I was sitting in the waiting room of the sex therapist feeling extraordinarily anxious. It was my first time ever having to see a therapist and I was worried that I wouldn't say the right thing or it would be awkward. I also didn't really feel like I needed to see her, but my partner insisted. Anyways, she sounded good on the phone, like she knew about vulvar vestibulitis but I just didn't get the right vibe. Maybe I'm just projecting because of what happened. Either way, I was also worried about the costs. $\$ 100$ for one session. There was no way that I could pay that for long, so I was hoping that we could do some sweet brief therapy as I had a total of $\$ 1000$ to spend over the summer and that 
had to include our trip back home, my other treatments, and oh, rent and food.

She invited me in and it was okay. The office was comfortable but I was more intrigued by the plethora of certificates she had on the wall behind me. It was as though she really wanted to prove that she knew what sex was and she had the certificates to prove it! There had to be twenty or so - I felt like she would definitely be the person I could talk to about becoming a therapist... but then I wasn't going to pay $\$ 100$ for that. I also remember that she was sitting really far away. In the place where I work, there is a three, maximum four foot space between my clients and me. With her, I think she was like 10 feet away. I think she eventually moved closer to another seat, but all I can see right now is that distance....

Anyways, we started off okay. She talked a lot about herself and her family. I couldn't stop thinking that every word she said about her took time/money away from me. I was absorbed by the cost of this experience. She kind of reminded me of [a friend] in the way I would say something, she wouldn't listen and she would follow it up with something else. She also hmmm'd a lot, which started to annoy me.

This is where it becomes blurry. I'm telling this story like it all happened in one session, but it's very possible it happened in two - I can't remember as the whole experience has melded together. We talked about my vulvar stuff and she made a point to correct me on the way I said dyspareunia "(dis-pahroo-nee-ah)" so all of a sudden I felt stupid. I felt like we were having some competition about who knew the illness more and she was determined to win. She then did the old "if you had a magic wand question" (which I hate, but have subsequently used in my own work)... I think I said, "um, I guess I would want my vulvar pain to go away?" It felt like a dumb question given my specific reasons for coming.

Anyways, I told her about my partner and she fixated on it. She told me that experiencing trauma like that was most likely the root of my condition. "Trauma" I didn't use the word trauma to describe it so I felt odd hearing her say it. I know that I originally felt like it was traumatic, but then I haven't felt like I had experienced "trauma." It was as though she was so excited to have discovered the root of all my evils right there in the first session. "ha! You've been sexually abused and now we can begin..." I told her that I hadn't said I was assaulted, rather that I felt silenced because of my gender, my inexperience.... 
Then, and this is the funny part, she reaches behind her chair and pulls out a light bright board, which I now know is an EMDR board.44 She tells me that because of my "trauma," this new therapy would be an excellent tool for us to use. It would require around 12 sessions, but it could really work. Two things.... Again with the trauma. And 12 sessions? I told her that I needed to think about it. I came back two more times; the last time with my partner I wasn't present at all throughout the entire session, but he loved it. She told him he had intimacy problems, which I told him afterwards on the bus that I could have easily told him for free.

While it is clear from the script that I was reluctant to enter into the counselling relationship with anyone, ("I also didn't really feel like I needed to see her, but my partner insisted") I was determined to "get better" and save my relationship. As a way of convincing myself to go, I used my future profession as a cloak to hide my discomfort. Yalom's (2002) suggests that to be a reflective therapist requires being in the client chair (see Chapter 5 for more on reflective practice). My hesitation was nonetheless connected to feeling "worried that I wouldn't say the right thing or it would be awkward." I credit my overall unease with the therapeutic treatment to my previous experiences of living in Japan and being diagnosed with depression (so as to access my Amytryptaline medication), which involved a degree of stigmatisation within not only my school, but also in the town where I was living.

Also connected to my distaste for therapy were the prohibitive costs for private counselling. Regarding the treatment of vulvar vestibulitis, Weijmar Schultz et al., (2005) argue that the counselling intervention requires patience insomuch as it is a time consuming endeavour:

\footnotetext{
${ }^{44}$ EMDR stands for "Eye Movement Desensitization and Reprocessing"
} 
This treatment...requires great empathy, sensitivity to nonverbal signals, and insight into relationship interactions. The health care provider must be able to identify the woman's ambivalent feelings regarding coitus, sex, her partner, her own body, her desire to have children. He or she must be able to bring to light serious relationship problems or sever traumatic experiences (sexual violence,) and he or she has to realize that being able to have sex down not automatically mean that the coitus is enjoyed. It is highly recommended that the health care provider receive suitable training (Weijmar Schultz et al., 2005: 312)

One could argue that this kind of approach requires a great deal of time to build the relationship to be effective. However, for low-income individuals, such as myself, with no insurance to cover the costs of the therapy, paying the average rate of $\$ 130$ per hour 45 would be prohibitive, let alone the scaled rate of $\$ 100$. With possible long-term weekly visits, on top of my other medications, I was unable to continue. Moreover, the cost of my session prohibited me from remaining present throughout the session ("I was absorbed by the cost of this experience"). My raising the issue of money five times in the script exemplifies the harsh reality that paying money for long-term treatment was a barrier to this approach.

Throughout this paper, I have attempted to explore how narratives are performances that intersect with the self and are situated within a historical moment in time (see sections, "Shifting Powers Through Confession" (page 45) and "Discomforted Disclosures" (page 70)). The act of telling a story requires an interpreter and an actor, suggesting agency on behalf of both participants (Friedman, 1999). Throughout this script, a performance was certainly taking

\footnotetext{
${ }^{45}$ In searching for sex therapists, I have found this to be the average cost per hour in Ottawa.
} 
place where both myself and the therapist ${ }^{46}$ were trying to gain control over the session. My control operated as a form of resistance, whereas her control manifested itself as trying to convince me that her 'expert' knowledge was relevant to my healing process. An example could be her correction of the way I said "dyspareunia" or her insistence of me using the EMDR board. However, by the time she suggested using the EMDR as a tool (to work with what she associated to trauma), I had already removed myself from the counselling relationship and was no longer a willing participant. I once again felt unheard as the professional chose to follow her own agenda to diagnose and treat, as opposed to listen and support.

The choices that sex therapists (and social workers) make throughout the sessions place them in powerful positions. The exchange of money for counselling services implies that the client is in need of "advice," "support," or "resources" of which she would otherwise not have access for free. In fact, the moment I walked through the office door, I, the consumer, expected the therapist to be knowledgeable, trained, interested and capable at 'bettering my situation.'

As a result, power is not without its consequences. The therapist position carries with it the authority of the professional or active listening role of a confessional discourse. Foucault asserts,

[t]he confession is a ritual of discourse in which the speaking subject is also the subject of the statement; it is also a ritual that unfolds within a power relationship, for one does not confess without the presence (or virtual presence) of a partner who is not simply the interlocutor but the authority who requires the confession, prescribes and appreciates it, and

\footnotetext{
${ }^{46}$ This narrative is recounted from my memories and is therefore, a one-sided portrayal of the therapist.
} 
intervenes in order to judge, punish, forgive, console and reconcile; a ritual in with the truth is corroborated by the obstacles and resistances it has had to surmount in order to be formulated' and final a ritual in which the expression alone, independently of its external consequences, produces intrinsic modifications in the person who articulates it; it exonerates, redeems and purifies him;...(61-62).

The therapeutic narrative is authoritative in its ability to categorise/diagnose my experience as trauma based on a series of professional judgements. These judgements were assumed perhaps because of previous experience, informed understanding of the situation and knowledge learned through formal (social work education) or informal (life) education. Perhaps my therapist felt that her assumption was intuitive. However, I felt that it came across as yet another diagnosis. In turn, I felt judged and thus, I resisted the ways in which she was making sense of my vulvar pain.

At the same time, I had some degree of agency within the therapeutic relationship and this section would be incomplete if I chose to ignore it. For instance, I was in the position to choose how much information I wished to disclose, to make the decision to follow through with the support or suggestions that she offered and finally, and often most importantly, in continuing to attend the sessions. My decision to talk back to her diagnosis of trauma, lessen the information I offered, and stop attending the sessions illustrates agency on my behalf. Meanwhile, the forces at play (the diagnosis, our cultural and social positions) ruptured the way in which I understood how sex therapy could possibly support my healing of vulvar pain. It also highlighted how this act of confession intersected with my interpretation of my sexual subjectivity. 
This confession, which situated me in the subject position, was an inherent part of the therapeutic/client power relationship. This relationship presented my therapist with the conditions of possibility for her to diagnose my sexual body, which was not the reason that I was there - I wanted support for my vulvar pain. Our ritual of the needy client (girlfriend/patient) and listening therapist (boyfriend/doctor), as presented in scripts presented before, was once again played out. While I felt no purification in the act of confessing, I did experience relief in my decision to no longer see the therapist. Further, I was inspired by the incongruity of our therapeutic/client relationship to become involved in the sex therapy profession. My original intention was to provide women with an alternative to therapeutic practices that do not cater to women experiencing vulvar pain.

It is for this reason, among others, that I believe this project becomes important as a social work thesis. How have the experiences with my medical practitioners (my four physicians) and the sex therapist shaped my healing journey and informed my sexual subjectivity? I would argue they have pushed me towards finding alternative healing forms. Over the course of nine years, I have learned to find my voice, identify where I have exerted my agency and have challenged the assumed power imbalance in the treatment relationship. This contrasts my earlier feelings of being silenced. Further, my original journey to become a therapist, to "take back the control" that I felt I had lost in this process and to contribute to the discussion not only as a sex therapist, but also as a feminist social worker meant that I was taking my personal dominant narrative of 
pain and making it political. I did this by speaking out about the condition within both the private and public arena. I also began developing support systems with other women and sexual health centres (i.e., Planned Parenthood, Women's Health Centres). The following chapter lays the groundwork that allowed me to move beyond that original goal of politicising my vulvar pain and discusses the importance of multistorying that resulted as part of my healing journey. 


\section{Chapter 3: Shifting from Pain to Pleasure}

Writing the last two chapters of this thesis proved to be very difficult for me. Each snapshot came with a host of feelings and anxieties that Birch and Miller (2000) would argue are expected outcomes of the reflexive, narrative approach. It is the hermeneutic method that "emphasizes the narrative and textual analysis of the material as a means of approaching the socio-symbolic contents brought into play in the narrative" (Chanfrault-Duchet, 1991: 79). Put differently, a fracturing of self took place by having chosen only certain snapshots, located within historical moments, to share with the readers. These moments also presented opportunities "which allow[ed] for transformations to be effected upon [my selves] and the political body" (Foucault, 1988 cited in Probyn, 1993: 30). Sharing these snapshots created the conditions of possibility to reorganize and reconceptualise my dominant narratives of self to include being sexual:

The sexualized body is often a passive body, looked at or acted upon; the sexual body implies more, a body capable of sexual pleasure, a body which, in experiencing desire and pleasure, cannot be just a body abstracted from mind, self and social context (Jackson \& Scott, 2001: 101).

My understanding of becoming a sexual body was produced through fantasy, reimagining authority and disclosure. This chapter is about healing. I begin by explaining how pornography has been a useful tool for re-imaging positive sexual narratives. I follow this by examining a script that recounts when I decided to become a sex therapist and thus, began the shift from a singular narrative to 
multiple and complex narratives. The final section of this chapter explores my discourse on disclosing my pain to a possible sexual partner.

\section{Vulvar Pain, Self and Fantasy}

The ebbing and flowing, as well as the constant feeling of having to overcome yet another hurdle to healing from my vulvar pain was exhausting and may be the reason behind Hooijer's (2002) assertion that vulvodynia is a "misogynist disease" (264). It was common for me to feel that my vulva, the (socially constructed) centre of my feminine and sexual power, was under attack in my moments of pain. For instance, I was and continue to be unable to wear, what some consider, seductive clothing. Hosiery, undergarments and trousers can still cause me extreme pain sensations. And the idea of foreplay often shifted me into a rigid, painful state where I was consumed with thoughts about how I could incorporate frozen peas into the post-coital, cuddling phase. It should come as no surprise then that my pain condition diminished my fragile sex drive.

Having tried the medical approach (without a positive outcome) and having decided to become a sex therapist, I explored other possible treatments. I read numerous books about reclaiming one's sexual self. I also examined articles about treating the emotional connection for vulvar pain sufferers. Few of the articles, although certainly helpful in other respects, provided me with practical tools to address the way I "saw" sex. Consequently, I chose to address the absence of sexuality (within my pain paradigm) by reintroducing fantasy as part of my sexual practice (see Hooijer, 2002). I used visual imagery as a tool to reimagine 
sexual pleasure because, void of positive images, my mind saw sex in sharp, red, angry ways. The introduction of pornography, erotic literature and sexual toys were tools I used to help me with my emotional and psychological healing. MacKinnon once stated, "[i]f pornography is part of your sexuality, then you have no right to your sexuality" (cited in Strossen, 1995: 111). When I was just emerging as a new feminist, I agreed with this sentiment. However, I changed my mind upon reframing sexual imagery as a significant tool that I saw necessary for my healing. Employing porn and erotica provided me with the means to shift pleasure back into my perceptions of sex and sexuality.

Reintroducing pleasure was no easy feat. It required a consciousness of self, bodywork and the safety to explore different alternative sexual selves. Part of my healing process over the past nine years also involved using sex toys and dilators. Glazer and Rodke (2002) suggest that these are "common and noninvasive....medical devices that gradually stretch the vaginal circumference" (20). The benefit of using dilators, together with pornography and erotica, was that I controlled the pace, location and timing of the sexual play (Hooijer, 2002; Maltz, 2001). If the pain was too severe, I could stop at any time. If the sex on TV was too violent, I could turn off the DVD player. If I was exhausted from a long day, there was no pressure for me to engage. These aspects of taking back my sexual power proved to be pivotal to decreasing my pain sensations. Further, the employment of exercising my body in this manner allowed me to remain emotionally present during intimate moments with my partners. Many 
therapists would argue that this is a crucial part of the healthy sexual practice (see Hall, 2004 or Maltz, 2001 for techniques on sexual healing).

While I would also like to relate in this section the wonderful responses I had in openly discussing my vulvar pain with my partners, friends and family, I am afraid I would be lying. Goffman (1963) identifies these non-chronic illness sufferers, those who lack the relevant frame of reference, as "unsensitised." This term speaks to me insomuch as I often felt as though my chronic pain made many people uncomfortable.

\section{Script \#8: Becoming "Whole" and Finding Sex Therapy}

The following script explores the negotiation that took place each time I met someone new who asked me about my profession, my thesis or about sexuality in general.

\section{May 2006}

I was living in Japan and taking these medications that were totally playing with my body. I had met my partner and we were having this on and off relationship, but in the meantime having fantastic sex. It was great and for first time I felt like a whole woman again. In the process of our relationship $I$ decided to create this web magazine (www.bombamag.com) and it grew into this giant resource for all JETS47 living in our prefecture. It was an amazing experience to be a part of. Anyways, I was responsible for the "Lifestyles" and "Chicks" pages ${ }^{48}$ where I was writing about being a woman living in Japan. My chosen purpose was to write articles about body image, feminism and sex, where I included an article titled, "Painful Sex? Read this." 49 While I

\footnotetext{
47 "JETS" is the term commonly used to refer to people working for the Japanese Exchange and Teaching Programme, of which I was a part for two years.

${ }^{48}$ There is an interesting analysis that could be read into the gendered choices of pages that my partner and I had made. He was responsible for international and local political pages, while I was responsible for the practical living, women's issues and teaching tools.

${ }^{49}$ See Appendix $\mathrm{C}$ for a copy of the article.
} 
signed it anonymously (ignoring the fact that I was the only woman writing for the magazine at the time), it was my first true "outing" as a woman living with chronic vulvar pain. It was also kind of the first time I had found my voice in a world where I felt silenced. After so many years of being ignored, misdiagnosed and disbelieved, I became the authority.

Women began calling me to ask me questions and two women came to see me. They shared with me that they too had experienced long-term sexual pain. One woman told me she was just happy to know that she wasn't alone. Then there were others. All of a sudden I was sharing with the world that I had vulvodynia. It was an exodus of information. My friend $M$. and I were joking one day that I should have my own TV sex show, "sex with bexxx" and become a sex therapist. The seed was planted I guess, because from that moment on, I knew what I wanted to do.

My transition from privately feeling silenced to publicly sharing my story is far from unique. In fact, the practice of taking the personal and making it political is the foundation of what it is to be a feminist (Gamble, 2001). This transforming narrative (becoming a "whole woman again," finding "my voice in a world where I felt silenced" and becoming "the authority") also illustrates how the aspect of confession, a common theme throughout this thesis, moves within the margins of feminist praxis. This confession (unlike the others) was less about wanting to gain exoneration from something and more like a testimonial of experience and the capturing of my own history.

Similar to many twelve-step support groups, the practice of sharing ones' story can be extremely beneficial to the healing process. $5^{\circ}$ It also serves to authenticate and legitimise the person's commitment to healing. The political discourse (connecting the personal to the larger social relations) also presents an

${ }^{50}$ The benefit of situating this script within an oral history paradigm is the universality that it offers to other women's stories. Put differently, Berger Gluck and Patai (1991) (Eds.) wrote a book that examined the transcendence of feminist practice and oral history across gender, class and racial boundaries. 
opportunity to discuss shared narratives with women who may not wish to publicly claim their sexual pain (Salazar, 1991). One example of this is my account that "Women began calling me to ask me questions and two women came to see me. They shared with me that they too had experienced long-term sexual pain. One woman told me she was just happy to know that she wasn't alone. Then there were others." Based on my own personal experiences, I know how important it was to find the name, receive the correct diagnosis and then discover that possibly millions of other women suffer from a similar condition (Harlow \& Stewart, 2003). I no longer felt alone; however, I also recognise that these feelings are not universal. Put differently, I know that space can be created for women to resist such definitions.

Identifying these alternative spaces leads me to the next theme of making the decision to become a sex therapist. I worked from a model of empowerment, based on the "underlying premise...that personal experience served as a critical basis for knowledge and skill acquisition" (Benmayor, 1991: 161). In doing so, sharing $m y$ story became my way of recovering and politicizing the everyday experience of living with vulvar pain. Deciding to become a professional, who could address the needs of other women like me, was originally a way of filling the gap in the services that I had experienced. Wanting to ensure that I was in an "ethical professional" position, I wanted to engage as a reflective practitioner, which meant reflecting on my personal experiences, understanding them and naming them so that I could separate my own desires and experiences from those of my clients. As such, it became clear that my original intentions to become a 
sex therapist could not just be operationalised by supporting women living with vulvodynia and their partners. In short, choosing to become a sex therapist originally became a way for me to make sense of my pain condition and to talk back and work within to better the pain experiences of other women. In this way, this transformation from "women living with vulvar pain" to "sex therapist having experienced vulvar pain" began.

My passion for raising awareness and increasing supports for women were certainly well intentioned, yet now I recognize that it was both dangerous and lacking in reflection. ${ }^{51} \mathrm{I}$ know now my narratives of living with vulvar pain can inform the way in which I worked with couples and women; however, I believe that as an ethical practitioner it is my responsibility to separate my experiences from those with whom I am working. This thesis, therefore, has provided me with the space to be reflective about my experiences. It has also shifted my passion to work with women suffering from vulvar pain by containing and separating myself from their narratives. $5^{2}$

Notwithstanding, my script to become as sex therapist incorporates other important themes. For instance, the transformation that involved becoming a "whole woman" is an intriguing concept. Over the course of my pain journey, I have often felt 'damaged,' a sentiment shared by many survivors of sexual abuse

${ }^{51}$ Thus far, my thesis has been personally reflective, but the shift to become a professional provides me with the opportunity to be reflexive about my future practice. Reflexivity recognises practices as socially organised and that produce assumptions and contributions that account for how we encounter our clients, our colleagues and our profession.

${ }^{52}$ In fact, over the past few months, I have decided that I no longer want to specialize only in chronic vulvar pain. Instead, I will continue to conduct workshops and educational seminars on the topic, but I will not focus my practice to work only with women suffering from vulvar pain. I expand upon this idea further in the final chapter of this thesis 
(Maltz, 2001). While I maintain that my experiences with my male partners or with my childhood girl friend were not abusive, my interpretation of the narrative (as suggested by my partner) was that I had been abused. Further, my pain condition left me feeling as though I was unable to engage sexually with a partner, leaving me feel incomplete. It was only when I was able to reframe my "sexual dysfunction" as a manageable sexual and vulvar pain condition that I became open to other possibilities. That is not to say that my past pain narratives would not inform my future scripts, rather, I became open to reclaiming my sexual spirit/body. Lindemann (1997)53 may describe this as the experienced body informing the experiential body.

In framing my pain as both experienced and experiential, I began to see it in a different light - it was no longer unmanageable or unchanging. It was most likely at this moment that I began to be open sexually and was able to "[have] phenomenal sex." I had a partner that respected me, listened to me and went at my pace both intimately and emotionally. With this partner, I was able to explore, try new things and produce different sexual selves. That is not to say that being open to "phenomenal sex" meant that I was always able to have penile/vaginal intercourse. On the contrary, my pain was very much a part of my lived, every day, personal experience; yet, having a supportive partner and being gentle on myself allowed me to understand and manage my vulvar pain differently. In those moments of joy, I embraced the feeling of being the "whole woman." Achieving sex, as defined by mainstream, heteronormative

${ }^{53} \mathrm{He}$ describes the sensory body, that which experiences sensations through sight, hearing, taste, touch etc. as experiential. 
constructions, no longer became the significant moment. In those moments of pain, I looked beyond my self and was open to other alternatives. The following section explores these alternatives and the ways in which I was challenged to step beyond the margins of accepted sexuality to find relief from the sexual pain.

\section{The Art of Disclosure (or lack thereof)}

As evidenced throughout this thesis, my day-to-day life for many years involved living with vulvar pain. It took many different personal experiments to identify those objects/experiences that maintained or intensified the pain. To date, I have identified scented soaps, lubrication (both my own and synthetic), bleached toilet paper, penile/coital intercourse, tampons, chlorinated pools, fabric softener and underpants to be problematic as they intensify the pain. Fortunately, I was able to remove most from my day-to-day life and thus, had much more control over the pain sensitivities. With the encouragement of my family and friends, as well as my own renewed confidence about my body, I decided I was in the position to "put myself out there."

While the process of opening oneself to dating at first felt exciting and plausible, the immediate reality of sexual intercourse as part of dating/seeing someone made it daunting. Further, I often felt it necessary to disclose my pain condition almost ritually on the second date. It was at this moment that I felt when intimacy54 was often imminent. My disclosures while almost always

\footnotetext{
${ }^{54} \mathrm{I}$ use this term to describe any physical/sexual intimacy (including kissing, hugging, holding hands, and of course sexual play)
} 
awkward, still required a certain amount of finesse, trust and courage. Goffman (1969) refers to this process as "information control" (123).

The question becomes, "[t]o display or not to display, to tell or not to tell, to let on or not to let on, to lie or not to lie, in each case, to whom, how, when and where" (Goffman, 1963: 57). Due to the surreptitious nature of my pain condition, I often felt that those in my community (dates, family, friends and colleagues) saw my openness to discuss my condition as a form of seeking attention. I would argue, however, that my disclosure manifested itself as a form of coping, an opportunity to educate both men and women about the condition and/or to raise awareness about possible resources. Vickers' (1997) includes these, as well as others are possible reasons for disclosure:

1) It is a routine illness and does not need to be hidden

2) It is a form of coping; person requires support

3) It provides an opportunity for raising awareness of others

4) It is a form of seeking attention (123)

While I do not argue that there was some attention seeking behaviour over the past few years, I contend that my 'disclosures' have shifted from denial to silence, and from secrecy to awareness, as evident at the beginning of this chapter. While I am now in the space where I am very open about the condition, I continue to gauge who, when, where and how I want to tell. To make sense of my disclosure, I believe it is important to see how coping and awareness are significant within a dating context. 


\section{1) It is a form of coping; person requires support}

My decision to disclose to a man I was dating about my vulvodynia, the causes, the impacts and my subsequent sexual experiences, was very much a coping mechanism. While some may argue that making oneself vulnerable through disclosure on the second date was hardly the ideal, I saw it as performing multiple tasks. First, it laid down that I had sexual issues and attempted to alleviate any future awkward moments prior to engaging in a sexual relationship. Second, disclosing that I suffered from sexual pain created an instant barrier to moving the relationship forward. That is to say, I assumed that no man would want to be with me; thus removing my responsibility from having to engage in sex. This was very much in relation to my fear of entering into a relationship, disappointing my partner (once again) and finding out that the treatments I had been using were not working (once again). After much hesitation to try further medical interventions, I had committed to using Gabapentin, Xylocaine and the Trigger Point therapy on a regular basis. Therefore, to find out that these treatments were not working would most likely have set me back emotionally and psychologically on my healing journey. Notwithstanding, my disclosure could be understood as a way to protect myself from further disappointment.

My fears of getting close also created an intimacy barrier; thus, making it more difficult to enter into a sexual relationship. This seemed ironic considering that I was choosing to date; however, the concept of sabotaging one's romantic opportunities is a common experience for women living with vulvar pain 
(Kellogg-Spadt, 2002). Although dating once having sexual pain can be a traumatic experience, there appears to be little information on dating and disclosures as it relates to sexual dysfunction (Kleinplatz, 2001; Leiblum \& Rosen, 2000; Maltz, 2001). Consequently, I was left to make sense of my own protective measures and, as such, using my disclosures of vulvar pain as a coping mechanism, a barrier or a call for support served to protect my self and my sexual body.

\section{2) It provides an opportunity for raising awareness of others}

Given the relative silence of my condition, being able to discuss sexual issues and concerns from the beginning of the relationship (without being crass) was very important to me. It protected me from committing to someone who was unwilling to expand his understanding of sexuality to include sexual pain. As well, having read about the importance of communicating with one's partner regarding sexual dysfunction, it allowed me to test the waters before investing time into the relationship (Binik, Bergeron \& Khalifé, 2000; Hooijer, 2002; Kellogg-Spadt, 2002; Stewart \& Spencer, 2002). I also conclude that this was a pre-emptive approach to fielding the questions that often ensued upon telling my date what I do. Given that my work, studies and passion all focus on sexual issues, I was often asked to explain why I chose to study sex therapy. Moreover, I found that I no longer felt that discussing sexual issues difficult or scandalizing one could argue that I was desensitized from the topic. Raising awareness about 
my condition could be understood as a protective measure, as well as a means to normalize sexuality on a personal level.

Stewart and Spencer (2002), while explaining that disclosure is very difficult for women who are single, advise that it is not necessary to disclose on the first date. They instead suggest that women tell the story piece by piece, including more as the relationship grows. While I agree that this is the ideal, there exists some fallacy in the notion of incremental disclosure. My experience suggests that once I discuss my thesis or mention that, "I have pain in my vulvar region" questions immediately follow. My experience in trying different ways of disclosure (from not telling to telling immediately) suggested that there was no easy solution and that I had to cater my disclosures to each person.

Upon reflection, I believe that disclosure and healing can arguably go hand in hand. My transition to no longer seeing myself as broken or fragmented, to working through difficult disclosures as a future sex therapist meant that I was that much closer to accepting my pain narrative and rescripting it to something more erotic, embodying and pleasurable. It is interesting to note that throughout the process of writing the first two chapters of this thesis, my pain sensations increased dramatically. This perhaps suggests that my pain is embodied through the act of sharing my pain narratives. However, in coming to the end of the writing process, I feel little-to-no pain whatsoever. I strongly believe that my emotional and physical connection to this project, and its reflective methodology has allowed me to reframe my pain narratives and somehow lessen their hold upon my lived experience. That is, I am no longer a woman who lives with 
chronic vulvar pain, but a woman who manages her vestibulitis. With regards to this thesis, I would hope that what has come of this project is the ability to understand and separate my emotions and experiences from my future practice as a sex therapist.

I would argue that my project has provided me with the space to accomplish this task. The first two chapters have focused on naming and understanding my experiences of vulvar pain, while this chapter has explored the beginnings of my separation. The following chapter then encompasses the professional role that social work plays in working with women with vulvar pain. 


\section{Chapter 4: Reflections on Social Work Practice}

When vulvodynia made it on to prime time television, during an episode of "Sex in the City," 55 I was both surprised and upset. This was in response to Samantha's suggestion that Charlotte feed French fries to her "depressed vagina" as a means of curing her vulvar pain. Although I was pleased to hear that vulvar pain was making it to prime time television, I felt that the information provided was problematic insomuch as it minimized the pain experiences of women. As a long time sufferer of vulvar pain, I felt that portraying the illness as something that could so easily be cured by fast food mocked the invisible chronic pain narrative. At the same time, the episode performed a purpose. Working on a much larger scale, the show offered the possibility to raise awareness about vulvodynia to the North American public. While the episode was farcical and misleading, it put sexual pain on mainstream TV and arguably had other more profound impacts regarding research, treatments and supports for women. I would never presume that "Sex in the City" was a benchmark in my decision to become a sex therapist, but it played a role in helping me find my voice. After reading much of the backlash on the vulvar pain lists (www.vulvodynia.com), I wanted to get involved in broadening awareness of the topic and challenging the myths that exist(ed) concerning women's sexual pain. My decision to write about sexual pain while living in Japan, undertake my Masters of Social Work and write this thesis are ways I extended my own personal narrative into the public arena.

\footnotetext{
${ }^{55}$ The episode was aired in their Fourth Season (2001)
} 
How I understand this role, the strengths and struggles of writing this thesis, and the ways in which they will influence my counselling role lays the groundwork to this final chapter. To make sense of what I am taking away from this process, this chapter explores reflective, ethical practice and explicates what I learned in the process of writing this paper, how this reflection will inform my practice as a social worker and my reflective approach to counselling. The first section comments upon my reflection of writing this paper. It explores what I have learned, the struggles I had to overcome and the skills I believe that I have gained in the process. The second section explains how I believe this thesis will make me a more effective practitioner. As a woman who has experienced vulvar pain for nine years, I believe that it would be dangerous of me to enter into a counselling relationship without having unpacked much of my experiences and having tried to make sense of them. Such a process helps me be clear around my experiences and feelings in order to work against the problematic practice of transference or the confusing of one's own feelings with those of one's clients. As such, this section delves into how I would like to approach working with women and couples suffering from vulvodynia and painful sex. The final section considers the role of the competent professional in relation to responsible approaches to vulvodynia. Over the past nine years, I have struggled to find a therapist or physician who was able to help me adequately navigate the medical system or my pain experiences with my partners. As many professionals working with vulvodynia sufferers agree (Glazer \& Rodke, 2002; Harlow \& Stewart, 2003; Spencer \& Stewart, 2002), there exist certain standards that must be met in 
providing sex therapy to women and couples. I explore practicing ethical care by being aware of one's position of power in the therapeutic role, remaining current on therapeutic tools, and following the guidelines laid out by the American Association of Sexual Educators, Counsellors and Therapists and the ways I can integrate them into my practice.

\section{Reflections of Writing the Thesis}

When I began this thesis, I mentioned that I never intended my personal pain narratives to take form in a Master's paper. This process serves as the beginning to what will hopefully become a lifelong reflective project. For instance, my gendered experiences of sexuality, sexual play and healing offer points of departure for analysis in every chapter; thus intimating that my being a woman, with all of its social, political, economic and cultural relevance, has greatly influenced the way I understand my sexual self. Perhaps this is an unimaginative idea considering my feminist framework and background. However, I had not connected the thematic narratives so clearly prior to writing this paper. By exploring my gendered sexuality on a personal (fantasy), social (medical) and healing (dating) level, I saw how gender, or more importantly my understanding of gender affected my interactions with my partners, my community (family, friends, colleagues) and medical professionals. For instance, my partner and I negotiated gender coherence by trying to step outside of our prescribed roles in a fantasy setting. As the female patient, I had to navigate a system that was developed to address the needs of the male sexual body. My 
vulvar pain was deemed psychological multiple times or considered as a result of an STI because of the lack of information available to physicians regarding women's sexual pain prior to 2000 .

Also thematically relevant to the project was the concept of power. In all three chapters, I argued that I had assumed a victim role (whether it was because I was a younger friend, a woman or a patient) and I saw this in my interactions with others. I assumed that being situated as "less powerful" meant the complete loss of agency within relationships and systems. However, upon reflection, I have reimagined the ways in which my assuming the "victim" role represented my complicity in replicating existing power relations. Yet, as Butler (1996) notes, such complicity also produces a moment of resistance. I became the politicized active subject of vulvodynia. Moving away from the "essentialised woman" (a fixed identity) as a victim of patriarchy toward complex self (an unfixed identity) offered me a textured understanding of the way in which power is a relation of both resistance and oppression. Framing my experiences in this manner profoundly altered how I see the past nine years. Retrospectively, I produced and reproduced victimization and power over others, including women who lived with chronic vulvar pain, through practices of projecting a common, yet singular experience of vulvodynia. In an effort of give voice and legitimacy to my own experience, I had articulated it as the vulvodynia experience. I had not yet learned how to make sense about these experiences of "powerlessness" with my physicians, partners, peers or professors. Consequently, my naïve approach to 
understand the complexities of these power relationships meant that I compromised the support offered to me or that I could in turn offer to others.

\section{The Struggles}

The process of de/compartmentalizing my pain narratives meant bringing up memories and wounds that I had chosen to put away over the past nine years. They were confusing and unnavigable at times and choosing what was appropriate, safe, risky or provocative was much more difficult than I had earlier imagined. My initial outline seemed simple and manageable as it focused a great deal on the physiological and psychological research being conducted in Canada and United States..$^{6}$ However, over the course of a year, it shifted dramatically. After coming to the conclusion that it would be impossible to capture all that I have felt over the past nine years in one hundred and fifty pages, what I offer in this final thesis are neatly packaged narratives that are meant to share, dislocate, reconstruct and make sense of my pain. What I have chosen to present are but fragments of my experience, twisted and reworked through practices of reflection and writing. Through a process of reimagining the real, I was able to be more present with my experiences - to understand their textures, limits and possibilities so that they could remain part of my journey to sex therapy. Shifting into a space that is open to a plethora of stories I have yet to hear or imagine, my

\footnotetext{
${ }^{56}$ Readers may notice that this thesis does not include many references to the physiological aspects of vulvar pain. I chose to take out the science behind vulvar pain because of the autobiographical nature of the project. For information on the latest studies and information regarding vulvar pain, please see the comprehensive bibliographies offered on www.nva.org or www. vulvodynia.com.
} 
story no longer has to be the story. Rather, it is one of many legitimate narratives and expressions of self.

While choosing which narratives would be most helpful to the project was difficult, other struggles provided much larger roadblocks. For instance, I noticed that my pain sensitivities increased while writing the thesis. Chapters one and two were especially difficult for me as my pain elevated to such an extent that I was having a difficult time sitting down to write or focus. I cannot conclude whether or not my physical or emotional parts of self needed to be tended first before the other, but the increased pain and the emotional experience of remembering narratives led to moments of "catastrophizing" (making the pain narrative become dominant and at times in the past nine years, my sole narrative). 57 To address the physical pain, fortunately, my gynaecologist was able to prescribe me with a medication (Gabapentin) that over the course of four months has not only worked to lessen my pain, but almost erase it completely. Yet, this posed another problem. For the first time in years, I was pain free and still, I had to dedicate much of my life to a project that required me to remember, critique, explore and make sense of my vulvodynia narratives. I almost needed to feel the pain to continue. It seems contradictory, but experiencing the pain made it such that I was reminded about the importance of the project. At the same time, being given space to explore my vulvar pain created the possibility to see a practice of sex therapy as not situated in or growing out of my unique stories. Instead, vulvar pain became an experience that shapes multiple bodies in various

\footnotetext{
${ }^{57}$ See Ellis \& MacLaren (2004) for more information on catastrophizing.
} 
ways, some which connect with, or even overlap with others and mine that are separate, even contradicting.

\section{The Triumphs}

Overcoming struggles often co-exist with acquiring new skills, and this project is no exception. At the beginning of writing this thesis, I had valiant ideas of chronologically writing and critiquing my narratives and coming to a grandiose conclusion that I had unpacked the story and was now ready to work with women. This is not the case. Although I did write the story somewhat chronologically, it was more out of necessity to contain my thoughts than adhering to a methodological framework. Surprisingly, I credit not coming to a grandiose conclusion as part of the success of this thesis. That is, I recognise my difficulty to find closure with these experiences as they will continue to shape who I am and what I will become. The success, however, was in presenting these narratives, examining why I presented them in such a way, looking at assumptions upon which my arguments were being made and the effects they had on my understanding and interactions with my self and others. Undergoing a conscious reflective project, which challenges how I think and the underpinnings upon which these thoughts are built, lay the foundation for becoming a reflective practitioner.

This process also helped me to see my experiences as unique. For the first seven years, finding a name, a treatment and a shared community were my priority. My identity as a woman was very much wrapped up in my vulvar pain 
and specifically the ways in which people helped or interacted with me. I saw myself in other women's pain narratives and, supported by the literature at the time, assumed that we shared common experiences of pain (Glazer \& Rodke, 2002; Northrup, 1994; Stewart \& Spencer, 2002). The shift in seeing my pain as a unique experience did not happen prior to writing this thesis. That is to say, I now see that my pain is individually experienced and shaped by my immediate environment and the interactions I have with others. ${ }^{8}$ While the physical pain is real, I cannot assume that other women experience the exact same sensations. In my experience, and as evidenced by the ISSVD's Terminology and Classification of Vulvar Pain (2004), the medical community asks us to describe our pain using terms like "sharp, knifelike, acid, burning." However, I have never experienced the sensation of acid burning my skin, nor have I been slashed by a knife. As such, could one not argue that my sensations are projections of what I have read or that my assumption of a knifelike sensation could be very different than another woman's knifelike pain? Given that we interpret pain and understand it within a context, I believe it is important that I see women's pain narratives as individually understood by the storyteller. I see this having profound relevance to my future practice as a social worker and sex therapist.

\section{How My Narratives Will Make Me a Better Counsellor}

My position as a future therapist and as a woman having lived with vulvar pain arguably will both underlie and influence my work. This is especially

\footnotetext{
${ }^{58}$ My vulvar pain sensitivities increasing while writing this thesis or feeling stress are excellent examples of how my social contexts influence my body.
} 
important given that my actions are situated within a social, political, cultural and ethical framework. With that in mind, I believe that it has been equally important for me to locate my own awareness of social relations as it pertains to my narratives of self and social work.

Foucault describes power as that which is "tolerable only on condition that it masks a substantial part of itself. Its success is proportional to its ability to hide its own mechanisms" (1990, p. 86). He also argues that historically specific and culturally determined power mechanisms construct the ways in which we understand how our experiences are defined and controlled (1990). I have attempted to unmask the mechanisms of power shaping my experiences by exploring moments in which I was trying to make sense of my self in relation with family, partners and institutions. While local and specific, these moments came together to expose the network of power in which vulvar pain was created/silenced/exploited/managed. However, I have found that living as part of a social system where sexuality is openly discussed, but is masked behind what is appropriate (heterosexual, adult, post-marital, penile/vaginal, protected, consensual, able-bodied, etc.) and inappropriate (queer, childlike, pre-marital, non-penetrable, unprotected, forced, etc.), serves to contain the ways in which vulvodynia is explained, recognized and treated. My pain narratives arguably have been shaped by a variety of readings of sexuality. These readings are not only those I felt were imposed upon me, but also those through which I have come to recognize as produced by myself. 
How I understand sexuality or sexual pain and my underlying assumptions, therefore, play very much into how I make sense of the relations of power that shape my relationships (be they therapeutic, professional or personal). Consequently, Yalom (2002) contends that all therapists would benefit from engaging in their own personal psychotherapy. He reasons that because therapists' greatest tools are themselves, it is important for them to, ...be familiar with their own darkside and be able to empathize with all human wishes and impulses...Young therapists must work through their own neurotic issues; they must learn to accept feedback, discover their own blind spots, and see themselves as others see them; they must appreciate their impact upon others and learn how to provide accurate feedback. Lastly, psychotherapy is a psychologically demanding enterprise, and therapists must develop the awareness and inner strength to cope with the many occupational hazards inherent in it (Yalom, 2002: 40-41).

While this thesis was not a therapeutic exercise, it achieved similar objectives of exposing my blind spots to practice and undertaking a psychologically (and academically) demanding enterprise. While solely an intellectual exercise on paper, this project was always in excess - both emotionally and psychologically. Notwithstanding, I believe that to maintain this position of scepticism and to be open to hearing other women's multiple, ambiguous and complex stories, relies on my commitment to being reflective about my future practice.

To be successful, I believe that it is my responsibility to keep abreast with vulvar pain research, attend conferences and increase my knowledge regarding creative, complimentary and effective therapeutic techniques. My experiences of being a woman having lived the narrative of chronic pain have informed and continue to inform my practice in many ways. Having unpacked my experiences 
in this thesis, I would hope that I would be able to attend to/own/be responsible to my preconceived ideas, understandings or feelings towards vulvar pain experiences. Further, I would strive to create a space that invites women and couples to openly share their concerns in a comfortable way. To do this, I need to be able to put my stories aside - drawing on them only in abstract ways or where moments of self-disclosure are clearly required to enhance the therapeutic relationship.

One of the possible therapies that I see as being highly relevant to sex therapy is a narrative approach grounded in feminist counselling techniques. It is most likely because it requires that the therapist move away from the diagnosis and employs a "non-blaming approach to counselling" (Morgan, 2000: 1). Equally attractive to using this approach with vulvar pain sufferers, is the theoretical underpinning of creativity. Because vulvar pain is a complex and difficult-to-diagnose condition, working from a creative standpoint (i.e., employing art or drama therapy) may provide the woman with a different avenue to make sense of her pain narrative (Howard \& Wirtz, 1999; White, 1995). For instance, it would not be my goal to reframe the experience so that women see it in a different way, but to frame the questions "so as to underline the decisions and actions the woman has taken in order to deal with [her] concerns" (Howard \& Wirtz, 1999: 4). Situating these questions within a feminist framework serves to find the gendered commonalities that may exist and that may provide support in alternative ways. 
Externalizing the pain narrative may be equally relevant to supporting women. This process involves questioning the internalizing practices that are such a pervasive part of our day to day (Carey \& Russell, 2002). Put differently, it means removing the problem from the person and seeing the problem as the issue to be explored. Throughout my thesis, I have worked to challenge those internalized practices (i.e., heteronormative understandings of sex, unique or universal experiences of vulvar pain, necessity to perform pleasure). Similar to my own narrative, often by the time women come to see a therapist, they have seen many physicians and internalized the problems with which they are dealing, influencing the ways in which they see themselves (Binik, Bergeron \& Khalifé, 2000). Rooted in poststructuralist school of thought, externalizing the issue(s) offers a possible solution to this by locating the problem as something that is "socially constructed and created over time" (Carey \& Russell, 2002: 1) (for examples, see pages 44-59). By posing creative questions, the therapist is separating the vulvar pain from the woman and "de-centres" it as the dominant narrative. A possible shift takes place where the woman can see this narrative no longer as something that has "control over her," but an external issue over which she can gain control.

Feminist narrative therapies also work on the assumption that the therapeutic relationship between the therapist and the woman is interactive and collaborative (Morgan, 2000; Kelley, 1996, White, 1995). By staying in tune with how the woman is feeling throughout the session, the therapist instils a sense of co-authorship of the alternative stories (Russell \& Carey, 2003). This is very 
important as it challenges the assumed or socially constructed power binary of therapist/woman and situates them in productive spaces to move through, construct and make sense of the narrative(s). By addressing power and creating a partnership in the therapeutic relationship, the woman is able to see herself as capable; thus, providing her with the opportunity to begin unpacking or making sense of the "privileged story line." In short, the feminist narrative approach provides women with the space to attend/own/be responsible to her own preconceived ideas/feelings towards her vulvar pain expériences.

Entering this space within the therapeutic process not only encourages a woman to move away from the notion that there is only one story (the vulvar pain) or self (the vulvar pain sufferer), but also to embrace multiple story lines or consciousnesses that exist. The process of finding the non-chronicled stories, according to White (1990), is the search for the "unique outcomes" (15). These are defined as experiences that are not part of the dominant story line, but that would be useful for re-authoring the woman's experiences. For example, a woman who has managed to decrease her pain at some point or remembers a positive sexual experience may want to remind herself of that "feeling" when her pain sensitivities are high. I would argue that it is in discovering one's unique outcomes that a woman begins to see herself as a more complex and "multistoried" self.

Equally important to this process employing a feminist narrative approach is working with a woman's sexual partner (if that is possible) to help them navigate possible resources, such as the medical system, alternative therapies, 
support groups and research. It may also be helpful to provide tools that would improve their communication about their fears of pain, sexual play or intimacy possibly enhance their relationship, and ultimately decrease their levels of stress and anxiety (Binik, Bergeron \& Khalifé, 2000; Nusbaum, Hamilton \& Lenahan, 2003). It may also be useful to offer guidance that would alleviate the possible financial, emotional and physical stresses endured by the complex medical system (Glazer \& Rodke, 2002; Stewart \& Spencer, 2002).

In short, I see my job as a social worker/sex therapist to employ effective counselling techniques, such as the feminist narrative approach. I also believe that it is important to act as an advocate on behalf of my clients for their social, emotional, physical and sexual well-being. That is to say, I see my role as one that incorporates advocacy by challenging the way we see and understand sexual dysfunctions and pain conditions that impact women's sexuality.

\section{Reflections on the Responsible Counselling Process}

This thesis has provided me the space to reflect upon what I believe are necessary tasks to becoming a responsible and effective practitioner. While many of the following suggestions may appear prosaic, they address the gaps in practice that I have previously identified through my own experiences. For example, I believe that supportive, responsible practice relies upon being aware of current resources regarding new research, appropriate therapeutic models and medical practitioners (i.e., physiotherapists, physicians, gynaecologists or alternative 
healers). Maintaining partnerships with other health practitioners ensures that the therapist is working from the well supported multidisciplinary approach.

Equally important to the counselling process is understanding pain theory. While my journey has just begun to explore generalised pain from an academic perspective, I believe understanding it could greatly enhance the ways in which therapists support their clients. Similar to the narrative approach, much of the new pain therapies work to help clients manage their pain intellectually, emotionally and physiologically (Bonham, 2001)59

While each of the above suggestions would enhance the therapeutic relationship, I believe that it is equally relevant for counsellors to engage in a process whereby they unpack their own sexual subject positions. In doing so, they are offered the opportunity to attend to their biases, and other impasses they may encounter when discussing sexuality with their clients. One obstacle may be the differential power relation between the therapist and woman/couple. As such, counsellors wishing to engage reflectively about their practice may wish to address how they perceive their role in the counselling relationship. Fahy and Smith (1999) include the following excerpt in their paper when exploring the perceived power differences that exist in the doctor's office:

This doctor does not know me and does not introduce himself. Why doesn't he introduce himself? It is as if his personal identity does not matter; what matters is that he is in the doctor subject position. If we had been introduced, or at least exchanged names he may have had to acknowledge me as a subject (84).

59 (see www.pain.com for excellent, current resources on pain management) 
The act of depersonalizing the medical and counselling relationship serves to create a professional space; however, it also bolsters the unevenly polarized physician/patient paradigm. As such, recognizing power differentials, as well as the ways in which structural realities (such as race, gender, sexual orientation, age, dis/ability and/or class) play into the relationship is crucial to engaging in an effective practice. Binik, Bergeron and Khalifé (2000) suggest the following script when describing to women the possible benefits of sex therapy in relation to vulvodynia/dyspareunia:

By using sex therapy, pain management and cognitive interventions, we can work towards reduce the negative effect that your thoughts, emotions and interactions with your partner can have on your pain. In fact, these interventions can help maximize the beneficial effects that positive thoughts, a good sex life and a positive relationship can have on reducing or elimination of your pain" (168).

Recognizing the importance of good $\operatorname{sex}^{60}$ and its relations to pain, brings us to the final task suggested by Binik, Bergeron and Khalifé (2000) - re-establishing a pleasurable sex life. Kellogg-Spadt's (2002) dissertation developed a model for sex education for women living with vulvodynia/dyspareunia. Her research provided the following three (of five) conclusions that relate to vulvodynia/dyspareunia sufferers and pleasurable sex:

1) Women with vulvodynia were infrequently given any relevant sexuality education by healthcare providers.

2) Women viewed sexuality education as most useful when it included facts about vulvodynia and partner communication issues.

3) Resilient adaptation to sexual pain involved the rescripting of initiation patterns and intimate behaviors (vii).

${ }^{60}$ Good sex, like all subjective experiences, is defined by the persons involved. 
Glazer \& Rodke (2002), Kellogg-Spadt (2002), and Meana et al., (1997) all argue that women, at the time of their diagnosis, receive little sexual education regarding physical intimacy and sexual knowledge.

Firestein (2001) outlines that part of the therapist's role is to "assist women to develop comfort with asking a new or potential male or female partner specific questions about his or her prior exposure to STDs..." (30). On a personal note, at the time of my diagnosis, I would argue that I did not receive any education regarding possible alternatives to sexual intercourse. As such, providing clients with sexual play alternatives for both themselves and with their partners can be beneficial. As well, communication between partners plays an equally important role in therapeutic interventions.

\section{Reflections on Sexuality within the Social Work Profession}

Sexuality, specifically concerning counselling, is seemingly absent from Social Work curricula across Canada. Over the past two years, I have dedicated much of my degree to learning about sexuality and the ways in which it intersects with social work practice. While my professors appeared to welcome my work, I found that limited class discussion and available resources on the topic presented me with many obstacles. I did not find that sexuality and the practice of sex (as beneficial to a person's well being) was a priority in any of the general social work courses. Perhaps it is our preoccupation to see sexuality as a luxury - one that with our limited budgets and overworked staff, we have few resources to dedicate (Trotter et al., 2006). Or perhaps it has to do with our fear to engage in the 
discussion of sexuality with classmates or clients informally from a clinical/objective perspective. Trotter et al., (2006), when exploring the reflective social work practice and the invisibility of sexuality, declared that, "[o]ne common misconception was that sexuality was irrelevant to social work because (it was thought) that it was about sex - and therefore a solely private and personal matter (383-384). The authors also found, as I did, that one could spend hours researching journal databases, libraries and websites for articles that link key words, such as "sex therapy" and "social work" or "sex dysfunction" and "social work" and, more often than not, receive few hits. ${ }^{61}$ In my experience, however, the articles I did find explored the ways in which social work practice interacts with HIV/AIDS, abuse, and the orientation or regulation of relationships between clients and professionals (Lundy, 2004: Trotter et al., 2006; Turner, 2002). Consequently, they do not attend to vulvar or sexual pain, or to sex therapy.

The academic invisibility of social work/sex therapy would suggest that there exist few therapists in the field. That is not my experience. On the path to becoming a sex therapist, I met numerous social workers along the way. As well, there exist social work academic/practitioners, such as Dr. Mary Valentich (previously at Carleton University, now University of Calgary) and Dr. James Gripton (formerly University of Calgary)62, who are certified sex educators and sex therapists. In fact, Valentich and Gripton have done a great deal to raise

\footnotetext{
${ }^{61}$ This is using Google, Google Scholar, Ingenta, PubMed, the Carleton library database and Ottawa University library database.

${ }^{62} \mathrm{Dr}$. Gripton recently passed away this year, but his contributions to the field of sex therapy are profound.
} 
awareness about the importance of sexuality in our profession (Valentich \& Gripton, 1984, Valentich \& Gripton, 1985). Unfortunately, there have been few academics following in their footsteps to explore the ways in which disability, sexual dysfunction and social work intersect.

In talking with many of my social work colleagues, it is clear that issues of sexuality do arise in practice, albeit informally and often in conjunction with other concerns. When I ask how they address the issue, the responses vary. Some, who are interested in the topic, research the specifics and then refer them to the most appropriate specialist or resource. Others awkwardly wade through the discussion and count the minutes until it is over. Of the social workers to whom I have spoken, all appear enthused about my passion for addressing sexuality, aspects of sexual pain, disorders and difficulties with clients and concur with the need to enter the therapy debate in the social work practice.63 Notwithstanding, social workers may be able to play a pivotal role in the healing and discussion of sexuality with their clients. We are in the unique position to bridge the division between the medical and social impacts of dysfunction and sexuality.

\footnotetext{
${ }^{63}$ As evident in the paragraphs above, much of my understanding about social work practice and sexuality has evolved into discussions with other practitioners during my placements and in paid positions. Moreover, the absence of academic literature leaves me with little data to further support my argument that social work practitioners are indeed a necessary part of the biopsychosocial treatments needed to support women living with vulvar pain.
} 


\section{Conclusion}

We have to understand that with our desires, through our desires, go new forms of relationships, new forms of love, new forms of creation. Sex is not a fatality; it's a possibility for creative life. (Foucault, 1991: 166)

Like Frodo battling the mountain of Mordor (Tolkein, 1999), the journey even to begin considering myself as a woman living with multiple subjective positions has been fraught with detours. I had the best of intentions to include in my last chapter a slide illustrating my "healed" self; however, I do not believe that I am there yet. In fact, I do not think that I will ever be "cured" nor ever leave what I have learned about my vulvar pain behind me. My pain narrative has informed so many of my "selves" that to rescript or reconceptualise would lessen their importance. However, I no longer want this script to be my dominant narrative.

Over the years, I have concluded that our current health system has not fit my needs as a woman and, especially, when discussing vulvar pain. For instance, the system privileges male sexuality (Laqueur, 1998; Tiefer, 1996). Society's values have "mirrored the medical community's indifference" towards women's sexual bodies (Stewart \& Spencer, 2002, p. 12). This can be seen in the ways that I felt my physicians often "minimized" my pain. I have suggested that this was because my condition was associated to sex, but I believe it is part of a larger issue. Female genitalia remain a mystery for many women, as well as many general medical practitioners. Consequently, for women who are searching for information about their vulvar pain, there exist few mainstream, popular texts focussing on vulvar and vaginal health. Related to this is the difficulty facing doctors and patients who are hard pressed to find up-to-date, easily understood 
and factual information (Glazer \& Rodke, 2002; The Boston Women's Health Book Collective, 1998).

In relation to vulvar pain, Glazer and Rodke (2002) argue that many well meaning gynaecologists prescribe medicine because, one, they do not know what else to do, and two, because "[t]reating symptoms is part of their job" (2002, p. 18). Sometimes their prescriptions do work, but it is more common that they do not.64 As evidenced throughout this thesis, my experiences often fit within the latter. It is most likely the trial and error nature of my diagnoses and subsequent treatments that made this experience so difficult to navigate. It is unsurprising, therefore, that my thesis, a project that is meant to be a reflection of the process has been taxing, both emotionally and physically. ${ }^{65}$

The element of reflection in this academic project required taking risks, because the result was ideally to know oneself and move beyond the self. I believe that my journey to examine vulvar pain through the multiple lens of a feminist, Foucauldian analysis will certainly have a lasting effect on my future practice as a sex therapist. Although the autobiographical nature of the thesis proved difficult, I can say, without question, the project will shape my self, the way in which I understand my dominant narratives and the technologies of power as they relate to living with chronic vulvar pain and sexual subjectivity. Just as French fries do not heal vaginas, a thesis does not cure vulvodynia. Nonetheless, I am open to new understandings, truths and narratives. In fact, I

\footnotetext{
${ }^{64}$ See Table 1 (page 58 ) for a complete list of treatments I have been prescribed over the past nine years.

${ }^{65}$ This refers to the heightened pain experiences that occurred while writing some of the more exposing scripts and their critical reflections.
} 
never imagined that Foucault would touch my life in such a way, but I believe that navigating the complexities offered by technologies of the self are now an essential piece to the reflective project.

With regards to my intended profession as a sex therapist, some may ask whether sexuality and vulvar pain are truly relevant to social work practice. This is in light of our current cuts to salaries, staff and qualifications within the social work field. However, as evidenced throughout this paper, sexuality is an issue that is important to our community. Illnesses, stresses, and the way in which we treat them change the way our bodies sexually respond. And despite the overwhelming physical, emotional, spiritual and psychological benefits of participating in a healthy sexual relationship, we continue to ignore sexuality as a purposive tool to promote healing. That said, it is important that we as social workers help our clients make sense of the social discourses, changing subjects and impacts of medical interventions to their sexuality/sexual identity to the best of our ability. Furthermore, it becomes our job within the role of social work to challenge not only our selves reflectively, but also that of our colleagues regarding their discomforts surrounding sexuality.

As a future practitioner, this thesis offered me the opportunity to take my pain narratives and reflect upon them within a social work framework. I can openly say that as a result, it has profoundly shifted my professional goals. I now believe that I am in the space where I can work with women living with vulvar pain and hear their story, not through my eyes as one who has lived the experience, but through theirs. Put differently, I am now able to hear a person's 
story (be it concerning pain, the medical system, or sexuality) without thinking about how my narratives fit into their words. This revelation comes from me having the space to reflect upon/un pack/attend to and be responsible for the separation of my personal narratives from my professional practice. It is the beginning of what I foresee being a dynamic, lifelong journey. While the separation from the personal and the professional is not exclusive, it is profoundly important. Finding ways to negotiate this (through reflective practice and on-going pain management) will no doubt have lasting impacts on my future work as a therapist, an educator, a social worker or an author.

To conclude, I feel that my metaphoric title, "Those Flaming Lips: Giving Voice to a Woman living with Chronic Pain" requires some explanation. At first, I loved its witty double entendre and the way in which it provoked discussion and the occasional chuckle. It was my way of stepping beyond conventional and constricting margins of sexuality within social work academia. However, in the process of writing my conclusion, I considered changing the title to something more "respectable" and safe. Obviously, I resisted. Instead, I liken it to my tattoo, which is of an eye, a sun and a moon in the shades of the all-in-one, fourcoloured BIC pen. I was eighteen when I decided permanently to mark my leg. Twelve years later, it feels childish and no longer captures the person I choose to represent. Although I have thought of removing it since, or shading it black to cover up the juvenile colours, I again have resisted. To do this would remove the history, and thus the meaning, of the tattoo. I was eighteen, spirited and enjoyed lighting small fires to spark conversation. I was also a woman who was just 
discovering feminism, the outdoors and my power. The common link between my eighteen-year-old self and my thirty-year-old self is that I continue to enjoy pushing boundaries. Although my flame has tempered somewhat, I hope never to lose that eighteen year old, fiery passion upon which my current self has been inspired. However, I would like to say that my lips, while perhaps still flaming and passionately committed to advocating and supporting those women living with the condition, are now more content to raise awareness about sexuality in alternative, less blazing ways. 


\section{References}

Abramov, L., Wolman, I. \& David, M.P. (1994). Vaginismus: an important factor in the evaluation and management of vulvar vestibulitis syndrome. Gynecology Obstetrics Investigation, 38, 194-7.

Barni, S. \& Mondin, R. (1997). Sexual dysfunction in treated breast cancer patients. Annals of Oncology, 8, 1-5.

Basson, R. (2001). Human sex-response cycles. Journal Sex Marital Therapy, 27, 33-43.

Belenky, M., Clinchy, B., Goldberger, N. \& Mattuck Tarule, J. (1997). Women's Ways of Knowing: The Development of Self, Voice, and Mind, New York: Basic Books.

Benmayor, R. (1991). Testimony, Action Research, and Empowerment: Puerto Women and Popular Education. In S. Berger Gluck and D. Patai (Eds.) Women's Words: The Feminist Practice of Oral History, 159-74.

Berger Gluck, S. \& Patai, D. (Eds.) (1991). Women's Words: The Feminist Practice of Oral History, New York: Routledge.

Bergeron, S. \& Binik, Y. (1997). Vulvar vestibulitis syndrome: A critical review. Clinical Journal of Pain, 13, 27-42.

Bergeron, S. \& Binik, Y. (1997b). The treatment of vulvar vestibulitis syndrome: towards a multimodal approach. Sexual and Marital Therapy, 12, 305-311.

Berglund, A-L., Nigaard, L. \& Rylander, E. (2002). Vulvar pain, sexual behaviour and genital infections in a young population: a pilot study Publicerad i: Acta Obstetricia et Gynecologica Scandinavia. 81(8), 738-742.

Berman, J. \& Berman, L. (2001). For women only: A revolutionary guide to overcoming sexual dysfunction and reclaiming your sex life. New York: Henry Holt and Company.

Besley, A. C. (Tina). (2001). Foucauldian influences in narrative therapy: an approach for schools, Journal of Educational Enquiry, 2(2), 72-93.

Besley, A. C. (Tina). (2005). Self-denial or self-mastery? Foucault's genealogy of the confessional self. British Journal of Guidance \& Counselling, $33(3), 365-382$. 
BESTCO (2004). BESTCO'S history. Retrieved on February 4, 2006 from http://www.bestco.info/history.htm.

Binik, Y.M., Bergeron, S. \& Khalifé, S. (2000). Dyspareunia. In S. Leiblum \& R. Rosen (Eds.). Principles of Sex Therapy: Third Edition. New York: The Guilford Press, 154-180.

Birch, M. \& Miller, T. (2000). Inviting intimacy: the interview as therapeutic opportunity. International Journal of Social Research Methodology, 3(3), 189-202.

Blumenreich, M. (2004). Avoiding the Pitfalls of 'Conventional' Narrative Research: Using Poststructural Theory to Guide the Creation of Narratives on Children with HIV. Qualitative Research, 4(1), 77-90.

Bonham, V.L. (2001). Race, ethnicity, and pain treatment: striving to understand the causes and solutions to the disparities in pain treatment. Journal of Law and Medical Ethics, 29(1), 52-68.

Bornstein, J. et al. (1996). Severe vulvar vestibulitis. Relation to HPV infection. Journal of Reproductive Medicine

Boston Women's Health Book Collective. (1998). Our bodies ourselves for the new century: A book by and for women. New York: Simon \& Schuster.

Brookes, A. (1992). Feminist Pedagogy, An Autobiographical Approach. Halifax, Fernwood Publishing.

Butler, J. (1990). Gender Trouble: Feminism and the Subversion of Identity, NY: Routledge.

Butler, J. (1996). Sexual Inversions. In S. J. Hekman (Ed.), Feminist Interpretations of Michel Foucault: Re-Reading the Canon. University Park: Pennsylvania State University Press, 59-75.

Carr, A. (1998). Michael White's Narrative Therapy. Contemporary Family Therapy, 20(4), 485-503.

Carey, M. \& Russell, S. (2003). Feminism, Therapy and Narrative ideas: Exploring some not so commonly asked questions. The International Journal of Narrative Therapy and Community Work, No 2, 67-91.

Chaitow, L. (2002). Conquer Pain the Natural Way: A Practical Guide. San Francisco: Chronical Books. 
Chanfrault-Duchet M. (2000). Textualisation of the Self and Gender Subjectivity in the Life-Story. In T. Cosslett, C. Lury \& P. Summerfield, (Eds.) Feminism and Autobiography: Texts, Theories, Method. London: Routledge, 60-75.

Chapkis, W. (2002). The Meaning of Sex. In C. Williams \& A. Stein (Eds.). Sexuality and Gender. Oxford: Blackwell Publishing, 208-221.

Chatterji, R., Chattoo, S. \& V. Das. (1998) The death of the clinic? Normality and pathology in recrafting aging bodies. In M. Shildrick and J. Price (Eds.). Vital Signs: Feminist Reconfigurations of the Bio/logical Body. Edinburgh: Edinburgh University Press, 171-196.

Collins, P.H. (2002). The Sexual Politics of Black Womanhood. In C. Williams \& A. Stein (Eds.). Sexuality and Gender. Oxford: Blackwell Publishing, 193-207.

Conn, M. \& Fox, R. (1998). Undoing medical conditioning. In K. Somerville (Ed.). Issues in Women's Health: Women's Studies 303 Reader. Athabasca: Athabasca University, 35-38.

Daniluk, J.C. (1998). Women's Sexuality across the Life Span: Challenging Myths, Creating Meanings. New York: Guilford Press.

Davies, C. \& Davies, A. (2004). The Trigger Point Therapy Workbook, 2nd Edition: Your Self-Treatment Guide for Pain Relief. New Harbinger Publications Inc.

Diedrich, L.L. (1998). Hysterical Men: Shell-shock and the Destabilisation of Masculinity. In M. Shildrick and J. Price (Eds.). Vital Signs: Feminist Reconfigurations of the Bio/logical Body. Edinburgh: Edinburgh University Press, 146-170,

Diprose, R. (1998). Sexuality and the Clinical Encounter. In M. Shildrick and J. Price (Eds.). Vital Signs: Feminist Reconfigurations of the Bio/logical Body. Edinburgh: Edinburgh University Press, 30-44.

Dodson, B. (1996). Sex for One: the Joy of Selfloving. New York: Three Rivers Press.

DSM-IV (200o). American Psychiatric Association: Diagnostic and statistical manual for mental disorders, 4th (Ed.) Washington: the Association.

Edwards, L. (2003). New Concepts in Vulvodynia. Journal of Obstetrics and Gynecology, 189 (3 Suppl), 24-30. 
Egoscue, P. \& Gittines, R. (2003) Pain Free for Women: The Revolutionary Program for Ending Chronic Pain. New York: Bantam Books.

Ehrenreich, B. \& English, D. (1973). Witches, Midwives, and Nurses: A History of Women Healers. New York: The Feminist Press.

Elbaz-Luwisch, F. (1997). Narrative Research: Political Issues and Implications In Teaching and Teacher Education, 13(1), 75-83

Ellis, A. \& MacLaren, C. (2004). Rational Emotive Behavior Therapy: A Therapist's Guide. Atascadero, Calif: Impact Publishers Inc.

Enns, C. Z. (2004). Feminist theories and feminist psychotherapies: Origins, themes, and diversity (2nd ed.). Binghamton, NY: Haworth Press.

Fahy, K. \& Smith, P. (1999). From the sick role to subject positions: A new approach to the medical encounter, 3(1), 71-93.

Faludi, S. (2002). The Naked Citadel. In C. Williams \& A. Stein (Eds.). Sexuality and Gender. Oxford: Blackwell Publishing, 63-87.

Firestein, B. (2001). Beyond STD Prevention: Implications of the New View of Women's Sexual Problems, Women and Therapy, 24(1/2), 27-31.

Fishman, S. \& Berger, L. (2001). The War on Pain. New York: Harper Collins.

Foucault, M. (1980). Power/Knowledge: Selected Interviews \& Other Writings 1972-1977. Colin Gordon (Ed.), New York: Pantheon Books.

Foucault, M. (1988). The History of Sexuality, Vol. 3: The Care of the Self, Robert Hurley (trans.), New York: Vintage Books

Foucault, M. (1990). The History of Sexuality, Vol. 1: An Introduction, Robert Hurley (trans.), New York: Vantage Books

Foucault, M. (1997), Essential Works of Foucault, 1954-1984, Volume 1, Ethics: Subjectivity and Truth, Paul Rabinow (Ed.), Robert Hurley et al. (trans.), New York, NY: The New Press.

Foucault, M. (2003). Abnormal: lectures at the Collège de France 1974-1975, V. Marchetti \& A. Salomoni, (Eds.) G. Burchell (trans.), New York: Picador.

Foucault, M. (2006). The Hermeneutics of the subject: lectures at the Collège de France 1981-1982. F. Gros, (Ed.), G. Burchell (trans.), New York: Picador. 
Francoeur, R.T. (Ed.) (2001). International Encyclopedia of Sexuality, v.4. New York/London: Continuum International.

Fraser, H. (2004). Doing Narrative Research. Qualitative Social Work 3(2), 179-201.

Freedman, J. \& Combs, G. (1996). Narrative therapy: the social construction of preferred realities, New York: Norton.

Gamble, S. (Ed.) (2001). Second Wave Feminism. The Routledge Companion to Feminism and Postfeminism, London: Routledge, 29-42.

Gherardi, S. (1995). Gender, Symbolism and Organizational Cultures. London: Sage.

Gilmore, L. (1994). Autobiographics: A Feminist Theory of Women's SelfRepresentation, Ithaca: Cornell University Press.

Gilmore, L. (2001). The Limits of Autobiography: Trauma and Testimony, Ithaca: Cornell University Press.

Glazer, H.I. \& Rodke, G. (2002). The Vulvodynia Survival Guide: How to Overcome Painful Vaginal Symptoms and Enjoy an Active Lifestyle. Oakland: New Harbinger.

Glenton, C. (2003). Chronic Back Pain Sufferers - Striving for the Sick Role, Social Science \& Medicine, 57, 2243-2252.

Goetsch, M.F. (1991). Vulvar Vestibulitis: Prevalence and Historic Features in a General Gynecologic Practice Population. Journal of Obstetrics and Gynecolgy, 161, 1609-17.

Goetsch, M.F. (1996). Simplified Surgical Revision of the Vulvar Vestibule for Vulvar Vestibulitis. Journal of Obstetrics and Gynecolgy, 174, 17011707.

Goffman, E. (1963), Stigma: Notes on the Management of Spoiled Identity. New Jersey: Prentice-Hall.

Goffman, E. (1969). The Presentation of Self in Everyday Life. Allen Lane, London: The Penguin Press.

Gordon, C. (Ed.). (1980). Power/Knowledge: Selected Interviews \& Other Writings by Michel Foucault, 1972-1977. New York: Pantheon Books.

Gray, J. (1992). Men are from Mars, Women are from Venus: A practical guide for improving communication and getting what you want in 
your relationships, New York: HarperCollins.

Graziottin, A. (2001). Clinical Approach to Dyspareunia Sex and Marital Therapy, 27, 489-501.

Grumet, M. (1980). Autobiography and Reconceptualization, In W.F. Pinar and Peter Lang (Eds.), Contemporary Curriculum Discourses: Twenty Years of JCT, New York: Deakin University, 24-30.

Haefner, H.K., Collins, M.E., Davis, G.D. et al., (2005). The Vulvodynia Guideline. Journal of Lower Genital Tract Disease, 9, 40-51.

Hall, K. (2004). Reclaiming your Sexual Self: How you can bring desire back into your life. New Jersey: John Wiley \& Dond, Inc.

Harlow, B.L. \& Stewart, E.G. (2003). A Population-based Assessment of Chronic Unexplained Vulvar Pain: Have We Underestimated the Prevalence of Vulvodynia? Journal of Med Womens Assoc. Spring. $58(2), 82-8$.

Harowitz, G. (1987). The Foucaultian Impass: No Sex, No Self, No Revolution. Political Theory, 15(1), 61-80.

Heath, H. \& White, I. (Eds.) (2002). The Challenge of Sexuality in Health Care. Oxford: Blackwell Science.

Hooijer, K. (2002). Vulvodynia - How Porn Made Me a Woman. In M.L. Johnson, (Ed.), Jane Sexes it Up, New York: Four Walls and a Window.

Howard, J., \& Wirtz, H., (1999). Putting the pieces back together again: Narrative therapy and ideas of restoration in working together with victims of crimes of violence. Paper presented at the Restoration for Victims of Crime Conference. Australian Institute of Criminology and Victims Referral and Assistance Service. Melbourne. Retrieved 16 December 2006 from http://www.aic.gov.au/conferences/rvc/howardwr.pdf.

Hsu, B., Kling, A., Kessler, C., et al., (1994). Gender differences in sexual fantasy and behavior in a college population: A ten-year replication, Journal of Sex and Marital Therapy, 20, 103-118.

Kadri, N., Mchichi Alami, K.H. \& Mchakra Tahiri, S.C. (2002). Sexual dysfunction in women: population based epidemiological study, Archives of Women's Mental Health, 5(2), 59-63. 
Kaplan, H.S. (1974). The New Sex Therapy: Active Treatments of Sexual Dysfunctions, New York: Brunner-Mazel Book Center.

Kaplan, H.S. (1988). The New Illustrated Guide to Sex Therapy (2 ${ }^{\text {nd }}$ Edition). New York: Brunner-Routledge.

Kaschak, E. \& Tiefer, L. (Eds.). (2001). A New View of Women's Sexual Problems, New York: The Haworth Press, Inc.

Kaufman, M., Silverberg, C. \& Odette, F. (2003). The Ultimate Guide to Sex and Disability: For All of Us Who Live With Disabilities, Chronic Pain, and Illness, San Francisco: Cleis Press.

Kelley, P. (1996). Narrative theory and social work treatment. In F. J. Turner (Ed.), Social work treatment: Interlocking theoretical perspectives. 4 th ed., $461-470$.

Kellogg-Spadt, S. (2002). Listening to the voices of women diagnosed with vulvodynia: A model for sexuality education. Unpublished Doctorate Dissertation. $\square$ Philadelphia, Pennsylvania: University of Pennsylvania.

Kinsey, A.C., Pomeroy, W.B., Martin, C.E. \& Gebhard, P.H. (1953). Sexual Behavior in the Human Female, Philadelphia, PA: W.B. Saunders.

Kleinplatz, P. (Ed.) (2001). New Directions in Sex Therapy: Innovations and Alternatives, Ann Arbor, MI: Brunner-Routledge.

Kleinplatz, P. (2001b). On the Outside Looking In: In Search of Women's Sexual Experience. In E. Kaschak \& L. Tiefer (Eds.). A New View of Women's Sexual Problems. New York: The Haworth Press, Inc., 123132.

Kogan, S. M., \& Gale, J. E. (1997). Decentering therapy: Textual analysis of a narrative therapy session. Family Process, 36, 101-126.

Kohler Riessman, C. \& Quinney, L. (2005). Narrative in Social Work: A Critical Review. Qualitative Social Work, 4(4), 391-412.

Kopala, M. \& Keitel, M. (Eds.)(2003) Handbook of Counselling Women, Thousand Oaks, CA: Sage.

Laqueur, T. (1998). Orgasm, Generation, and the Politics of Reproductive Biology. In R. N. Lancaster \& M. di Leonardo (Eds.), The Gender sexuality reader: Culture, history, and political economy. New York: Routledge, 219-243. 
Leiblum, S. \& Rosen, R. (Eds.). (200o). Principles of Sex Therapy: Third Edition, New York: The Guilford Press.

Leiblum, S.R. and Segraves, R.T. (1995). Sex and aging. In J.M. Oldham and M.B. Riba (Eds.) American Psychiatric Press Review of Psychiatry, Vol. 14. Washington, D.C.: American Psychiatric Press.

Levine, J. (2002). Harmful to Minors: The Perils of Protecting Children from Sex. Minneapolis, M.N.: University of Minnesota Press.

Lief, H. (1963). What Medical Schools Teach About Sex. Bulletin of the Tulane University Medical Faculty, 22, 161-168.

Lief, H. (1965). Sex Education of Medical Students and Doctors. Pacific Medical Surgery, 73, 52-58.

Lindemann, G. (1997): The Body of Gender Difference? In K. Davis (Ed.), Embodied Practices. Feminist perspectives on the Body, Great Britain: Cromwell Press Ltd., 73-92.

Lo Piccolo, J. (1978). The Professionalisation of Sex Therapy: Issues and Problems. In J. Lo Piccolo \& L. Lo Piccolo (Eds.), Handbook of sex therapy, New York: Plenum Press, 511-526.

Lorber, J. \& Moore, L.J. (2002). Gender and the Social Construction of Illness. Walnut Creek, C.A.: AltaMira Press.

Loulan, J. (1984). Lesbian sex. San Francisco: Spinsters.

Lupton, D. (1997). Foucault and the Medicalisation Critique. In A. Peterson \& R. Bunton (Eds.) Foucault: Health and Medicine. New York: Routeledge, 94-112.

Lynch, P.J. (1986). Vulvodynia: A Syndrome of Unexplained Vulvar Pain, Psychologic Disability and Sexual Dysfunction. Reproductive Medicine 31, 773-9.

MacKinnon, C.A. (2002), Pleasure under Patriarchy In C. Williams \& A. Stein (Eds.). Sexuality and Gender. Oxford: Blackwell Publishing, 21-33.

Maltz, W. (2001). The Sexual Healing Journey. New York: HarperCollins.

Marinoff, S.C. \& Turner, M.L.C. (1992). Vulvar Vestibulitis Syndrome. Dermatology Clinical, 10, 435- 444.

Masheb, R.M., Lozano-Blanco, C., Kohorn, E., Minkin, M.A. \& Kerns, R. (2004). Assessing Sexual Function and Dyspareunia with the Female 
Sexual Function Index (FSFI). Journal of Sex \& Marital Therapy, $30(5), 315$.

Masters, W.H. \& Johnson, V.E. (1966). Human Sexual Response. Boston: Little, Brown.

Masters, W.H., Johnson, V.E., \& Kolodny, R.C. (1995). Sexual Dysfunctions and Sex Therapy. In W.H. Masters, V.E. Johnson \& R.C. Kolodny (Eds.). Human sexuality, $5^{\text {th }}$, New York: HarperCollins, 580-606.

McInnes, R. (2003). Chronic Illness and Sexuality. Medical Journal of Australia, 179, 263-266.

McWilliam, E. \& O'Donnell, S. (1998). Probing Protocols: The Genital Examination as a Pedagogical Event. Body Society, 4, 85-101

Meana, M. \& Binik, Y. (1994). Painful Coitus: A Review of Female Dyspareunia. Journal of Nervous and Mental Disease, 182, 264-272.

Meana, M. (1995). Deconstructing Dyspareunia: Description, Classification and Biopsychosocial correlates of a Pain Disorder. Unpublished PhD Dissertation, McGill University, Montreal, Canada.

Meana, M. \& Binik, Y. (1997). Dyspareunia: Sexual Dysfunction or Pain Syndrome? Journal of Nervous and Mental Disease, 185, 561-569.

Meana, M. \& Binik, Y. (1997b). Biopsychosocial Profile of Women with Dyspareunia. Dyspareunia, 90, 583-589.

Miehls, D. \& Moffatt, K. (2000). Constructing Social Work Subjectivity Based on the Reflective Self. British Journal of Social Work, 30, 339-348.

Mitchinson, W. (1979). Historical attitudes toward women and childbirth. Atlantis, 4(2), 13-34.

Monga, T.N., Tan, G., Ostermann, H.J., Monga, U. \& Grabois, M. (1998). Sexuality and Sexual Adjustment of Patients with Chronic Pain. Disability Rehabilitation, 20(9), 317-29.

Morantz-Sanchez, R. M. (2000). The Technology of Orgasm: "Hysteria," the Vibrator, and Women's Sexual Satisfaction (review), Bulletin of the History of Medicine, 74 (2) Summer, 382-383

Morgan, A. (2000). What is Narrative Therapy? An easy-to-read introduction. Adelaide, South Australia: Dulwich Center Publications 
Morris, E. \& Mukhophadyay, S. (2003). Dyspareunia in Gynaecological Practice. Current Obstetrics \& Gynaecology, 13, 232-238.

Moyal-Barracco M. \& Lynch P.J. (2004). 2003 ISSVD terminology and classification of vulvodynia: a historical perspective. Journal of Reproductive Medicine, 49(10), 772-7.

Muntigl, P. (2004). Ontogenesis in Narrative Therapy: A Linguistic-Semiotic Examination of Client Change. Family Process, 43, 109-131.

Naccache, H., Manhes, G., Fortin, C., et al., (1993). Frequency of Sexually Transmitted Diseases amongst University Students. Canadian Medical Association Journal, Jun 1, 148(11), 1937-40.

Northrup, C. (1994). Women's Bodies, Women's Wisdom, New York: Bantam Books.

Nusbaum, M.R.H., Hamilton, C., \& Lenahan, P. (2003). Chronic Illness and Sexual Functioning, American Family Physician, 67(2), 347-354.

Nylund, D. \& Nylund, D. (2003). Narrative Therapy as a Counter-Hegemonic Practice. Men and Masculinities, 5(4), 386-394.

Overcash, J.A. (2003). Narrative Research: A Review of Methodology and Relevance to Clinical Practice. Critical Reviews in Oncology/Hematology, 48, 179-184.

Parker, R.G., Barbosa, R.M., Aggleton, P. (Eds.). (2000). Framing the Sexual Subject: The Politics of Gender, Sexuality and Power. Berkeley, Los Angeles and London: University of California Press.

Parsons, T. (1951). The Social System. Glencoe, IL: Free Press.

Phelan, S. (1990). Foucault and Feminism. American Journal of Political Science, 34(2), 421-44.

Planned Parenthood. (2006). Sexual Health Glossary. Received May 14, 2006 from www.plannedparenthood.org/pp2/portal/ medicalinfo/sexualhealth/glossary/.

Plummer, K. (2002). Symbolic Interactionism and Sexual Conduct. In C. Williams \& A. Stein (Eds.). Sexuality and Gender. Oxford: Blackwell Publishing, 5-19.

Presser, L. (2005). Negotiating Power and Narrative in Research: Implications for Feminist Methodology. Journal of Women in Culture 
and Society, 30(4), 2067-2090.

Price, J. \& Shildrick, M. (1998). Uncertain Thoughts on the Dis/abled Body. In M. Shildrick and J. Price (Eds.). Vital Signs: Feminist Reconfigurations of the Bio/logical Body. Edinburgh: Edinburgh University Press, 224-249.

Probyn, E. (1993). Sexing the Self: Gendered Positions in Cultural Studies. London: Routledge.

Rainbow, K. (2003). From Margin to Mainstream: Lesbian Health and Social Service Needs. Unpublished Master's thesis, Carleton University, Ottawa, Ontario, Canada.

Read, S., King, M., \& Watson, J. (1997). Sexual dysfunction in primary medical care: prevalence, characteristics and detection by the general practitioner. Journal of Public Health and Medicine, 19(4): 387-91.

Rosen, R. \& Kellogg-Spadt, S. (2003). Self-Management of Vulvodynia: A Combined, Self-Massage and Cognitive-Behavioral Model of Treatment. Key Slides. Received on 1 June, 2005 from http://ccoe.umdnj.edu/rwjms/Vulvodynia/Keyslides/keyslides.htm.

Rosenthal, M.S. (2003). Gynecological Health: A Comprehensive Sourcebook for Canadian Women. Toronto: Viking.

Rudman, L.A. \& Fairchild, K. (2004). Reactions to counterstereotypic behavior: The role of backlash in cultural stereotype maintenance. Journal of Personality and Social Psychology, 87, 157-176.

Salazar, C. (1991). A Third World Woman's Text: Between the Politics of Criticism and Cultural Politics. In S. Berger Gluck and D. Patai (Eds.) Women's Words: The Feminist Practice of Oral History, New York: Routledge.

Sanchez, D.T., Crocker, J, \& Boike, K.R. (2005) Doing gender in the bedroom: Investing in gender norms and the sexual experience. Society for Personality and Social Psychology, 31(10), 1445-1455.

Sanchez, D.T. Keifer, A., \& Ybarra, O. (2005) Sexual submissiveness in women: Costs for sexual autonomy and arousal. Society for Personality and Social Psychology, 32(4), 512-524.

Sandelowski, M. (1981). Women, Health and Choice, Englewood Cliffs, New Jersey: Prentice-Hall. 
Sawicki, J. (1988). Feminism and the Power of Discourse. In J. Arac (Ed.) After Foucault: Humanistic Knowledge, Postmodern Challenges. New Brunswick and London: Rutgers University Press, 161-178.

Schover, L.R. \& Leiblum, S.R. (1994). The stagnation of sex therapy. Journal of Psychology and Human Sexuality, 6 (3), 5-30.

Schover, L.R. (2000). Sexual Problems in Chronic Illness. In S.R. Leiblum \& R.C. Rosen (Eds.) Principles and Practice of Sex Therapy. Third Edition. New York: Guilford, 398-422.

Shaw, J. (2001). Approaching sexual potential in relationship: a reward of age and maturity. In P. Kleinplatz (Ed.). New Directions in Sex Therapy: Innovations and Alternatives, 185-210, Ann Arbor, MI: BrunnerRoutledge.

Sherwin, S. (1979). The implications of a sexist culture. Atlantis, 3(2), 5-12.

Smith, S. (1999). Constructing Truth in Lying Mouths: Truthtelling in Women's Autobiography. In M. Watson Brownley \& A.B. Kimmich (Eds.). Women and Autobiography, 33-52. Washington: Scholarly Resources Inc.

Stacey, J. (1997). Teratologies: A Cultural Study of Cancer, London: Routledge.

Stewart, E.G. \& Spencer, P. (2002). The V Book: A Doctor's Guide to Complete Vulvovaginal Health. New York: Bantam Books.

Strossen, N. (1995). Defending pornography. New York: Doubleday.

Temple-Smith, M., Mulvey, G., \& Keogh, L. (1999). Attitudes to Sexual History-Taking in General Practice in Victoria, Australia. Sexually Transmitted Infections, 75 (1), 41-44.

Tenni, C, Smyth, A. \& Boucher, C. (2003). The Researcher as Autobiographer: Analyzing Data Written about Oneself. The Qualitative Report, 8 (1), 1-12.

Thomas-MacLean, R. (2000). Altered Bodies/Altered Selves: Exploring Women's Accounts of Illness Experiences. In B. Mieddema, J.M. Stoppard \& V. Anderson (Eds.). Women's Bodies/Women's Lives: Health Well-being and Body Image. Toronto: Sumach, 42-61.

Thorne, B. \& Luria, Z. (2002). Sexuality and Gender in Children's Daily Worlds In C. Williams \& A. Stein (Eds.). Sexuality and Gender. 
Oxford: Blackwell Publishing, 5-19.

Tiefer, L. (1994). Three crises facing sexology. Archives of Sexual Behavior, 23, 361-374.

Tiefer, L. (1996). The medicalization of sexuality: Conceptual, normative, and professional issues. Annual Review of Sex Research, 7, 252-282.

Tolkien, J.R.R. (1999). The Lord of the Rings, London: HarperCollins.

Trotter, J., Brogatzki, L., Duggan, L., Foster, E. \& Levie, J. (2006). Revealing Disagreement and Discomfort through Auto-ethnography and Personal Narrative: Sexuality in Social Work Education and Practice, Qualitative Social Work, 5 (3), 369-388.

Turner, B. (1987). Medical power and social knowledge. Beverly Hills: Sage.

Turner, B. (1992). Regulating bodies. London: Routledge.

Turner, F.J. (2002). Diagnosis in social work: New imperatives. New York, NY: Haworth Social Work Practices Press.

Vasseleu, C. (1998). The Mouth and the Clinical Gaze. In M. Shildrick and J. Price (Eds.). Vital Signs: Feminist Reconfigurations of the Bio/logical Body. Edinburgh: Edinburgh University Press, 66-77.

Vickers, M.H. (1997). Life at Work with Invisible Chronic Illness: the "Unseen," Unspoken, Unrecognised Dilemma of Disclosure. Unseen Chronic Illness and Work: Authentic Stories, Journal of Workplace Learning: Employee Counselling Today, 9(7), 240-252.

Vickers, M.H. (2001). Unseen Chronic Illness and Work: Authentic Stories, Women in Management Review, 16(2), 62-64.

Weeks, J. (1981). Sex, Politics and Society. The Regulation of Sexuality since 180o. London: Longman.

Weeks, J. (1985). Sexuality and its Discontents: Meanings, Myths and Modern Sexualities. New York: Routledge and Kegan Paul.

Weijmar Schultz, W.C., Basson, R., Binik, Y.M., Eschenbach, D.A., Wesselman, U. \& Van Lankfeld, J. (2005). Women's sexual pain and its management. Journal of Sexual Medicine, 2, 301-316.

Weir, L. (1998). Pregnancy Ultrasound in Maternal Discourse. In M. Shildrick and J. Price (Eds.). Vital Signs: Feminist Reconfigurations of the 
Bio/logical Body. Edinburgh: Edinburgh University Press, 78-101.

White, M. \& Epston, D. (1990). Narrative means to therapeutic ends. New York: W.W. Norton \& Company.

White. M. (1995). Re-authoring lives: interviews and essays. Adelaide: Dulwich Centre Publications.

WHO (2004). Sexual Health. Progress in Reproductive Health Research. No. 67. Retrieved February 4, 2006 from http://www.who.int/reproductive-health/hrp/progress/67.pdf.

Yalom, I.D. (2002). The Gift of Therapy: An Open Letter to a New Generation of Therapists and Their Patients. New York: HarperCollins Publishing.

Zurbriggen, E.L. \& Yost, M.R. (2004). Power, desire, and pleasure in sexual fantasies, 41(3), 288-300. 


\section{Appendix A}

\section{Key Concepts}

This thesis used the following definitions to frame my understanding of chronic vulvar pain and sexual subjectivity:

Chronic Vulvar Pain (vulvar pain): Pain experienced in the vulvar area for a period that exceeds three months. Pain can be described as sharp, shooting, knifelike, burning and/or dull. It can be located in specific places, but also can affect the entire pubic, upper leg and genital regions. The condition is highly variable and has both psychogenic and organic causes. Often referred to in this paper as vulvodynia.

Dyspareunia: Painful sexual intercourse that is best considered a pain disorder. Causes can be both psychogenic and organic. Treatment and assessment requires a multidisciplinary approach from physicians, psychologists, physiotherapists, and sex therapists. Most often associated to women, but can affect men as well (see DSM-I, 2000)

Gender:

Refers to "cultural and social phenomena - divisions of labo[u]r, activity, and subjectivity which are associated with but no fully determined by biological sex" (Thorne \& Luria, 2002: 128). Often associated to behaviours and desires of being female or male, feminine or masculine.

Sexuality:

"A central aspect of being human throughout life and encompasses sex, gender identities and roles, sexual orientation, eroticism, pleasure, intimacy and reproduction. Sexuality is experienced and expressed in thoughts, fantasies, desires, beliefs, attitudes, values, behaviours, practices, roles and relationships. While sexuality can include all of these dimensions, not all of them are always experienced or expressed. Sexuality is influenced by the interaction of biological, psychological, social, economic, political, cultural, ethical, legal, historical, religious and spiritual factors" (WHO, 2004)

Sexual Dysfunction: A psychological or physical disorder of sexual function (Planned Parenthood, 2006) 
Sexual Health: "A state of physical, emotional, mental and social wellbeing in relation to sexuality; it is not merely the absence of disease, dysfunction or infirmity. Sexual health requires a positive and respectful approach to sexuality and sexual relationships, as well as the possibility of having pleasurable and safe sexual experiences, free of coercion, discrimination and violence. For sexual health to be attained and maintained, the sexual rights of all persons must be respected, protected and fulfilled" (WHO, 2004).

Sexual Subjectivity: This term is not isolated to orientation, such as lesbian, gay, bisexual, two-spirited or queer, but includes those behaviours, ideas, values and experiences that form a person's sexual being. Also includes the multilayered gender, gender role and gender subjectivity.

Sexual Scripts: “... [D]efining who does what, with whom, when, how, and what it means - are related to the adult society's view of gender" (Miller \& Simon in Thorne \& Luria, 2002: 128)

Vaginismus: "Recurrent or persistent involuntary contraction of the perineal muscles surrounding the outer third of the vagina when vaginal penetration with penis, finger, tampon or speculum is attempted" (Kadri et al., 2002: 59-60). Vaginismus is considered a sexual pain disorder.

Vulva:

A woman's external sex organs, including the clitoris, the labia (majora and minora), the opening to the vagina (introitus), and two Bartholin's glands (Planned Parenthood, 2006).

Vulvar Vestibulitis (vulvar vestibulitis): Inflammation (can be visible or invisible) in the vestibule area of the vulva. Condition may be isolated or in conjunction with other vulvar pain symptoms. Women experience sharp, burning, knifelike, raw, dry pain that ranges from mild to severe. Pain is most often experienced with pressure or contact, but can exist without. Most women experiences dyspareunia as a result and diagnosis is often confused with the latter condition. Some women feel pain continuously. Can lead to vaginismus or other sexual dysfunctions if not treated early.

Vulvodynia: Please see chronic vulvar pain. 


\section{Appendix B}

\section{Living with Vulvodynia: Brief Outline of my Experiences}

1. At twenty years old, intercourse became painful almost overnight. I was in a solid relationship with a long-term partner at the time and just starting university.

2. December 1995 (1) ${ }^{66}$ : I went to the University Health Centre.

a. Physician gave me a pap smear and a chlamydia, gonorrhoea, yeast, and HIV test immediately.

b. After all of those tests came back negative, physician told me to use more lubrication, as there were no physical symptoms in my vaginal area; thus, implying that there was nothing wrong with me.

3. February 1996: After three long months, decided to go back as intercourse and tampons were still extremely painful.

a. Was given another pap smear and then told that it must be psychological as, again, there were no physical symptoms.

b. Physician referred me to the leading gynaecologist in the area and to the University Counselling Centre.

4. March 1996 (2): I finally had the appointment with the gynaecologist.

a. First thing he did was take me into a small consulting room and told me that the pain that women often results from sexual anxiety. The second leading cause of the pain stems from STIs.

b. Twenty minutes later, I laid down on the examining table where the doctor spread my knees and without any hesitation, explanation or lubrication, placed his finger into my vagina.

c. The next five minutes involved me crying from the intense pain I experienced from his insensitivity, enduring another series of STI tests and fighting the need to clench my knees together. To his credit, he did discover many small fissures in my vestibule area.

d. His diagnosis was that I was just experiencing some dryness and he prescribed estrogen cream $(\$ 50)$.

e. He provided me (and I never asked) with no explanation of what it was or why the estrogen cream would help me or what the side effects were from topically applying estrogen.

f. My STI test results came back negative.

g. I lost my faith in doctors and the cream provided no relief.

h. My partner and I soon broke up.

5. July 1998 (3): I visited a doctor in Calgary. Another expert in his field.

a. Without gloves, he examined my vulvar area and found nothing. I never addressed the fact that he did not wear any gloves. He said

${ }^{66}$ The "(1)" refers to the number of health care professionals I have seen. 
that I had no physical symptoms, that I should use lubrication, cotton underwear and that my symptoms were psychological.

6. September 1998: While sitting in Chapters, I discovered Women's Bodies, Women's Wisdom (Northrup, 1994). I incidentally opened it to the page of vulvar pain and finally, euphorically, discovered an explanation for my symptoms.

7. November 1998: Finally realised that my vulvar pain resulted from me repeatedly having sex with my ex-boyfriend when I did not want to (despite it being consensual). Accepted that there was a psychological side to my dysfunction, but knew that there were still physical aspects that needed to be addressed.

8. February 1999 (4): Went to the University Health Centre again, armed with a name of my dysfunction, and spoke to a female doctor about Vulvodynia.

a. She had never heard of it.

b. Physician gave me another painful pap smear, a series of STI and yeast tests.

c. Again, they were negative.

9. October 1999 (5): Move to Ottawa and visit the Sexual Health Centre regarding my condition.

a. Underwent a consultation with a health nurse, given a blood test (for STIs) and a pap smear.

b. Again, they were negative.

10. June 2000 (6): See family clinician - performs a pap smear. Unsure what to call my condition.

11. July 2000 (7): Aunt convinces me to try seeing a Reiki practitioner for my vulvodynia. Unfortunately, my vulvar pain remained but my scoliosis and misplaced spleen were cured $(\$ 80)$.

12. July 2000 (8): Went to an OBGYN specialist at the University hospital.

a. He agreed that I had Vulvodynia and prescribed me with low levels of Amytryptaline (to be gradually increased from 10mg to $70 \mathrm{mg}$ ), used mostly for depression, but has some pain relieving properties when used at low doses.

b. Physician did not tell me about any side effects of the drug, but gave me his email address in the event I had any questions while I was living in Japan.

c. Decided to start the low-oxalate diet.

13. September 200o: discovered www.vulvodynia.com website 
14. September 2000 (9): Went to a Psychologist in my small town in Japan (his office was located in a mental hospital) and requested that he refill my prescription.

a. Had to bring my supervisor with me to translate and explain what Vulvodynia was, how it started, and the benefits of Amytryptaline $(\$ 300)$.

b. In order to receive the medication, the physician diagnosed me for depression that would go on my non-confidential medical records (my school had access to this information). The emotional experience of explaining my sexual history aside, going to a mental hospital when you are an obvious foreigner in a small town was extremely disconcerting.

15. December 200o: Suffering from severe constipation, dry mouth, weight gain and mild depression as, from what I assumed, was a result of the Amytryptaline.

16. Tried to email the original doctor in Canada who prescribed this to me, but never received a response.

17. Have a new boyfriend who is extraordinarily supportive. Sexual intercourse and tampons were still very painful. The side effects of the low oxalate diet and the Amytryptaline were very apparent.

a. Am able to have occasional painless intercourse.

18. April 2001: Decided to become a sex therapist so that I can help women (and consequently couples) who suffer from vulvar and vaginal pain or the resulting effects.

19. July 2001 (10): Went back to the Foothills hospital, original doctor is gone, but I saw a new resident.

a. She prescribed me with Lidocaine.

b. Glanced at my file while waiting for the doctor - original doctor had written, "Patient believes she has vulvodynia, yet has no physical symptoms, only psychological."

20.Went off Amytryptaline because the side effects are too great (halitosis, weight gain, etc.).

21. March 2002 (11): Go to see my mother's doctor.

a. He has recently heard of vulvodynia and prescribes me with Buspirone - apparently, it will numb the pain in the vaginal area.

b. I take it once; it numbs my entire body - have never tried it again (costs \$30). 
22. September 2002 (12): Go to a female GP who is covering for my father's doctor in $\mathrm{BC}$.

a. I come with a list of issues that need addressing: constipation, back pain, haemorrhoids, dizziness, vaginal pain, skin rash and birth control.

b. Within the fifteen-minute session, she prescribes me a topical hydrocortisone cream with for my vaginal pain and then tells me that I will have to come back if I want an examination (costs $\$ 70$ ).

23. November 2002 (13): Go back to the same doctor's office to see my father's doctor.

a. Without hesitation, he tells me that it is mostly psychological and that I just need to use sexual aids, such as dilators of different sizes so that I can become more comfortable with intercourse

b. The visit is not a complete loss as he prescribes me haemorrhoid cream, a high fibre diet, and daily baths without scented soap to alleviate both my vulvar pain and my haemorrhoids.

c. Eventually purchase dilator (\$30) and special lubricants (\$10-20). Must toss three kinds of lubricants due to sensitivity.

24. Begin changing lifestyle - no longer using fabric softeners or other scented products. Purchase only cotton goods.

25. December 2002: Go back to the female GP, after waiting three weeks for an appointment.

a. I asked that the physician provide me with a full physical examination (pap smear, breast exam, yeast cultures, oxalate tests and blood tests). Finally someone believes me that I do not have an STI.

b. We sit down for a consultation and she has done some homework regarding vulvar vestibulitis and vulvodynia. She asks if I have seen a therapist. She asks about my doctor history. She agrees with me that my constipation is a result of the Amytryptaline (two years of haemorrhoids - Japan is not an easy place to find stool softeners or fibre as I was embarrassed to ask my teachers to help me and most products are processed or without wheat).

c. Tells me that she would like to follow up in a couple of weeks after the tests, consult an expert that she knows and refer me to both a dermatologist and a sex therapist (latter is not covered under the B.C. Medical Services Plan).

26.February 2003: Did not really use the cream, as it is messy, bothersome and speaking from history, believed that it would not work.

a. Doctor phones to tell me that she has given me the incorrect dosage of chromium in the hydrocortisone cream but that I can continue using it if I would like. 
27.April 2003 (14): Go to a naturopath and am told that it has to do with my liver. Told to drink Aloe Vera twice a day, douche with goldenseal, drink two litres of sugared water and use natural lubricants during intercourse $(\$ 100)$.

a. Decide to purchase the Aloe Vera as the logistics behind it are sound and continue to drink 2 litres of non-sugared water a day.

28. May 2003 (15): Saw dermatologist - did not do an exam. Told that I would have to come back for a full appointment (despite mentioning that I was leaving for UK next day). Did not follow through.

29.August 2003 (16): Go to a homeopath in Romania.

a. With the help of my partner translating, we discover that she, too, experiences vulvar pain.

b. She suggests that I try Cantina (Vaseline base) and Galbanela salves in the vulvar area every night and especially as a lubricant for intercourse $(\$ 100)$.

c. Although it initially tingles, it appears to be helping quite a bit.

d. Get engaged to partner

30.August 2003: Discover the $V$ Book and continue on my journey of selfhealing.

31. September 2003: Move to Ottawa for Partner's law school

a. Begin volunteering for Planned Parenthood

b. Apply for Carleton University

32. March 2004: Begin working for Sexual Assault Network

33. March 2004 (17): See physiotherapist trained in pelvic floor injury and trigger point therapy $(\$ 110)$. She teaches me certain techniques that require 40 minutes every morning and night to do.

a. Unable to follow through with therapy due to busy work/school schedule - partner is getting frustrated that I'm not following through with treatments.

34.June 18, 2004: Call off wedding (Date for August 28, 2004)

a. Partner stated that he is concerned and frightened to get married without having a strong sexual intimacy or relationship.

b. Promised that I would work on addressing my sexual "issues" and vulvar pain.

35. July, 2004 (18): See male doctor taking new clients. Ask to be referred to gynaecologist or vulvar specialist - told that this is unnecessary - he will work with me. 
a. See sex therapist for first time. States that I have experienced sexual trauma and this is the site of trauma that we will work on. Suggests using EMDR to work through sexual trauma. Challenge her by stating that I don't identify as having experienced "sexual trauma." Uncomfortable with her counselling style. Feeling very confrontational, unheard and disempowered.

b. See her three more times ( $\$ 130$ each session) and bring partner to final visit.

c. Provided me with booklist, began purchasing texts on vulvar pain (to date, have spent approx. $\$ 1000$ on literature)

36.August 2004 (19): Brought partner to another physiotherapist in Calgary - She showed us certain techniques to try together $(\$ 100)$

a. Difficult to follow through because treatment is extremely painful

37. September 2004: Start MSW program at Carleton University - one of many necessary degrees to become a sex therapist

38.January 2005 (20): See GP at walk in clinic for referral to gynaecologist and other condition. Unsure what happened.

39. March 2005: Met with sex therapist in Ottawa. Discussed possible professional options.

40.June 2005: Receiving benefits while working at community agency committed to seeing specialists regarding my condition

41. June 2005: Present, "Those Flaming Lips" workshop at the OASW conference - very good feedback - feel as though this experience secures my choice in speaking out about the condition in Canada.

a. Attend the Guelph Sexuality Conference

b. To date, I have spent approx. $\$ 1900$ on attending conferences to learn more about this condition.

42.July 2005: Went to the New View (Female Sexual Dysfunction) Conference

a. Met a woman presenting on her experiences living with vulvodynia

b. Speak to C. Silverberg, asked to conduct a workshop at the feminist sex store, "Come as you are."

43. July 2005 (21): Went to walk-in clinic for gynaecologist referral. Spoke to female physician. Told that because she had never heard of the illness, it must not exist. Sent the clinic information about the vulvodynia.

a. Physician referred me to a Physiotherapist (22) stated that she unfortunately had no expertise on pelvic floor - told to go to another physiotherapy clinic across town. 
b. Before receiving treatment, I must have GP sign consent for treatment form. Original GP refused as she was uncomfortable with signing a consent form for walk-in patient.

c. (23) Saw another walk-in GP for a referral. She refused to sign as I, again, was not her patient and she was unaware of the physiotherapist's treatment (biofeedback, a popular treatment for women with vulvar pain)

d. Referred to Dr. T. (24) (gynaecologist/surgeon) taking new patients and who was familiar with the treatment. She consents to signing the form

44.July 2005: Decide to use Lidocaine ( $\$ 20)$, which numbs the area prior to sexual intercourse.

45. July -October 2005 (25): Seeing physiotherapist ( $\$ 100 /$ visit -8 visits) to address pelvic pain - doing biofeedback exercises - while effective in working to control pelvic muscles (relaxing and contracting), not relieving pain

46. October 2005: Break up with partner

a. In part because I did not focus enough attention to my vulvar pain.

47. November 2005: Physiotherapist feels that she can no longer go further - suggests seeing Dr. T. for further treatment

48.December 2005: Dr. T. unfamiliar with vulvar vestibulitis treatments beyond surgeries. But will speak to vulvar specialists in US for support.

a. Prescribes estrogen cream (\$60)

b. Finding that the cream burns and am unable to continue beyond the 2 /day treatment.

c. Dr. Thorne suggests doing steroid injections, but will speak to specialist first

49. March 2006: Came in for 15 minutes appointment with Dr. T. She said she has taken me as far as she can, but will refer me to vulvar pain specialist - appointment for June 30

50.June 2006 (26): Met with vulvar specialist - given Xylocaine and cream to try $(\$ 70)$ 


\section{Appendix C}

\section{Painful sex? Read this...}

(Warning: This article contains explicit terms regarding female anatomy. Not intended for the weak at heart).

I love sex. I love talking about sex. I love the act of sex. However, in the past four years, I've associated sex with extreme pain and emotional frustration. Let me say that it took me two years, several negative VD tests and 13 doctors for me to realise that I would have to take my illness into my hands, so to speak. Two and a half years ago, while perusing the women's health section in Chapters, I opened Women's Health, Women's Bodies directly to the page of vulvar pain and I realised that the book described every symptom that I was experiencing. For the first time, I had a name for my illness - vulvodynia.

In the most literal of terms, vulvodynia means, "pain in the vulva." For me, it consists of painful intercourse or more specifically, an uncomfortable burning sensation in the vulvar and vestibular area during and especially after sex. In laypersons terms, it feels like a have a thousand razor cuts in an around my vulvar area (now imagine using a tampon...). Yet for many women, it goes beyond sex and affects their daily life.

Possible symptoms (taken from www.vulvarpainfoundation.org):

- Pain in the vulvar area

- Itching, stinging, parchedness, drying and swelling

- Hypersensitivity of the labia, making it difficult to walk

- Pain or discomfort on touching or pulling pubic hair.

- Hypersensitivity of the clitoris

- Pain that shoots up the abdomen

- Pain when inserting tampons

According to the vulvodynia site, www.vulvodyniasupport.com, approximately $15 \%$ or all women develop and suffer from variations of vulvodynia. What is surprising is that many general practitioners and even some gynaecologists (all the ones I knew) have little to no knowledge of the condition; thus, making women feel entirely alone in their pain. Most of the doctors I've seen told me that there was nothing physically wrong and that it was purely psychological. Other doctors have told me that I had a variation of hepatitis, chlamydia or various other venereal diseases (despite the numerous tests that proved otherwise). One doctor, a 60 year old specialist in the area, after hearing a ten minute description of my situation, spread my legs and without lubrication pushed his fat pointer finger in the very source of my pain. Shortly thereafter, he informed me that I simply have some "dryness" in the area and that all I need is a little cortisone cream and I would be fine. With tears in my eyes and the feeling that someone had taken a small razor and sliced my entire vaginal area, I took the cream home 
and crawled into bed. I think that it was at this point that I started to lose respect for doctors.

Why I have it:

My theory behind why I can no longer have sex is rather personal. Thus, without going into detail, I'll just say that I was having sex when my body wanted otherwise. Instead of following my body's signs of dryness, tightening etc., I continued to have sex with my partner until it became no longer bearable. In short, my body said that it was enough. But that's not to say I don't have psychological problems associated with my vulvodynia, I do. For one, why was it necessary for me to continue having sex with my partner when physically, I didn't want to. Further psychological problems exist in that now when I think of sex, I often associate it with extreme pain - a problem that is very difficult to overcome without proper therapy.

Other causes behind it:

According to the national vulvodynia association (www.nva.org), the causes of vulvar pain are unknown. In fact, for many women, the factors vary and are multiple. However, some speculate that it may be caused by;

- An injury to the nerves in the vulvar area

- A hypersensitivity to yeast (candida)

- An allergy to environmental irritants (laundry detergent, soap, synthetic fibres)

- High levels of oxalate crystals in the urine

- Spasms of the muscles that support the pelvic organs

- Past or present genital warts (that's nice...)

- Rashes in the genital area

- Sexual trauma

What to do:

1. Listen to your body. The most important thing to remember is that if sex is painful in any way - STOP! Your body has pain sensors that will tell you if something is meant to be or not. Listen to them. If you are having sex with a man and it is painful, either lube up or see if that works or stop all together. Remember that there are other ways to have intimacy without intercourse, just be creative.

2. Be willing to try new things. After four years of searching, one absolutely wonderful doctor diagnosed me as having dysesthetic vulvodynia (DV) and vulvar vestibulitis. As a result, he put me on trycyclic antidepressants and in all honesty, the pain certainly was 
more manageable. However, the side affects of the drugs, even at such low doses (those taking Amytryptaline for depression take 5oX the amount that those with vulvar pain take), were unbearable. Thus, I quit. As a result I've restarted the Low Oxalate Diet

3. Be honest with yourself and your partner. Considering the pain didn't come over night, healing won't either. Sharing your story with your partner will not only make him a more compassionate lover, it will help you to be honest with him and yourself. There have been times when during sex I would just burst into tears because of the pain or the emotional stress that I was experiencing and because my partner knew what was going on, he was able to support in the ways that I needed at the time.

4. Take control and start reading. Fortunately for many women, word IS getting out there and support is available via the Internet. Further, general knowledge regarding vulvar pain is being taken more seriously and is thus, reaching the informed and current doctors. Unfortunately, the majority of general practitioners or older schooled doctors are unaware that the condition exists or know the details of what it is or why it happens. Therefore, it is essential that you arm yourself with knowledge. Women's health books (specifically gyno focused ones) and information on the Internet are there for the reading. Trust me when I say that being armed with information before you spread those legs for your gyno exam will certainly prevent you from being in an awkward or painful situation.

5. See a counsellor. The emotional consequences of not being able to have sex can be traumatic to say the least. And for many of us suffering from painful sex, there are emotional reasons that unless worked on, will prevent us from being cured. However, one can't forget that there are indeed physical symptoms. Having your doctors repeatedly tell you that it is all in your head is frustrating enough. That said, work both angles. Talk to a sex therapist or someone you trust, write down the possible reasons why you think this started, but don't forget to take care of the physical symptoms as well.

6. Follow these simple words of advice taken from http://familydoctor.org

- Don't use soap in the genital area. Just wash with water.

- Avoid using creams, petroleum jelly, bubble bath stuff, bath oils or feminine deodorant sprays (although dove milk wash seems to be fine!)

- Be careful not to let shampoo drip on the genital area when showering or bathing. 
- Wash your genital area frequently with plain water to wash away any vaginal secretions that may cause irritation.

- Check your oxalate levels. Some doctors believe that

- Wear only all-cotton underwear and loose clothing. 